INSTITUTO DE PESQUISAS ENERGÉTICAS E NUCLARES

Autarquia associada à Universidade de São Paulo

CARACTERIZAÇÃO DAS FLUTUAÇÕES DO SINAL LASER DOPPLER DO FLUXO MICROVASCULAR

Melissa S. Folgosi-Corrêa

Tese apresentada como parte dos requisitos para a obtenção do Grau de Doutor em Ciências na Área de tecnologia Nuclear - Materiais.

Orientador: Gesse Eduardo Calvo Nogueira

SÃO PAULO 
INSTITUTO DE PESQUISAS ENERGÉTICAS E NUCLARES

Autarquia associada à Universidade de São Paulo

CARACTERIZAÇÃO DAS FLUTUAÇÕES DO SINAL LASER DOPPLER DO FLUXO MICROVASCULAR

Melissa S. Folgosi-Corrêa

Tese apresentada como parte dos requisitos para a obtenção do Grau de Doutor em Ciências na Área de tecnologia Nuclear - Materiais.

Orientador: Gessé Eduardo Calvo Nogueira 
"A diferença entre o possível e o impossível está na vontade humana." (Louis Pasteur) 


\section{DEDICATÓRIA}

Ao meu querido e amado marido André por todo amor, paciência e incentivo que demonstrou à mim para que eu continuasse a realizar este trabalho. Obrigada pelo marido, amigo, companheiro e pai maravilhoso que você é; por aguentar-me nos momentos de estresses e ansiedades, me perdoa se descontei em você meus estresses e frustrações. Você faz parte desse trabalho! Não teria conseguido chegar até aqui, sem seu apoio. Eu amo muito você!

À minha filha, Ana Luiza Folgosi-Corrêa, que participou e dividiu comigo todos os sentimentos vividos neste último ano de doutorado e por esses primeiros meses de sua vida que tenho dividido o tempo que deveria ser só seu! Eu amo muito você!

Aos meus pais, César e Amália, pelos exemplos de vida, amor e por tudo que fizeram para me ver concluir este trabalho. Hoje entendo o amor que sentem por mim, e espero seguir seus exemplos com a minha filha. Em especial agradeço pelo cuidado com ela durante a realização dessa tese, seria impossível escreve-la sem a ajuda de vocês! Na minha ausência, minha filha não poderia estar em melhores mãos! Amo vocês!

À minha irmã, Anamaria, por ser amiga e torcer por meus sonhos! Agradeço pelo o apoio! 


\section{Agradecimentos Especiais}

Ao meu orientador, Prof. Dr. Gessé Eduardo Calvo Nogueira, meus sinceros agradecimentos por dispor de seu conhecimento, tempo, dedicação, amizade e paciência nesses 7 anos que trabalhamos juntos! Aprendi muito com você!

À Profa. Dra. Martha Simões Ribeiro, obrigada pela amizade, pelo apoio nos momentos difíceis e por ter me recebido de coração aberto no seu grupo! Você é muito especial para mim!

A Silvia Cristina Nuñez, pela colaboração durante a realização desse trabalho! Obrigada pelo carinho, amizade e apoio nos momentos difíceis. Jamais me esquecerei de você!

À querida amiga Doralice Xavier (Dorinha), pelos bons momentos compartilhados durante esses anos de convívio. Aprendi muito com você, um exemplo de mulher! Obrigada por tudo! Você é muito importante para $\operatorname{mim!}$

À minha querida amiga Alessandra, pelos bons momentos que tivemos nesses anos. E, em especial, na nossa incrível viagem a Bélgica... Obrigada por estar presente nos momentos difíceis. São nessas horas que vemos quem são os amigos! 
Agradecimentos

Ao Instituto de Pesquisa Energéticas e Nucleares (IPEN) e ao Centro de Lasers e Aplicações (CLA), em especial à Dra. Sonia L. Baldochi e Dr. Nilson Dias Vieira Jr., por permitir trabalhar no CLA.

À Profa. Dra. Denise Zezell, pela amizade e colaboração durante esse anos.

Aos pesquisadores do Centro de Laser e Aplicações (CLA), Dr. Niklaus Ursus Wetter, Dr. Anderson Zanardi de Freitas, Dr. Ricardo Elgul Samad, Dr. Eduardo Landufo, Dra. Izilda Márcia Ranieri, Dr. Wagner de Rossi, Dra. Lilia C. Courrol, Dr. Armando Mirage, pelos anos de convivência.

Aos Amigos do CLA, Agnaldo, Luís Claudio (China), Maria Cristina, Ilka, Daiane, Antônio, Caetano, Eliane, Renata, Walter, Alessandro Deana, Marcus, Marcello, Ana Claudia, Leticia, Luciana, Carol, Vivi, Claudinha, Moisés, José Quinto, Juca, Andrezza, Cacau, Thiago, Leandro, Thiago, Fabiola, Jonas, José Pucci, José Tort e Solange, pela agradável convivência durante todos esses anos.

Aos funcionários do departamento de ensino, Fernando, Gisleine, Magali, Ilze, Verinha e Aninha, por ajudarem sempre e por serem tão solícitos.

Aos funcionários do CLA, Elsa, Sueli e Tito, obrigada por ajudarem nas necessidades do dia a dia.

Aos agentes Luís e Rubens, por serem sempre tão solícitos e agradáveis com todos que chegam ao CLA.

Aos voluntários, pela colaboração que possibilitou a realização desse trabalho.

À Capes, pela bolsa concedida

Ao Instituto Nacional de Ciência e Tecnologia de Fotônica, CNPq (INFO), pelo suporte financeiro. 
Ao Centro de Pesquisa em Óptica e Fotônica FAPESP (CEPID), pelo suporte financeiro.

Ao Instituto de Óptica não Linear, Fotônica e Bio-Fotônica (CNPq) (Milenio), pelo suporte financeiro.

À todos meus amigos, por entenderem minha ausência durante esses anos! Por fim,

À todos meu muito OBRIGADA! 


\title{
CARACTERIZAÇÃO DAS FLUTUAÇÕES DO SINAL LASER DOPPLER DO FLUXO MICROVASCULAR
}

\author{
Melissa S. Folgosi-Corrêa
}

\begin{abstract}
RESUMO
O sinal de fluxo cutâneo obtido via fluxometria Laser Doppler (SFLD) tem flutuações de baixas frequências que estão relacionadas a mecanismos de controle do fluxo microvascular. Análises espectrais, via transformada de Fourier e transformada de wavelet, têm sido usadas para correlacionar as flutuações de SFLD com os seguintes mecanismos de controle de fluxo: metabólico, metabólico NO-dependente, neurogênico e miogênico, nos respectivos intervalos de frequência $0,005-0,0095 \mathrm{~Hz}, 0,0095-0,02 \mathrm{~Hz}$, 0,02-0,05 Hz e 0,05-0,15 Hz. A potência do sinal, em cada intervalo de frequência, geralmente é usada como uma medida da atividade do mecanismo de controle microvascular relacionado. Uma vez que os métodos usados de análise são espectrais, as características das flutuações do SFLD, em cada intervalo de frequência, no domínio do tempo são desconhecidas. Como consequência, há ausência de critérios objetivos para medir adequadamente, em cada intervalo de frequência, os parâmetros hemodinâmicos relacionados. O objetivo deste trabalho foi caracterizar e quantificar flutuações temporais, espaciais e espaço-temporais do SFLD em cada faixa de frequência, usando um método no domínio do tempo. Os fluxos basais $\left(32^{\circ} \mathrm{C}\right)$ e termicamente estimulados à $\left(42^{\circ} \mathrm{C}\right)$ das regiões volares de antebraços de 20 voluntários saudáveis foram coletados em duas regiões próximas e analisados. As análises dos dados obtidos indicam que janelas temporais pequenas (1 minuto) são aceitáveis para a quantificação do fluxo médio, e que janelas temporais maiores são necessários para quantificar as flutuações de fluxo. A análise espaço-temporal revelou uma forte correlação entre sinais (em todas as bandas, exceto na banda B5) das duas regiões investigadas, durante longos intervalos de tempo, quando as duas regiões estudadas foram termicamente estimuladas, e menor variabilidade intragrupo quando comparada à obtida para os valores médios das flutuações, sugerindo que o intervalo de tempo de correlação é um parâmetro promissor para estudar mecanismos de controle do fluxo microvascular.
\end{abstract}




\title{
CHARACTERIZATION OF LASER DOPPLER SIGNAL FLUCTUATIONS IN MICROVASCULAR FLOW
}

Melissa S. Folgosi-Corrêa

\begin{abstract}
The laser Doppler flow signal from the skin (LDFS) has low-frequency fluctuations which are related to microvascular mechanisms of flow control. The Fourier and the wavelet spectral analysis has been used to correlate fluctuations in the LDFS with the metabolic, metabolic NO-dependent, neurogenic and myogenic mechanisms of control in the frequency intervals $0.005-0.0095 \mathrm{~Hz}, 0.0095-0.02 \mathrm{~Hz}, 0.02-0.05 \mathrm{~Hz}$ and $0.05-0.15 \mathrm{~Hz}$, respectively. The signal power, in each frequency interval, is generally used as a measure of the activity of the related mechanism of microvascular control. Since spectral analysis methods have been used, the time-domain characteristics of the fluctuations in the LDFS in each frequency interval are unknown. As a consequence, there is a lack of objective criteria to properly measure, in each frequency interval, the related hemodynamic parameters. The aim of this work was characterizing and quantifying temporal, spatial and spatial-temporal fluctuations in the LDFS in each frequency band, using a time-domain method. Baseline $\left(32^{\circ} \mathrm{C}\right)$ and thermally stimulated $\left(42^{\circ} \mathrm{C}\right)$ LDFS of volar forearms from 20 healthy volunteers were collected from two close regions and analyzed. The data obtained indicate that short-time windows ( 1 minute) are acceptable for quantifying the mean flow, and that larger time-windows are needed for quantifying the flow fluctuations. The spatialtemporal analysis revealed strong correlations between signals (all bands, except B5) from the two investigated regions, during large time intervals when thermally stimulated, and lower intragroup variability than the ones obtained for the mean values of fluctuations, suggesting that the time interval of correlation is a promising parameter for studying mechanisms of microvascular flow control.
\end{abstract}




\section{SUMÁRIO}

1 Introdução

2 Objetivo

3 Revisão de literatura

3.1 Microcirculação

3.1.1 As estruturas microvasculares

3.1.2 Microcirculação cutânea

3.1.3 Hemodinâmica

3.2 Mecanismos de controle do fluxo sanguíneo

3.3 Técnicas de estudo da microcirculação

3.4 Fluxometria Laser Doppler

3.4.1 Princípios de funcionamento

3.4.2 Fluxometria Laser Doppler na pele - aplicações e limitações

A Variabilidade do fluxo

B Estímulos vasodilatadores

C Vasomotividade

D Derivação dos intervalos de frequências das flutuações 
E Quantificação do fluxo e das suas flutuações

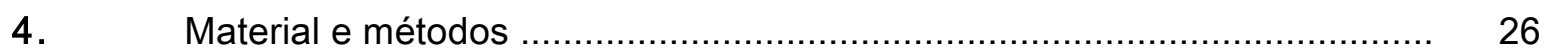

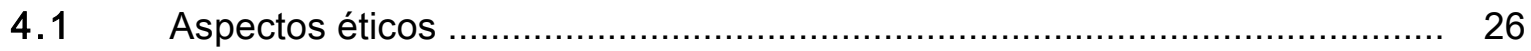

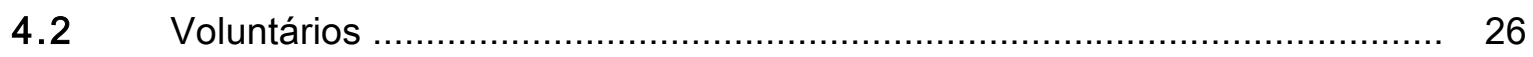

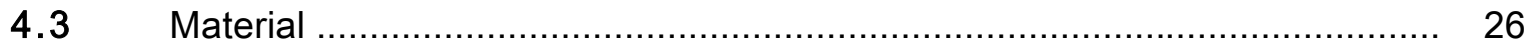

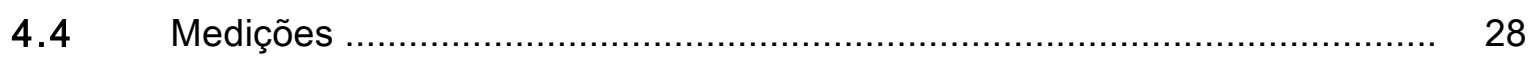

4.5 Aquisição e processamento dos dados ............................................... 30

4.6 Quantificação do fluxo e das parcelas flutuantes do fluxo .......................... 32

4.7 Análise da correlação espaço-temporal ................................................. 33

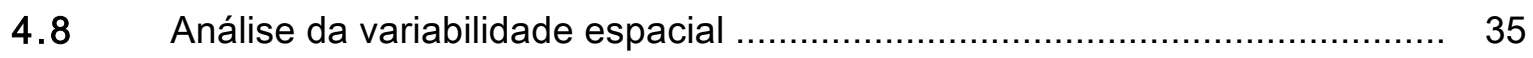

4.9 Análise estatística dos dados …..................................................... 35

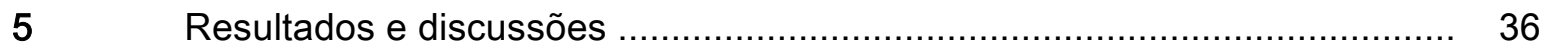

5.1 Quantificação do fluxo médio ...................................................... 36

5.1.1 Quantificação do erro na estimação do fluxo médio e de suas parcelas 43 flutuantes.

5.1.2 Quantificação da variabilidade temporal do fluxo e de suas parcelas 52 flutuantes

5.1.3 Quantificação do fluxo e de suas parcelas flutuantes

5.2 Variabilidade espacial do fluxo e de suas parcelas flutuantes 
5.4 Correlação espaço-temporal

5.4.1 Origem cardíaca - Banda B6

5.4.2 Origem respiratória - Banda B5

5.4.3 Origem miogênica - Banda B4

5.4.4 Origem neurogênica - Banda B3

5.4.5 Origem endotelial NO dependente - Banda B2

5.4.6 Origem endotelial NO-não-dependente - Banda B1

5.4.7 Banda B0

6

Conclusão

80

Anexos

82

Bibliografia 


\section{LISTA DE TABELAS}

Nún. Título

Pág.

3.1 Métodos correntes de estímulo em diferentes regiões de análise, com o objetivo de evidenciar contraste de parâmetros hemodinâmicos usados para discriminar o status microcirculatório

4.1 Faixas de frequências correspondentes a cada banda passante dos filtros usados

5.1 Valores médios de fluxo basal $\left(32^{\circ} \mathrm{C}\right)$ e durante o estresse térmico $\left(42^{\circ} \mathrm{C}\right.$ nas faixas B0 a B6 em unidades arbitrária (UA); e razão das variações de fluxo entre os dois estados (adimensional).

5.2 Coeficientes de correlação intraclasse $(\mathrm{CCl})$ e de correlação de Pearson 61 (r) entre valores médios de fluxo (B0) e de suas flutuações (B1 a B6) medidos em duas regiões distintas durante a temperatura basal $\left(32^{\circ} \mathrm{C}\right) \mathrm{e}$ durante o estresse térmico $\left(42^{\circ} \mathrm{C}\right)$ 


\section{LISTA DE TABELAS ANEXAS}

Nún. Título

Pág.

B.1 Erros percentuais dos valores médios de fluxo não filtrados $(F)$ e das amplitudes dos sinais filtrados nas bandas B0 a B6 calculados em 1 minuto tomando como referência os respectivos valores calculados em 20 minutos, de registros de fluxo durante um estresse térmico e basal. DP (desvio-padrão)

B.2 Erro percentual dos valores médios das amplitudes (A) e das potências (P) de sinais basais nas bandas B1 a B6, calculados em 1 minuto tomando como referência os respectivos valores calculados em 20 minutos

B.3 Valores de fluxos basais e respectivas amplitudes das oscilações de fluxo nas bandas $\mathrm{B} 0$ a $\mathrm{B} 6$, em unidades arbitrárias (UA), colhidos na região R1

B.4 Valores de fluxos basais e respectivas amplitudes das oscilações de fluxo nas bandas B0 a B6, em unidades arbitrárias (UA), colhidos na região R2

B.5 Valores de fluxos durante um estresse térmico e respectivas amplitudes das oscilações de fluxo nas bandas B0 a B6, em unidades arbitrárias (UA), colhidos na região $\mathrm{R} 1$

B.6 Valor de fluxo durante um estresse térmico e respectivas amplitudes das oscilações de fluxo nas bandas B0 a B6, em unidades arbitrárias (UA), 
colhidos na região $\mathrm{R} 2$

B.7 Desvio-padrão de registros de fluxo basal e das respectivas amplitudes das oscilações de fluxo nas bandas $\mathrm{B} 0$ a B6, em unidades arbitrárias (UA), colhidos na região R1

B.8 Desvio-padrão de registros de fluxo durante um estresse térmico e das respectivas amplitudes das oscilações de fluxo nas bandas B0 a B6, em unidades arbitrárias (UA), colhidos na região R1

B.9 Percentagem de tempo em que pares de sinais nas bandas B0 a B6 permaneceram sincronizados durante a duração do patamar e valores médios do grupo. $\left(^{*}\right)$ Significativamente diferente dos demais grupos (ANOVA, Tukey, p<0,05). DP (desvio-padrão)

B.10 Coeficiente de correlação de Pearson entre pares de sinais nas bandas B0 a B6 durante a duração do patamar e valor médio do grupo. (*) significativamente menor que 0,5 (teste t), $\left({ }^{* *}\right)$ Significativamente diferente dos demais grupos e $\left(^{* * *}\right)$ significativamente diferente dos demais grupos exceto B0, (ANOVA, p<0,05). DP (desvio-padrão)

B.11 Percentagem de tempo em que pares de sinais basais nas bandas $\mathrm{B} 0$ a 98 B6 permaneceram sincronizados e valor médio do grupo. $\left(^{*}\right)$ significa diferente das bandas B0 e B1 (ANOVA e Tukey, $p<0,05$ ). DP (desviopadrão)

B.12 Coeficiente de correlação de Pearson entre pares de sinais basais nas bandas B0 a B6 e valor médio do grupo. $\left({ }^{*}\right)$ significativamente menor que 0,5 (teste t), $\left({ }^{* *}\right)$ Significativamente diferente dos grupos B0 e B1 (ANOVA, p<0,05). DP (desvio-padrão) 


\section{LISTA DE FIGURAS}

Nún. Título

Pág.

3.1 Desenho esquemático da microcirculação. As estruturas circulares nas 08 arteríolas e nas vênulas representam fibras de músculos lisos e as linhas ramificadas representam fibras nervosas simpáticas. As setas indicam direções do fluxo sanguíneo. Adaptado de Berne et al., 2004

3.2 Esquema da estrutura vascular da pele. Adaptado de Nilsson et al.

3.3 Esquema de operação da FLD, mostrando as fibras ópticas e a profundidade de penetração da luz que o aparelho é sensível

3.4 Escalograma de um registro de fluxo cutâneo. O eixo das abscissas está dividido em seis faixas espectrais, segundo as origens das flutuações do sinal de fluxo

4.1 Fluxômetro Laser Doppler, modelo Moor Instruments, Moorlab ${ }^{\top м}$ (Axmminster, UK) acoplado a outro canal, usado para o armazenamento dos registros de fluxo

4.2 Disco de suporte e elemento de aquecer (esquerda) e sonda óptica 29 (direita), Moor Instrumments, Moorlab (axmminster, UK)

4.3 Unidade de aquecimento de pele, modelo SH02, Moor Instrumments, 29 Moorlab (Axmminster, UK)

4.4 Posicionamento das sondas nos dois sítios próximos estudados

4.5 Diagrama em blocos do banco de filtros digitais usados para separar sinais de registros de fluxo em sete faixas espectrais, segundo TAB. 4.1 
4.6 Gráfico de um registro de fluxo filtrado na banda B3 (superior) e de seu 33 valor absoluto (inferior)

5.1 Gráficos representativo de um registro de fluxo durante a temperatura 38 basal e de suas parcelas oscilantes, nas bandas B0 a B6

5.2 Gráfico de um sinal de fluxo filtrado na banda B3 e sua envoltória onde 39 pode ser verificado elevadas variações de amplitude. A envoltória varia mais lentamente que o sinal

5.3 Sinal de fluxo representativo durante um estimulo térmico sem filtragem 40 (traçado cinza) e filtrado (traçado preto, banda B0), suprimindo todas as frequências superiores a $0,005 \mathrm{~Hz}$

5.4 Figura 5.4: Gráficos representativos de um registro de fluxo e de suas parcelas oscilantes nas bandas B0 a B6 de um sinal de fluxo que sofreu um estimulo térmico

5.5 Erros percentuais (absoluto) de valores médios de fluxo e de suas parcelas flutuantes nas bandas B0 a B6 calculadas durante intervalos de 1 minuto quando comparados aos respectivos valores médios calculados durante 20 minutos

5.6 Erros percentuais dos valores médios de fluxo não filtrados $(F)$ e filtrados (B0), calculados em intervalos de um minuto tomando como referência os respectivos valores calculados em 20 minutos. Pares indicados por barras horizontais significam diferentes, ANOVA e Turkey, $p<0,05$. Barras verticais significam erros-padrão

5.7. Valores médios de duas senóides com frequências de $0,1 \mathrm{~Hz}$ e $1 \mathrm{~Hz} 48$ calculados em intervalos de tempo $\mathrm{T}$

5.8 Erros percentuais dos valores médios das amplitudes e das potências de sinais basais nas bandas B1 a B6. Barras horizontais significam diferenças entre pares (teste-t) e $\left({ }^{*}\right)$ significa diferente de todos os grupos, ANOVA e 
Turkey, $p<0,05$. Barras verticais significam erros-padrão

5.9 Erros percentuais dos valores médios das amplitudes de sinais no patamar durante estresse térmico nas bandas B1 a B6, estimados em um minuto, quando comparados aos valores estimados em 20 minutos. Pares (a, b, c, $d$, e) significam diferenças (ANOVA, Tukey, $p<0,05$ ). Barras verticais significam erros-padrão

5.10 Coeficientes médios de variações temporais de 20 registros de fluxo basal (F) e de seus respectivos sinais filtrados nas bandas $\mathrm{B} 0$ a $\mathrm{B} 6$ e de 20 registros de fluxo durante o estresse térmico. Barras horizontais significam diferenças entre pares (teste-t). $\left({ }^{*}\right)$ significa diferente dos grupos $\left.\mathrm{F} .{ }^{* *}\right)$ significa diferente dos demais grupos B1 a B6. ANOVA e teste de Tukey, $p<0,05$. Barras verticais significam erros-padrão

5.11 Fluxos médios de 20 registros durante temperatura basal e de 20 registros durante estresse térmico. Barras verticais significam erros-padrão

5.12 Amplitudes médias das oscilações (bandas B1 a B6) de 20 registros de fluxo durante temperatura basal e 20 registros durante estresse térmico. Barras verticais significam erros-padrão. Note-se que o eixo das ordenadas foi truncado para evidenciar as diferenças de amplitudes nas bandas B1 a B5

5.13 Valores médios de fluxo basal e de suas parcelas flutuantes nas duas regiões estudadas ( $R 1$ e $R 2$ ). Barras verticais significam erros-padrão

5.14 Valores médios de fluxo e de suas parcelas flutuantes nas duas regiões estudadas (R1 e R2), durante estresse térmico. Barras verticais significam erros-padrão. Note-se que o eixo das ordenadas foi truncado para evidenciar as diferenças de amplitudes nas bandas B1 a B5

5.15 Coeficientes de variação intragrupos nas bandas B0 a B6 
5.16 Segmentos de sinais de fluxo na região do patamar, durante um procedimento de estresse térmico, decomposto nas sete bandas espectrais estudadas (B0 a B6, de cima para baixo). Os sinais foram colhidos em duas regiões próximas ( $\mathrm{R} 1$, em azul e $\mathrm{R} 2$ em vermelho)

5.17 Segmentos de sinais de fluxo colhidos em duas regiões próximas de um voluntário, durante um procedimento de estresse térmico, decomposto na banda espectral B0, onde pode ser observado sincronismo entre as variações lentas e rápidas observadas nesta faixa espectral $(0$ a $0,005 \mathrm{~Hz})$

5.18 Valores médios da percentagem de tempo em que vinte pares de sinais nas bandas B0 a B6 permaneceram síncronos. $\left(^{*}\right)$ significa diferente das bandas B0 e B1 basais. ${ }^{* *}$ ) significa diferente das demais bandas. ANOVA e teste de Turkey, $p<0,05$. Barras verticais significam diferentes, teste-t. Barras verticais significam erros-padrão

5.19 Valores médios dos coeficientes de correlação de Pearson entre vinte pares de sinais nas bandas B0 a B6. $\left(^{*}\right)$ significa diferente das bandas B0 e B1 basais. $\left.{ }^{* *}\right)$ significa diferente das demais bandas. ANOVA e teste de Turkey, $p<0,05$. Barras verticais significam diferentes, teste-t. Barras verticais significam erros-padrão

5.20 Valores médios dos coeficientes de variação das percentagens de tempo em que vinte pares de sinais nas banda $\mathrm{B} 0$ a B6, permaneceram síncronos 


\section{LISTA DE ABREVIATURAS E SIGLAS}

$\begin{array}{ll}\text { AC } & \text { corrente alternada } \\ \text { AAV } & \text { anastomose arteriovenosa } \\ \text { CC } & \text { concentração de hemácias } \\ \text { F } & \text { corrente constante } \\ \text { F(UA) } & \text { fluxo } \\ \text { FDL } & \text { fluxo em unidades arbitrárias } \\ \text { SFLD } & \text { sinal De Fluxo Cutâneo obtido via fluxometria laser Doppler } \\ \text { ICC } & \text { parcela corrente contínua da fotocorrente } \\ \text { LASER } & \text { light amplification by stimulated emission radiation } \\ \text { LDI } & \text { laser Doppler imagem } \\ \text { NO } & \text { óxido nítrico } \\ \text { e-NOS } & \text { enzina sintetase do óxido nítrico } \\ \text { UA } & \text { unidades arbitrárias }\end{array}$




\section{LISTA DE SÍMBOLOS}

$\begin{array}{ll}\mathrm{m} & \text { metro } \\ \mathrm{nm} & \text { nanômetro } \\ \mathrm{mm} & \text { micrometro } \\ \mathrm{mW} & \text { milímetro } \\ \mathrm{s} & \text { miliwatt } \\ \mathrm{cm}{ }^{2} & \text { segundo } \\ \mathrm{mm}{ }^{3} & \text { centímetros quadrados } \\ \mathrm{mm}{ }^{3} / \mathrm{s} & \text { milímetros cúbicos } \\ \mathrm{g} & \text { milímetros cúbicos por segundo } \\ { }^{\circ} \mathrm{C} & \text { grama } \\ \mathrm{kHz} & \text { graus Celsius } \\ \mathrm{kg} & \text { quilohertz } \\ \mathrm{Hz} & \text { quilograma } \\ \end{array}$




\section{INTRODUÇÃO}

O sistema microvascular é responsável por vários processos biológicos, incluindo trocas gasosas, suprimento de nutrientes, transporte de hormônios e de células de defesa, retirada de metabólitos e controle da temperatura corpórea ${ }^{1,2}$.

O fluxo microvascular pode apresentar valores aproximadamente constantes durante vários minutos. $\mathrm{E}$ responde a vários estímulos, aumentando ou diminuindo consideravelmente seu valor médio. Os estímulos ocorrem constantemente e podem ser decorrentes de variações da pressão sanguínea ou de temperatura e, dentre outros, de injúrias.

Quando a musculatura lisa que envolve os microvasos não está ativa, os vasos respondem passivamente às diferenças de pressão transmural: o diâmetro aumenta ou diminui em face do aumento ou da diminuição da pressão sanguínea. Mas, quando os músculos estão funcionais, as arteríolas possuem a capacidade de responder ativamente a mudanças na pressão transmural: o diâmetro diminui quando a pressão transmural aumenta (vasoconstrição) e aumenta quando a pressão transmural diminui (vasodilatação). Desta forma, ao contrário do comportamento passivo, a relação entre pressão e diâmetro é inversamente proporcional. Tal mecanismo de regulagem é conhecido como miogênico, que é importante na manutenção do fluxo microvascular ${ }^{3}$. Outros mecanismos ativos de controle, além do mecânico, que induzem alterações no estado contrátil da musculatura lisa dos microvasos, são o neural e o metabólico ${ }^{3}$.

A avaliação do estado funcional microcirculatório tem sido alvo de intensa pesquisa $4,5,6,7,8,9$. Nos estudos realizados identifica-se que o controle ativo é composto por modulações do tônus vascular, resultando no relaxamento ou contração da musculatura lisa que envolve os vasos. Participam do controle ativo o endotélio (lâmina interna dos vasos), a enervação e a musculatura lisa que circunda os vasos $4,5,10$. 
No entanto, a capacidade de controle e resposta a estímulos pode estar alterada em face de uma série de disfunções ou hábitos comuns (ex., diabetes e o uso crônico do tabaco). Assim, é de interesse o entendimento dos processos fisiológicos e fisiopatológicos que ocorrem no plexo microvascular.

A Fluxometria Laser Doppler (FLD) tem sido amplamente utilizada com o propósito de analisar os processos fisiológicos e fisiopatológicos que ocorrem no plexo microvascular. Sobretudo, por ser uma técnica não invasiva, não destrutiva e que permite o monitoramento do fluxo microvascular em tempo real.

A FLD mede uma quantidade $(F)$ proporcional ao fluxo sanguíneo na região à qual o instrumento é sensível (aproximadamente $\left.1 \mathrm{~mm}^{3}\right)^{1,11}$, portanto, proporcional à perfusão sanguínea no volume estudado ${ }^{12}$. Uma vez que o fluxo microvascular varia no tempo, a quantidade (F) também apresenta variações temporais.

A quantidade $(F)$ média durante um intervalo de tempo, derivada do fluxo medido na pele intacta, tem sido usada na avaliação da capacidade de resposta microvascular a um estímulo destinado a provocar vasodilatação no fluxo cutâneo (ex., estresse térmico, fármacos vasoativos, hiperemia reativa ${ }^{5}$ ). A comparação do fluxo médio antes e depois do estímulo é um indicador da integridade da resposta microvascular ${ }^{13}$.

O fluxo microvascular, medido via FLD, apresenta um valor médio positivo, diferente de zero (valor constante). Modulando a fração constante, o fluxo microvascular (nos vasos com maiores calibres) é pulsátil, seguindo as diferenças de pressão macro-circulatórias. O fluxo apresenta ainda pequenas variações cíclicas (oscilações) decorrentes de processos de regulagem do fluxo, conhecidos por vasomotilidade. Tem sido observado que as flutuações cíclicas apresentam períodos distintos (e frequências distintas), segundo suas origens.

Por meio de ferramentas matemáticas correntes (análise espectral) foram identificadas seis faixas de frequências, em torno de $0,008 \mathrm{~Hz} ; 0,01 \mathrm{~Hz}$; $0,04 \mathrm{~Hz} ; 0,1 \mathrm{~Hz} ; 0,3 \mathrm{~Hz}$ e $1 \mathrm{~Hz}$, cujas origens são conhecidas: i) metabólica 
dependente do endotélio; ii) metabólica e NO-dependente do endotélio; iii) neurogênica; iv) miogênica; v) respiratória e; vi) cardíaca, respectivamente ${ }^{14}$. A identificação dessas bandas espectrais foi efetuada inicialmente através da transformada de Fourier e depois pela transformada de wavelet - que é, atualmente, é o método mais comum de análise da vasomotilidade.

Tem sido demonstrado que a amplitude das flutuações que ocorrem na faixa de frequência em torno de $0,01 \mathrm{~Hz}$ é um parâmetro microvascular que discrimina disfunções endoteliais, mesmo quando uma alteração mensurável do fluxo (F) a um estímulo vasodilatador não é identificada; sugerindo, assim, que a vasomotilidade detecte precocemente alterações endoteliais ${ }^{15}$. Embora estes resultados sejam relevantes, ainda há poucos trabalhos na literatura, e esses estudos somente demonstram que é possível diferenciar um grupo de indivíduos com respostas (vasodilatadoras a estímulos) normais de um grupo de indivíduos com respostas alteradas. A capacidade de um determinado teste (estímuloresposta) discriminar indivíduos (ao invés de grupos de indivíduos) cujas respostas sejam normais e alteradas ainda é inexplorada na literatura relacionada e de interesse no diagnóstico de disfunções microvasculares.

A capacidade de um teste discriminar grupos de indivíduos (ou de discriminar indivíduos) pode ser objetivamente medida, usando vários métodos conhecidos. Contudo, sem recorrer a métodos específicos de medição, geralmente a capacidade de discriminação de um teste aumenta quando a variabilidade do parâmetro discriminante diminui.

Os parâmetros discriminantes mais frequentemente usados são: fluxo médio medido $(F)$ ou parcelas de energia (E) das flutuações do fluxo (ou quantidades relacionadas com a energia: potência e amplitude). A quantidade ( $E)$ é proporcional à energia da parcela oscilante do fluxo na banda espectral considerada.

O fluxo medido via FLD varia no tempo e no espaço. As variações temporais decorrem das diferenças de pressão arterial e dos mecanismos de controle ${ }^{16}$. O fluxo medido via FLD também varia espacialmente, mesmo em 
regiões próximas em um mesmo indivíduo, face às variações morfológicas do plexo microvascular cutâneo ${ }^{1,17}$. Portanto, a variância de uma quantidade $(E)$ ou $(F)$, quando medida em um grupo de indivíduos, é função das variabilidades: i) temporal; ii) espacial e; iii) inter-indivíduos. Assim, quanto menor a variância das quantidades $(E)$ ou $(F)$, decorrente da variabilidade temporal, maior a capacidade de discriminação de um teste.

Embora seja conhecido que o fluxo $(F)$ medido varie entre indivíduos e até entre sítios próximos de um mesmo indivíduo, a variabilidade temporal de $(F)$ tem sido somente qualitativamente descrita na literatura ${ }^{1}$. Não foram encontrados estudos quantitativos ou qualitativos sobre a variabilidade temporal da quantidade $(E)$, talvez pela razão da análise espectral não ser adequada à análise temporal. Como consequência relevante, o intervalo de tempo (T) usado para computar o valor médio de (F) tem sido arbitrariamente escolhido. Como exemplo, intervalos entre $20 \mathrm{~s}^{18}$ e $600 \mathrm{~s}^{10}$ têm sido usados. Semelhantemente, o intervalo de tempo em que a quantidade $(E)$ é computada tem sido definido de forma arbitrária, variando entre 1 minuto ${ }^{19}$ até 30 minutos $^{14}$. Contudo, tem sido observado que as quantidades $(F)$ e $(E)$ variam vastamente em intervalos relativamente curtos de tempo. Assim, acredita-se ser importante caracterizar a variabilidade temporal das quantidades $(F)$ e $(E)$ e estabelecer critérios objetivos de quantificação de seus valores médios. Espera-se que a variância dessas quantidades possa ser conhecida, controlada e diminuída, aumentando, assim, a sensibilidade da técnica. 


\section{OBJETIVO}

O objetivo deste trabalho foi caracterizar, in vivo, as variações temporais, espaciais e espaço-temporais de sinais de fluxo sanguíneo cutâneo (medidos via Fluxometria Laser Doppler) em faixas espectrais segundo suas origens (cardíaca, respiratória, miogênica, neurogênica e metabólica) e propor critérios objetivos de quantificação de parâmetros hemodinâmicos de interesse ao estudo e diagnóstico de disfunções microvasculares. 


\section{REVISÃO DE LITERATURA}

Para a melhor compreensão deste estudo serão sucintamente delineados os aspectos morfológicos e funcionais da microcirculação, incluindo os mecanismos de controle conhecidos e, por fim, será apresentada uma síntese das aplicações da Fluxometria Laser Doppler no estudo do fluxo sanguíneo cutâneo incluindo as limitações da técnica.

\subsection{Microcirculação}

A microcirculação compreende a circulação do sangue nos vasos de menores calibres do corpo - nas arteríolas, capilares e vênulas com diâmetros menores de $100 \mu m^{1,20}$ - isto é, a circulação do sangue nos capilares através de arteríolas (entrada) e vênulas (saída).

A microcirculação consiste em uma unidade morfológica e funcional do sistema cardiovascular, tendo como função vital o transporte de nutrientes para as células à distância, bem como a troca de produtos residuais com os tecidos circundantes para suprir as necessidades corporais de oxigênio, de nutrientes e remover produtos de excreção. A microcirculação apresenta também funções hemodinâmicas específicas, com a finalidade de adequar as demandas específicas de cada tecido ou órgão. Seguem as definições das principais estruturas microvasculares:

\subsubsection{As estruturas microvasculares}

São compreendidas como estruturas funcionais da microcirculação, os seguintes segmentos, ilustrados na FIG. 3.1:

- Arteríolas: são as menores divisões do sistema arterial e atuam como válvulas de controle pelas quais o sangue entra nos capilares. Esses vasos variam entre $5-100 \mu m$ de diâmetro e são inervados por fibras nervosas não mielinizadas. Têm paredes revestidas por uma camada adventícia fina. Apresentam um revestimento endotelial e muscular liso 
resistente, o qual pode contrair ou relaxar, permitindo, assim, alterar o fluxo sanguíneo de acordo com a necessidade de cada tecido. As arteríolas dão origens aos capilares e às metarteríolas. As arteríolas, por apresentarem um raio pequeno, oferecem maior resistência ao fluxo sanguíneo e regulam o fluxo regional para o leito capilar ${ }^{20,21 .}$

- Metarteríolas ou Arteríolas terminais: são vasos que ligam as arteríolas e as vênulas diretamente. As metarteríolas apresentam diâmetros entre 10 a $20 \mu \mathrm{m}$ e não são revestidas por tecido muscular liso, mas apresentam fibras de músculo liso rodeando o vaso em pontos intermitentes. No ponto em que os verdadeiros capilares se originam das metarteríolas recobertas por fibras de músculo liso, encontram-se os esfíncteres pré-capilares, os quais podem, face a contração da fibra muscular, abrir e fechar a entrada do capilar. Os esfíncteres capilares apresentam alto tônus miogênico e são muito sensíveis às alterações metabólicas locais ${ }^{20,21 .}$

- Capilares: São vasos que variam de 5 a $10 \mu m$ de diâmetro. Suas paredes são compostas exclusivamente por uma única camada de células endoteliais mais ou menos fenestradas, o que os tornam altamente permeáveis a água e a diversas substâncias moleculares, o que permite que se assegure rápidas trocas de fluídos, gases, nutrientes, hormônios, metabólitos e produtos de excreção celulares entre o plasma sanguíneo e os tecidos. Os capilares ramificam-se de uma arteríola ou de uma metarteríola, que se encontra entre uma arteríola e uma vênula. Os capilares, devido à simplicidade de sua organização, não possuem vasomotricidade capaz de realizar vasoconstrição ou dilatação, sendo o fluxo capilar regulado pela abertura e fechamento dos esfíncteres précapilares $^{21}$. 
- Anastomoses arteriovenosas: são vasos curtos e retos ou

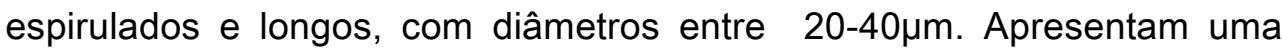
espessa camada muscular, ricamente inervada por nervos colinérgicos e com ação vasodilatadora - a qual é muito importante na termorregulação e na manutenção da pressão arterial. Essas anastomoses arteriovenosas (AAV) comunicam uma arteríola diretamente com uma vênula. Esses vasos são encontrados em regiões especificas, como, por exemplo, nas pontas dos dedos, nas palmas das mãos, nas solas dos pés, nas orelhas, na ponta do nariz e nos lábios ${ }^{21}$.

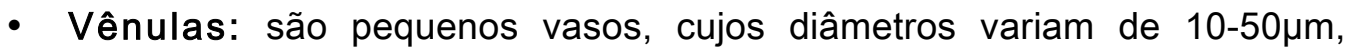
responsáveis por colherem o sangue dos capilares. As vênulas como as arteríolas possuem três camadas de tecido; porém, mais finas especialmente a camada média. A pressão nelas é mais baixa do que nas arteríolas. As veias atuam como condutoras para o transporte do sangue dos tecidos até o coração, mas, de forma igualmente importante, servem como reserva fundamental do sangue. As veias têm um calibre muito maior do que as artérias, sendo seu fluxo muito mais lento. As vênulas devolvem ao coração o sangue contra a gravidade e, por isso têm válvulas que fomentam o fluxo de retorno venoso ao coração 21

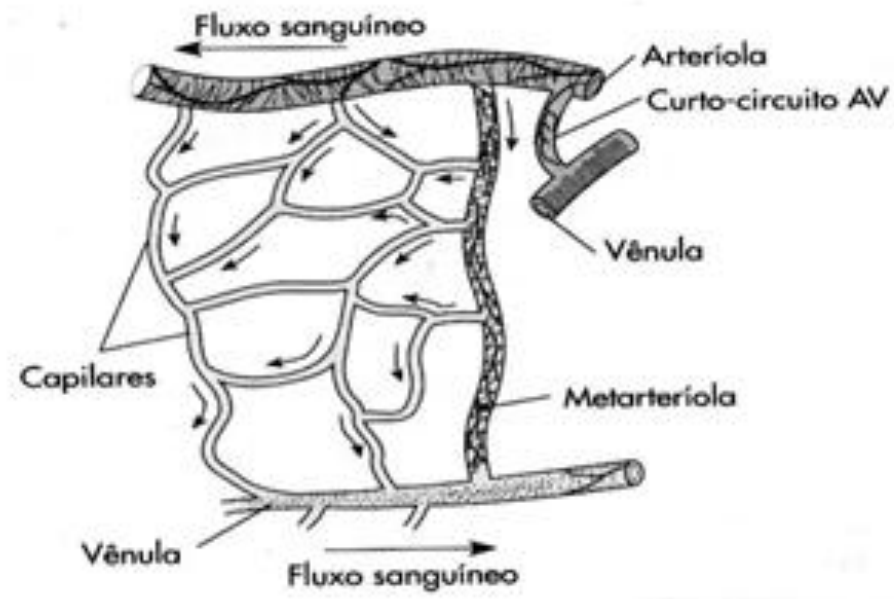

Figura 3.1: Desenho esquemático da microcirculção. As estruturas circulares na arteríola e na vênula representam as fibras de músculo liso e as linhas sólidas ramificadas representam fibras nervosas simpáticas. As setas indicam a direção do fluxo sanguíneo. Adaptado de Berne et al., 200421 


\subsubsection{Microcirculação cutânea}

A pele tem um sistema microvascular complexo, envolvido na realização de duas grandes funções 22: a) manutenção do débito sanguíneo para nutrição, participando das trocas metabólicas entre o sangue e os tecidos (ação logo-regional), esta função predomina nas regiões cutâneas reconhecidas como nutritivas; b) manutenção e regulação do débito sanguíneo para manter o tecido termorregulado (ação sistêmica) - tal função predomina nas áreas termorregulatórias da pele, as quais são ricas em anastomoses arteriolovenulares ou arteriovenosas (AAV).

A função principal da microcirculação cutânea é a manutenção de uma temperatura corporal constante $-85 \%$ do fluxo sanguíneo na microcirculação da pele é responsável pela termorregulação, enquanto que o restante corresponde à atividade nutricional ${ }^{2}$. Assim, o fluxo sanguíneo da pele sofre amplas flutuações de acordo com as necessidades de diminuição ou aumento da temperatura da camada cutânea em razão das variações da temperatura corporal interna ou das provindas do ambiente externo.

A pele é constituída, anatomicamente, por duas camadas: epiderme e derme. A epiderme é a camada mais externa, constituída por uma camada de queratina com espessura entre 40-50 $\mu \mathrm{m}$, e é livre de vasos sanguíneos. As regiões sujeitas a maior atrito (como, por exemplo, palmas das mãos e pés) têm uma camada mais espessa (conhecida como pele glabra, por não possuírem pelos), e, no entanto, a camada epidérmica atinge uma espessura de $200-400 \mu m$ 23.

A derme é um tecido conjuntivo que sustenta a epiderme, constituído por elementos fibrilares, como o colágeno e a elastina e outros elementos da matriz extracelular. A derme é subdividida em duas camadas: a camada papilar em contato com a epiderme, formada por tecido conjuntivo frouxo, e a camada reticular, constituída por tecido conjuntivo denso não modelado, onde predominam as fibras colagenosas. É na derme que se localizam os vasos linfáticos, os nervos e os órgãos sensoriais a eles associados e, também, os vasos sanguíneos que nutrem a epiderme. 
$\mathrm{Na}$ região da derme se verifica uma grande quantidade de capilares, os quais surgem das papilas da derme e retornam para as subpapilares do plexo venoso. E, em uma profundidade entre 0,04 e 0,27 $\mathrm{mm}$ da superfície da pele, verifica-se a presença de alças capilares, com comprimento entre 0,2 e 0,4 mm e diâmetro médio de $10 \mu \mathrm{m}^{23}$, conforme se pode observar na FIG. 3.2.

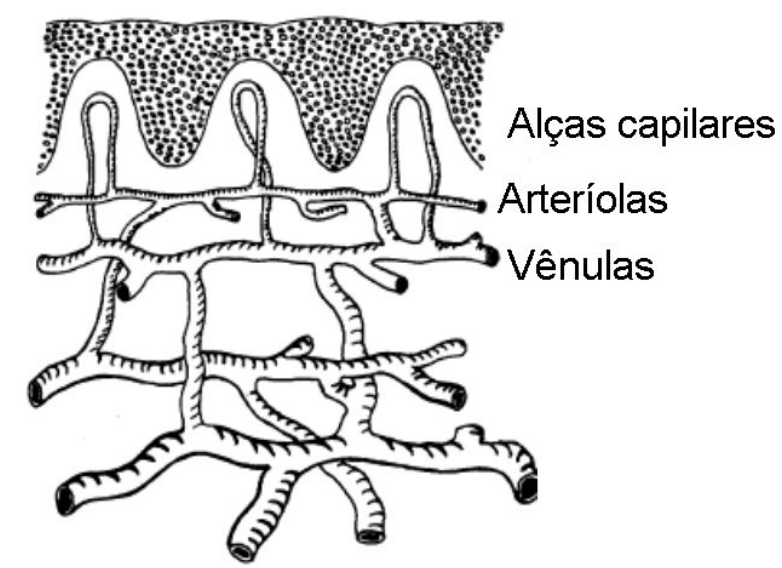

Figura 3.2: Esquema da estrutura vascular da pele adaptado de Nilsson, et al.23

\subsubsection{Hemodinâmica}

Para a compreensão do fluxo sanguíneo e suas variações, o sistema circulatório pode ser comparado a um tubo contendo um líquido, sujeito às leis da Física para poder se movimentar. O fluxo sanguíneo refere-se ao volume de sangue que é deslocado na luz do vaso, em relação a um dado intervalo de tempo, sendo expresso em unidade de volume por tempo (e.g., $\left.\mathrm{mm}^{3} / \mathrm{s}\right)^{24,25}$.

O fluxo em um vaso sanguíneo é proporcional ao gradiente de pressão $(\Delta P)$ ao longo do vaso. A relação entre o fluxo sanguíneo e a pressão pode convenientemente ser expressa em termos da resistência vascular $(R)$ :

$$
R=\Delta P / F
$$


O fluxo é diretamente proporcional à diferença de pressão e à quarta potência do raio do tubo, e inversamente proporcional ao comprimento $(l)$ do tubo e à viscosidade $(\eta)$ do fluido 24,25 , podendo ser expresso na seguinte forma (lei de Poiseuille):

$$
F=\frac{\pi r^{4}}{8 \eta l} . \Delta P
$$

Assim, quanto maior a diferença de pressão entre as extremidades, maior será o fluxo; já que o aumento da viscosidade e o comprimento do tubo colaboram para a diminuição do fluxo. Contudo, quando se trata de controle do fluxo, o elemento de maior relevância desta equação é o raio do tubo estar elevado à quarta potência - posto que, se for dobrado o raio do tubo, o fluxo aumentará em 16 vezes seu valor original, mantendo-se constante a diferença de pressão $(\Delta \mathrm{P})$.

\subsection{Mecanismos de controle do fluxo sanguíneo}

O fluxo sanguíneo em uma região varia de acordo com as suas necessidades fisiológicas e, de forma relativa, com a pressão de perfusão. A regulagem do fluxo sanguíneo é produzida pela autorregulação central, regional e/ou local. Aparentemente os três sistemas de controle se acoplam ou interpenetram para, em razão de perturbações, gerar o efetivo controle ${ }^{22}$. São sistemas de controle do fluxo sanguíneo:

1) Controle intrínseco ou local - Quando os tecidos regulam o fluxo sanguíneo local de acordo com suas necessidades. Tal mecanismo pode ser dividido em duas etapas:

a) Controle a longo prazo: quando ocorrem alterações lentas no fluxo sanguíneo - isto é, quando tais alterações ocorrem em períodos de dias, 
semanas ou mesmo meses. Esse mecanismo está correlacionado às alterações de grau de vascularização de um determinado tecido. Isto é, o número de vasos pode aumentar ou diminuir em razão de determinadas alterações em um tecido ou em relação ao tempo de exposição deste a condições metabólicas específicas (como, por exemplo, quando o metabolismo em um dado tecido é aumentado por um período prolongado, verifica-se o aumento da vascularização, e; quando o metabolismo diminui, por um período prolongado, observa-se uma diminuição daquela vascularização) ${ }^{22}$.

b) Controle agudo: quando ocorrem rápidas alterações no controle do fluxo para manter as necessidades adequadas do tecido local. Esse controle se dá através da dilatação ou constrição das arteríolas, metarteríolas e esfíncter pré-capilares em minutos ou até mesmo em poucos segundos 22 .

No controle local agudo do fluxo sanguíneo é possível ainda, ocorrer alguns mecanismos específicos de controle, como, por exemplo:

- Mecanismo miogênico - É caracterizado pela capacidade da musculatura lisa se contrair em resposta a um aumento da pressão transmural (diferença entre a pressão interna e externa do vaso) e relaxarse quando essa pressão diminui. Portanto, se a pressão interna do vaso aumenta, a tendência é reduzir o diâmetro desse vaso, ocorrendo assim uma autorregulação do fluxo sanguíneo ${ }^{22}$.

- Mecanismo metabólico - É determinado pelo aumento da atividade metabólica do tecido. Por exemplo, uma inadequada quantidade de suprimento de oxigênio $\left(\mathrm{O}_{2}\right)$ favorecerá a formação de metabólitos vasodilatadores, os quais atuarão sobre a musculatura lisa do esfíncter pré-capilar, da arteríola e metarteríola, relaxando-os e fazendo com que se aumente o fluxo nessa região 22 . 
- Mecanismo de regulação mediado pelo endotélio - O endotélio é uma fonte importante de substâncias que provocam a contração ou relaxamento da musculatura lisa vascular, as quais podem ser liberadas pelo endotélio em decorrência de um aumento na força de cisalhamento provocado por um aumento de fluxo. Uma substância que exerce uma grande influência na vasodilatação é o óxido nítrico (NO) - o qual é formado nas células endoteliais a partir do substrato da L-arginina pela ação da enzima NO-sintetase (e-NOS). A difusão do NO para células vasculares lisas é a mediadora ou a responsável pelo seu efeito relaxador. Desse modo, quando o endotélio é estimulado por substâncias vasodilatadoras, como, por exemplo, a acetilcolina, o NO é liberado, provocando, desta forma, uma vasodilatação 22 .

2) Controle extrínseco ou neural - Esse controle, na maioria dos tecidos, está relacionado com funções globais, tais como: redistribuição do fluxo sanguíneo para diferentes partes do corpo, aumento da frequência e da contratilidade cardíaca e, especialmente, ajuste rápido da pressão arterial.

Nas regiões glabras da pele, os vasos são somente inervados por fibras nervosas do sistema nervoso simpático e conduzem elevado número de fibras vasoconstritoras e poucas vasodilatadoras. Essa distribuição é maior em alguns tecidos do que em outros, em especial na pele, no intestino e no rim, e; menos acentuado no músculo esquelético e no cérebro. Essas fibras são do tipo adrenérgicas. Portanto, liberam noradrenalina e produzem vasoconstrição. Em regiões não glabras, os vasos são inervados por dois ramos do sistema nervoso simpático: nervos noradrenérgicos vasoconstritores e nervos colinérgicos vasodilatadores ${ }^{16}$.

3) Controle humoral - O mecanismo de controle humoral é definido pela regulação do fluxo sanguíneo por substâncias secretadas ou absorvidas (como, por exemplo, hormônios, substâncias vasoativas, entre outros). Os hormônios e as substâncias vasoativas apresentam ação sobre 
o sistema circulatório e participam dos mecanismos de regulação do fluxo, quer separadamente ou em colaboração com o sistema nervoso. Algumas destas substâncias são produzidas em determinadas glândulas e são liberadas no sangue, que as transporta pelo corpo todo. Outras são geradas na regiões de tecido em resposta a condições locais ou são liberadas por nervos excitados. Entre as substâncias mais importantes que atuam com controle humoral no sistema circulatório encontram-se: substâncias vasoconstritoras (Norepinefrina e Epinefrina, Angisotensina, Vasopressina e Endotelina) e substâncias vasodilatadoras (Bradicinina, Histamina e Prostaglandina). A Histamina está armazenada nos grânulos dos mastócitos, dos basófilos e plaquetas ${ }^{22}$.

\subsection{Técnicas de estudo da microcirculação}

Diferentes técnicas vêm sendo utilizadas ao longo dos anos para analisar o fluxo microvascular, tais como: estudo de cortes histológicos, injeção de microesferas fluorescentes ou radioativas, taxa de respiração tecidual e observação direta no microscópio (microscopia intravital). Porém, essas técnicas possuem limitações por serem invasivas e destrutivas, permitindo desta maneira uma única observação do fluxo sanguíneo; sendo, geralmente, aplicáveis somente em modelos animais. No entanto, há uma grande variedade de métodos nãoinvasivos para investigar a microcirculação da pele, tais como: técnicas que permitem apenas a visualização dos microvasos - como, por exemplo: vídeo capilaroscopia, tomografia por coerênca óptica (OCT) e imagem por ressonância magnética (MRI); técnicas que medem fluxo sanguíneo - como, por exemplo: a Fluxometria laser Doppler (FLD), Laser Doppler imaging (LDI) e a Fotopletismografia ${ }^{4}$.

A Fluxometria Laser Doppler, também conhecida por "single poinf', permite a medição do fluxo em tempo real, de forma contínua e em um determinado ponto. Enquanto que a Laser Doppler imaging é caracterizada por um sistema de imagem do fluxo, onde um feixe laser colimado varre uma região 
entre poucos milímetros quadrados $\left(\mathrm{mm}^{2}\right)$ até frações de metros quadrados $\left(\mathrm{m}^{2}\right) \mathrm{e}$ um sistema óptico remoto de coleção detecta a radiação espalhada ${ }^{5}$ - tal técnica requer um tempo maior para digitalizar a imagem do fluxo (entre 1 a 5 minutos, dependendo da área e resolução), o que dificulta realizações de medidas em tempo real ${ }^{4}$, limitando o uso da técnica no estudo de variações rápidas de fluxo; entretanto, cabe ressaltar que se compreende que os sistemas de imagem em tempo real poderão ser viáveis em um futuro próximo ${ }^{5}$.

E, tendo sido a Fluxometria Laser Doppler a técnica utilizada neste estudo, compreende-se que, para melhor compreensão desta, deve ser apresentada uma breve revisão dos seus princípios de funcionamento, de suas características e, também, da aplicação desta para detectar disfunções microcirculatórias. Considerações que serão realizadas no tópico seguinte.

\subsection{Fluxometria Laser Doppler}

Em 1842, o matemático, físico e astrônomo austríaco Johann Christian Andreas Doppler descreveu teoricamente pela primeira vez o princípio de quando uma onda é emitida ou refletida por um objeto que está em movimento em relação ao observador que está em repouso, ou parado. Descreveu, assim, que a referida onda sofre uma perturbação, gerando, por conseguinte, um desvio em frequência proporcional à velocidade do alvo. Esta é conhecida como efeito Doppler - o qual representa a alteração da frequência percebida pelo observador em virtude do movimento relativo (aproximação ou afastamento) entre fonte e observador.

Baseada neste princípio foi desenvolvida a Fluxometria Laser Doppler (irradiação do tecido biológico interrogado, normalmente usando-se um laser de baixa potência - entre $1 \mathrm{~mW}$ a $3 \mathrm{~mW}$ ), a qual possibilita medir, de forma não invasiva, variações sensíveis de parâmetros hemodinâmicos de microvascularização (tais como: fluxo sanguíneo, velocidade de fluxo e concentração das hemácias contidas em um dado volume) em vasos sanguíneos 
com diâmetros entre $4 \mu \mathrm{m}$ a $100 \mu \mathrm{m}^{1}$ (capilares, vênulas e arteríolas) contidos em um pequeno volume de tecido. Nos tecidos moles, o fluxômetro Laser Doppler é sensível a uma profundidade de aproximadamente $1 \mathrm{~mm}$ e a um volume de 1$1.5 \mathrm{~mm}^{3}$.

Segundo Humeau et al. ${ }^{12}$, em 1972, Riva et al. foram os primeiros a relatar medidas de fluxo microvascular através do efeito Doppler. Em 1975, Stern ${ }^{26}$ sugeriu que a perfusão tecidual, ao contrário do fluxo em um vaso único, pode ser medida com a técnica FDL.

\subsubsection{Princípios de funcionamento}

Os fluxômetros Laser Doppler servem para medir fluxo sanguíneo $(F)$, velocidade $(V)$ e concentração $(C)$ das hemácias. Tais medições são indicadas em unidades arbitrárias (UA), posto que o volume irradiado geralmente não pode ser conhecido.

Quando um determinado volume de tecido é irradiado por um Laser, verifica-se que parcela da radiação transmitida é espalhada tanto pelos tecidos estáticos quanto pelas células sanguíneas. A radiação espalhada pelas hemácias sofre um desvio de frequência (efeito Doppler) proporcional às suas velocidades. Uma parcela da radiação retro-espalhada, tanto pelas hemácias quanto pelos tecidos estáticos, é coletada e guiada por outra fibra óptica (posicionada próxima à que irradia, conforme ilustra a FIG. 3.3), até um detector no instrumento, o qual gera um sinal de fotocorrente.

O sinal de fotocorrente contém uma parcela de corrente constante (CC) proporcional à intensidade da radiação retro-espalhada e uma corrente variante (sinal Doppler) que contém as informações sobre a microcirculação sanguínea. 


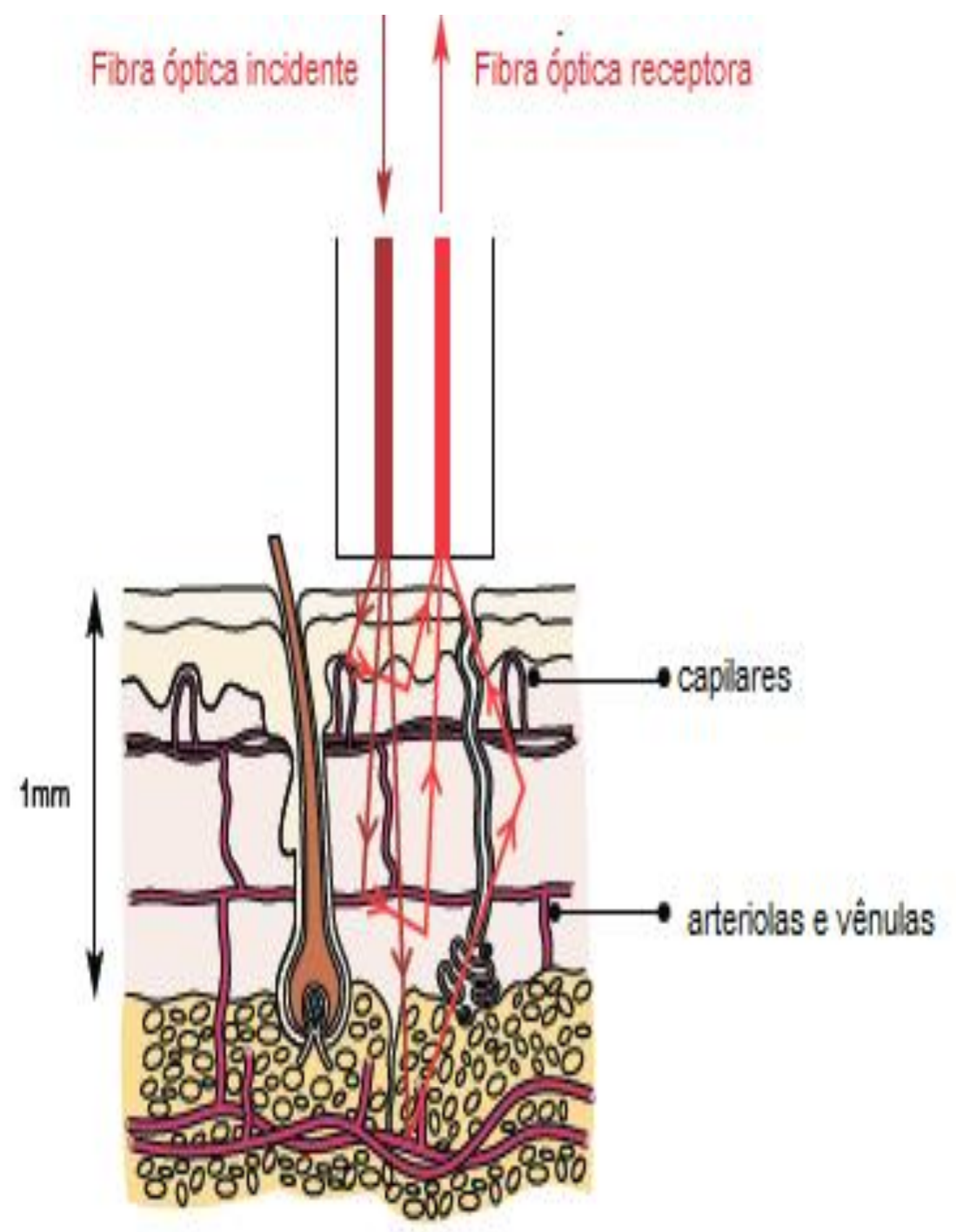

Figura 3.3: Esquema de operação da FLD , mostrando as fibras ópticas e a profundidade de penetração da luz que o aparelho é sensível ${ }^{27}$

O fluxômetro Laser Doppler é sensível a pequenos deslocamentos, da ordem de $0,1 \mathrm{~mm} / \mathrm{s}$. Assim, para evitar que os movimentos involuntários do paciente (respiração e contrações da musculatura) interfiram significativamente nas medições, torna-se necessária a fixação mecânica da sonda sensora.

Os fluxômetros laser Doppler indicam uma quantidade de fluxo (F) calculada a partir do primeiro momento do espectro de potência do sinal Doppler, conforme demonstra a expressão matemática (3) ${ }^{28}$ : 


$$
F=k \cdot \frac{\int_{f 2}^{f 1} f \cdot s(f) \cdot d f}{(I c c)^{2}}-\text { ruído }
$$

onde $\mathrm{F}$ é o fluxo medido, $k$ é uma constante que é dependente do instrumento, $S(f)$ é a densidade espectral de potência da parcela da corrente variante $(C V)$, sendo $f_{1}$ e $f_{2}$ a faixa de frequências que restringe o sinal Doppler (banda Doppler), Iccé a parcela relacionada à corrente constante $(\mathrm{CC})$ que é relativo à porção da potência total da radiação retro-espalhada 29 .

O primeiro momento do espectro de potência do sinal Doppler é normalizado pela parcela de corrente constante da fotocorrente, com a finalidade de corrigir as variações da intensidade da radiação retro-espalhada, decorrentes das variações da intensidade do laser, das diferenças da cor do tecido e do ângulo de irradiação. A frequência $f_{1}$ normalmente é fixada entre 20 a $250 \mathrm{~Hz}$, tendo como finalidade minimizar as variações intensas da parcela CV (não é sinal Doppler), decorrentes das variações dos caminhos ópticos da radiação retroespalhada em função do ciclo cardíaco (efeito pletismógrafo). A frequência $f_{2}$ restringe a banda Doppler em seu limite superior, geralmente em $3 \mathrm{kHz}, 15 \mathrm{kHz}$ ou $22 \mathrm{kHz}$. A parcela ruído refere-se a parcela de ruído do sinal Doppler, proveniente do próprio circuito eletrônico do aparelho e do Laser29.

Alguns equipamentos permitem a escolha da banda Doppler, a qual pode ser fixada em $3 \mathrm{kHz}$ para medir velocidades de até $1 \mathrm{~mm} / \mathrm{s}$, em $15 \mathrm{kHz}$ para medir velocidades de até $7 \mathrm{~mm} / \mathrm{s}$ e em $22,5 \mathrm{kHz}$ para medir velocidade acima de $10 \mathrm{~mm} / \mathrm{s}$. Quando a velocidade de fluxo é baixa (resultando baixos deslocamentos em frequência), limitar a banda Doppler em $3 \mathrm{kHz}$ ou $15 \mathrm{kHz}$ melhora a relação entre o sinal de fluxo e o ruído.

\subsubsection{Fluxometria Laser Doppler na pele - aplicações e limitações}

A Fluxometria Laser Doppler (FLD) tem sido aplicada em diversas áreas da medicina, como, por exemplo, na reumatologia, na angiologia, na dermatologia, na cirurgia plástica e, dentre outras, na endocrinologia. Essa técnica 
também tem sido largamente utilizada para estudar o fluxo cutâneo, pois acreditase que a função microvascular cutânea espelha o estado da microcirculação em outros leitos microvasculares, incluindo o músculo cardíaco ${ }^{5}$. Dada a relevância e interesse desta última aplicação da FLD, existe vasta literatura sobre métodos de estímulo-resposta úteis no estudo da função microvascular, assim como sobre as principais limitações da técnica, cuja síntese é apresentada na sequência.

\section{A- Variabilidade do fluxo}

A FLD apresenta vantagens em relação às demais técnicas, tais como ser não invasiva e apresentar uma aplicação simples ${ }^{1}$, possibilitando medir variações do fluxo microvascular de maneira contínua e em tempo real. Por outro lado, a técnica apresenta, também, algumas limitações. Além das limitações já anteriormente apontadas (não mede valores absolutos e apresenta elevada variabilidade intraindivíduos e interindivíduos) o fluxo também apresenta variabilidade postural, por diferenças de idade, temporal e espacial ${ }^{30,31}$. Também tem sido relatado a ocorrência de variações espaciais (quando medidas regiões próximas em um mesmo indivíduo) e de variações temporais (variações entre mínimos e máximos, quando uma região é continuamente monitorada em um intervalo de tempo $)^{1}$.

Assim o fluxo médio medido via FLD é um parâmetro que apresenta uma variabilidade grande. Em razão disto, tem sido comum o uso de métodos destinados a minimizar a variabilidade.

A normalização do valor médio do fluxo durante o estímulo pelo valor médio do fluxo basal tem sido usada para minimizar a variabilidade ${ }^{10,32}$. A normalização dos valores de fluxo medido em uma região de estudo, usando como referência o fluxo medido em um sítio sadio próximo ao interrogado, também tem sido sugerido para minimizar a variabilidade ${ }^{33}$.

A normalização do fluxo medido pela pressão sanguínea média é outro recurso usado para minimizar a variabilidade. Uma vez que a razão entre fluxo e pressão tem dimensão de condutância vascular (recíproco de resistência 
vascular), o parâmetro resultante tem sido denominado condutância vascular cutânea $(\mathrm{CVC})^{34}$.

\section{B- Estímulos vasodilatadores}

Tem sido verificado que a capacidade de vasodilatação (que é uma resposta a estímulos, tais como: alteração da pressão tissular local, infecções, estresse térmico) pode estar alterada em uma fração significativa da população (ex., em fumantes crônicos e diabéticos).

Uma técnica usada para evidenciar uma alteração de fluxo é produzir um estímulo vasodilatador e medir sua resposta. Contudo, é necessário o conhecimento das características anatômicas e funcionais das diferentes regiões microcirculatórias, para que seja possível compreender as mudanças induzidas por estímulos.

labichella et al. ${ }^{35}$ mediram o fluxo microvascular em diferentes regiões anatômicas, sendo uma o dorso do pé (região nutricional) e outra a polpa do hálux (região termorregulatória, com acentuada anastomose arteriovenosa AAV). Ambas foram medidas em condição de fluxo basal e após um estímulo térmico. Nestas condições, o estímulo térmico variou em $8^{\circ} \mathrm{C}$ : de $36^{\circ} \mathrm{C}$ para $44^{\circ} \mathrm{C}$. Pela análise dos dados fornecidos pelos autores ${ }^{35}$ é possível estimar que o fluxo medido na polpa do hálux a $44^{\circ} \mathrm{C}$ foi $466,6 \%$ maior que o fluxo medido a $36^{\circ} \mathrm{C} \mathrm{e}$ na região do dorso do pé o fluxo medido a $44^{\circ} \mathrm{C}$ foi $275 \%$ maior que o fluxo medido a $36^{\circ} \mathrm{C}$, evidenciando as diferenças nas respostas. Portanto, a escolha da região é um fator importante a ser considerado, pois existem regiões ricas em anastomoses arteriovenosas, as quais respondem mais intensamente à temperatura que outras regiões (conhecidas como nutricionais).

Tem sido demonstrado que um aquecimento local igual ou superior a $42^{\circ} \mathrm{C}$ é capaz de induzir máxima vasodilatação. Contudo, as alterações no fluxo sanguíneo em resposta ao estímulo térmico local dependem da temperatura, da taxa de sua elevação e da duração do calor ${ }^{10,13}$. É conhecido que baixas taxas de aquecimento, em torno de $0,1^{\circ} \mathrm{C} / \mathrm{min}$, ativa principalmente a vasodilatação 
mediada pelo óxido nítrico; enquanto taxas mais elevadas (taxas de aquecimento em torno de $\left.0,1^{\circ} \mathrm{C} / \mathrm{s}\right)^{36}$, o estímulo resulta uma resposta bifásica não dolorosa, induzida por reflexos neurogênicos e pela produção local de óxido nítrico (NO). A resposta bifásica é caracterizada por uma crista inicial de rápida duração de 3 a 5 minutos. Após a fase inicial segue-se um decréscimo moderado e um aumento lento, o qual se estabiliza numa fase de platô sustentado, que se dá entre 20 a 30 minutos após o início do aquecimento. A origem da crista inicial é neurogênica: a ativação de receptores termo-sensíveis fibras aferentes causam uma resposta antidrômica e liberação de um ou mais neurotransmissores vasodilatadores ${ }^{16}$. A fase de platô é dependente do óxido nítrico 10, 37, 38 .

A resposta ao estímulo térmico na pele tem sido largamente estudada objetivando diagnosticar precocemente doenças vasculares $5,1016,39,40$. Outros estímulos, tais como: a pressão local, manobras respiratórias (inspiração profunda; manobra de Valsalva) ${ }^{41}$ e fármacos (iontoforese), 5, 42, 43, 44, 45 também têm sido usados .

A iontoforese é uma injeção iônica de drogas. Com a técnica, pequenas doses de fármacos vasoativos são localmente injetadas. Exemplos de fármacos vasodilatadores ionizáveis são acetilcolina ${ }^{16}$ e 0 nitroprussiato de sódio 42 .

Manobras respiratórias são utilizadas para avaliar a integridade dos mecanismos de controle autonômico cardiovascular. As manobras respiratórias podem ser tanto a de Valsava como a inspiração profunda ${ }^{5,41}$.

A oclusão tem sido utilizada como estímulo para testar a resposta endotelial. Tal estímulo é também conhecido por causar uma hiperemia reativa como resposta a uma oclusão parcial ou total. Oclusões parciais acima de $25 \mathrm{~mm}$ Hg 46,47 são usadas para induzir a constrição venoarteriolar, enquanto que oclusões completas (pressão supra sistólica), por volta de $10 \mathrm{~s}$, são utilizadas para investigar respostas miogênicas transitórias na função endotelial 48,49, 50,51.

A TAB. 3.1 sintetiza os principais estímulos usados no estudo da função e disfunção microvascular. 
Tabela 3.1: Métodos correntes de estímulo em diferentes regiões de análise, com o objetivo de evidenciar contraste de parâmetros hemodinâmicos usados para discriminar o status microcirculatório.

\begin{tabular}{|c|c|c|c|}
\hline Autores & Estímulo & Região & Parâmetro hemodinâmico \\
\hline Stevens, M.J. et al. ${ }^{52}$ (1991) & Aquecimento & Pé e Hálux & Fluxo médio \\
\hline Aso, et al. ${ }^{41}$ (1997) & $\begin{array}{l}\text { Inspiração } \\
\text { profunda }\end{array}$ & Hálux & Fluxo médio \\
\hline Arora,S et al. ${ }^{43}(1998)$ & $\begin{array}{l}\text { Iontoforese e } \\
\text { aquecimento }\end{array}$ & Dorso do pé & Fluxo médio \\
\hline $\begin{array}{c}\text { Stefanovslka, A, et al. }{ }^{53} \\
\text { (1999) }\end{array}$ & Iontoforese & Antebraço & Analise espectral (wavelet) \\
\hline Pfützener,A et al. ${ }^{54}$ (2001) & $\begin{array}{l}\text { Iontoforese e } \\
\text { aquecimento }\end{array}$ & Pé & Fluxo médio \\
\hline Minson et $a l^{10}(2001)$ & $\begin{array}{l}\text { Aquecimento } \\
\text { microdialise }\end{array}$ & Antebraço & Fluxo médio \\
\hline Koïtka, et al. ${ }^{55}(2004)$ & $\begin{array}{c}\text { Iontoforese, } \\
\text { pressão e } \\
\text { aquecimento }\end{array}$ & Braço & Fluxo, condutância vascular cutânea(CVC) \\
\hline Wigington et al. ${ }^{56}$ (2004) & Aquecimento & Hálux e pé & Fluxo médio \\
\hline Brooks, et al. ${ }^{44}(2008)$ & Iontoforese & Dorso do pé & Fluxo médio \\
\hline Avery, et al. ${ }^{57}$ (2009) & Aquecimento & Antebraço & analise espectral \\
\hline Esen, F et al. ${ }^{58}(2009)$ & Aquecimento & Antebraço & Analise espectral (wavelet) \\
\hline Strom, et al. ${ }^{9}$ (2009) & Aquecimento & Antebraço & Fluxo, condutância vascular cutânea(CVC) \\
\hline Tew, et al. ${ }^{39}$ (2011) & Aquecimento & Antebraço & Analise espectral \\
\hline
\end{tabular}




\section{C- Vasomotilidade}

Geralmente é possível visualizar em um sinal de fluxo, medido via FLD, além das variações rápidas seguindo o ciclo cardíaco, ritmos mais lentos, com frequência entre 5 a 10 ciclos por minuto. Tem sido sugerido que essas variações cíclicas (oscilações) decorrem de processos regulatórios do fluxo e são conhecidas por vasomotilidade ${ }^{31}$. Assim, um registro de fluxo medido via FLD contém não somente informação de valores médios de fluxo sanguíneo da pele, como, também, contém informações sobre a vasomotilidade ${ }^{59}$. Mas a análise direta das flutuações em um registro de fluxo não é trivial, pois possuem padrões complexos e geralmente não é possível separá-las visualmente ou usando ferramentas matemáticas comuns.

Porém, nas últimas duas décadas, a análise do registro no domínio das frequências ${ }^{60}$ ou no domínio tempo-frequência ${ }^{14,61,62,63}$ permitiu separar as flutuações encontradas em um registro de fluxo, possibilitando uma maior compreensão dos mecanismos oscilatórios do fluxo sanguíneo cutâneo e de suas origens.

Inicialmente, análises das flutuações do fluxo, no domínio das frequências, eram realizadas usando transformadas de Fourier. Mais recentemente, a transformada de wavelet foi introduzida na área, com a vantagem de apresentar resolução superior em baixas frequências, permitindo encontrar flutuações com baixas frequências, ainda desconhecidas.

Usando a transformada de wavelet, tem sido verificado que o espectro do sinal medido apresenta várias faixas espectrais onde a energia das flutuações estão concentradas e que cada faixa espectral corresponde a uma origem especifica, a saber: atividade cardíaca $(0.4-2.0 \mathrm{~Hz})$, atividade respiratória $(0.15-0.4 \mathrm{~Hz})$, resposta vascular miogênica intrínseca $(0.06-0.15 \mathrm{~Hz})$, resposta vascular neurogênica-atividade simpática $(0.02-0.06 \mathrm{~Hz})$, resposta vascular metabólica de endotélio NO-dependente $(0.0095-0.02 \mathrm{~Hz})$ e resposta vascular metabólica de endotélio de NO-não-dependente $(0,005-0,0095 \mathrm{~Hz})^{63}$. 


\section{D- Derivação dos intervalos de frequências das flutuações}

A FIG. 3.4 mostra um exemplo de transformada de wavelet (denominado escalograma). No gráfico, há picos e vales. Um pico significa concentração de energia de flutuações com frequências próximas, enquanto o vale significa pouca concentração.

A exata posição de um pico muda no tempo (em um mesmo individuo) e entre indivíduos. Mas cada intervalo abrange possíveis variações (temporais e entre indivíduos).

Inicialmente foram sugerias cinco faixas de frequências, segundo suas origens, obtidas, seguindo os critérios acima, de 500 escalogramas de 100 indivíduos, incluindo indivíduos normais, atletas e portadores de insuficiência cardíaca ${ }^{53}$. Uma sexta faixa de frequência foi sugerida posteriormente ${ }^{14}$.

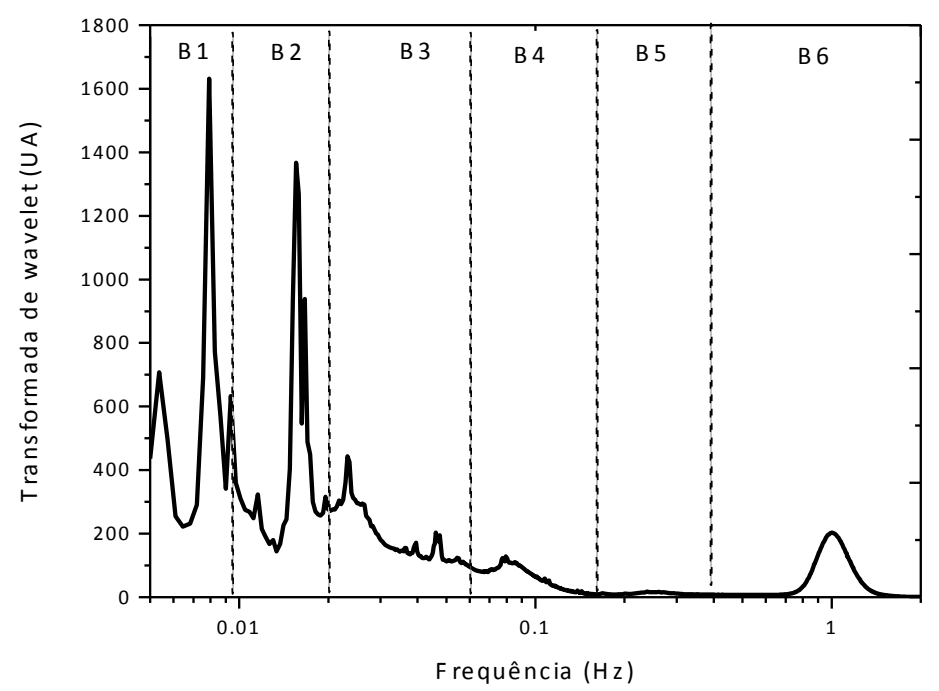

Figura 3.4: Escalograma de um registro de fluxo cutâneo. O eixo das abscissas está dividido em seis faixas espectrais, segundo as origens das flutuações do sinal de fluxo

\section{E- Quantificação do fluxo e de suas flutuações}

O fluxo médio tem sido um parâmetro largamente usado em estudos da microcirculação cutânea. Contudo, o valor do fluxo médio tem sido 
arbitrariamente determinado. Pelo que pode ser verificado não existe um critério razoável para determinar qual o tempo necessário para calcular o valor médio e, também, onde realizar a seleção do intervalo de tempo em que a média é realizada em um registro longo. Por exemplo, o fluxo médio tem sido calculado em intervalos de 2 minutos durante o final de um registro de fluxo basal e 2 minutos no final do registro durante um estresse térmico a $42^{\circ} \mathrm{C}^{9}$. Em outros estudos, o cálculo do fluxo médio é realizado sobre o valor total de 10 minutos no registro de fluxo basal e durante 1 minuto durante as duas fases de um estímulo térmico (região da crista e no platô) ${ }^{10}$.

Similarmente, quando o parâmetro analisado é a vasomotilidade, a potência (ou energia) média das flutuações em cada faixa espectral vem sendo efetuada usando intervalos entre 1 minuto ${ }^{19}$ até 30 minutos ${ }^{14}$, sem qualquer critério razoável. 


\section{MATERIAL E MÉTODOS}

Este trabalho foi desenvolvido no Laboratório de Instrumentação Biomédica (LIB) do Centro de Lasers e Aplicações (CLA), do Instituto de Pesquisas Energéticas e Nucleares (IPEN).

\subsection{Aspectos éticos}

Este projeto foi submetido e aprovado pelo Comitê de Ética em Pesquisa da Faculdade de Odontologia da Universidade de São Paulo (CEP FOUSP), Parecer-Projeto $n^{\circ}$ FR 3688328 (ANEXO A1). Todos os voluntários receberam o esclarecimento do objetivo e dos procedimentos do experimento deste trabalho. Os voluntários foram informados que a qualquer momento poderiam abandonar o projeto. Os consentimentos dos voluntários foram documentados por um termo de consentimento livre e esclarecido (ANEXO A2), conforme as diretrizes da Resolução CNS nº 1 de 13.6.98.

\subsection{Voluntários}

Este trabalho foi realizado em 20 voluntários saudáveis, de ambos os sexos, com idades entre 27 a 36 anos, sendo 10 do sexo feminino $(32.1 \pm 2.7$

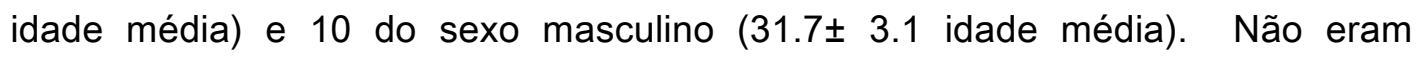
fumantes, não estavam tomando medicamentos que poderiam interferir no sistema microcirculatório e não tinham nenhuma história de doenças cardiovasculares, diabetes e neuropatias.

\subsection{Material}

As medições de fluxo foram realizadas usando um fluxômetro laser Doppler (MoorLab, Moor Instruments, UK), FIG. 4.1, e mais um canal adicional, 
equipado com um laser emitindo no comprimento de onda $\lambda=780 \mathrm{~nm}$ (infravermelho). O laser usado pelo fluxômetro pertence à classe $3 \mathrm{~A}$ de risco segundo a norma IEC 825-1:1993. Lasers classe 3A não oferecem riscos ao aplicador e a terceiros. Não há, portanto, a necessidade do uso de óculos de proteção. A banda Doppler do fluxômetro foi fixada em $15 \mathrm{kHz}$.

Foram utilizadas duas sondas modelo MP12-V2 (Moor Instruments,UK), FIG.4.2. Cada sonda contém duas fibras ópticas com diâmetros de $0,25 \mathrm{~mm}$, sendo uma incidente e outra receptora, com separação de $0,5 \mathrm{~mm}$, acondicionadas no interior de uma ponta de aço inoxidável medindo $12,7 \mathrm{~mm}$ de comprimento e $1 \mathrm{~mm}$ de diâmetro.

As sondas foram fixadas em um suporte equipado com uma pequena resistência elétrica aquecedora. $\mathrm{O}$ suporte foi fixado em contato com a área investigada por um adesivo dupla face. O controle da temperatura local foi realizado usando um equipamento de aquecimento de pele (Moor Instruments Skin Heating Unit "SH02 ${ }^{\mathrm{TM}}$ ", Moor Instruments, UK), FIG. 4.3. Este equipamento é composto por dois canais de aquecimento, que permite medir e aquecer duas regiões distintas em escala de medição, com as principais características: indicação de temperatura na faixa entre 0 a $50^{\circ} \mathrm{C}$; intervalo de aquecimento de 20 a $45^{\circ} \mathrm{C}$ com resolução de $0,1^{\circ} \mathrm{C}$ e precisão de $+/-0.3^{\circ} \mathrm{C}$. A sonda utilizada para aquecer foi SHP1 (Moor Instruments, UK), FIG. 4.4. O suporte aquecedor possui uma altura de $14 \mathrm{~mm}$, diâmetro (incluindo o disco suporte) de $16 \mathrm{~mm}$, e diâmetro (elemento de aquecimento) de $10 \mathrm{~mm}$ (área aquecida de $0,78 \mathrm{~cm}^{2}$ ).

O conjunto (duas sondas e fluxômetro com dois canais) foi calibrado seguindo as recomendações do fabricante, usando um padrão de fluxo também fornecido por ele (suspensão de microesferas plásticas, resultando fluxo igual a 250 UA). 


\subsection{Medições}

Em cada voluntário foram fixadas duas sondas no antebraço esquerdo, FIG. 4.4, destinadas aos registros de sinais de fluxo. Assim, foram realizados simultaneamente dois registros em sítios próximos aqui denominados regiões R1(distal) e R2 (proximal). A separação entre os sítios foi de aproximadamente $10 \mathrm{~cm}$.

Os voluntários compareceram em duas sessões em dias diferentes para a realização das medições. Estavam em jejum de $2 \mathrm{~h}$ antes de cada sessão, por volta das 16 horas, a temperatura ambiente na sala de estudo foi controlada a $23 \pm 1^{\circ} \mathrm{C}$ durante todo o experimento. Antes de iniciar as medições de fluxo, os voluntários permaneceram por 20 minutos em repouso para climatizar com a temperatura da sala do estudo. Durante todo o experimento os voluntários permaneceram em posição supina sobre uma maca.

$\mathrm{Na}$ primeira sessão, o fluxo basal foi registrado continuamente durante 20 minutos. Na segunda sessão o experimento foi baseado na proposta de Strom et al. ${ }^{9}$. Após a climatização, a temperatura na região onde as sondas estavam fixadas foi medida usando um termômetro sem contato, (digital ear thermometer- modelo: TET - 01 BN, SAMSUNG). Nesta condição o fluxo doravante denominado basal foi medido por aproximadamente 5 minutos e em seguida o elemento de aquecimento foi ligado e a região foi aquecida até $42^{\circ} \mathrm{C}$ com taxa de $0,1^{\circ} \mathrm{C} / \mathrm{s}$. O registro nesta temperatura foi mantido durante 35 minutos, totalizando um registro de aproximadamente 45 minutos, em razão do tempo que levou para a temperatura estabilizar em $42^{\circ} \mathrm{C}$. Os indivíduos foram questionados se sentiram alguma dor ou desconforto durante o aquecimento local; nenhum voluntário relatou sentir qualquer dor ou desconforto. 


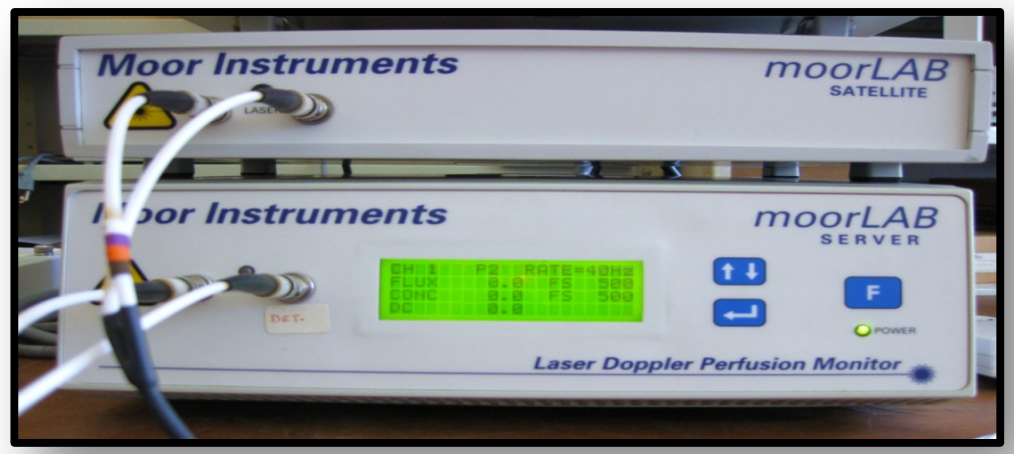

Figura 4.1: Fluxômetro Laser Doppler, modelo Moor Instruments, Moorlab ${ }^{\text {TM }}$ (Axmminster,UK), acoplado a outro canal, usados nos registros de fluxo.

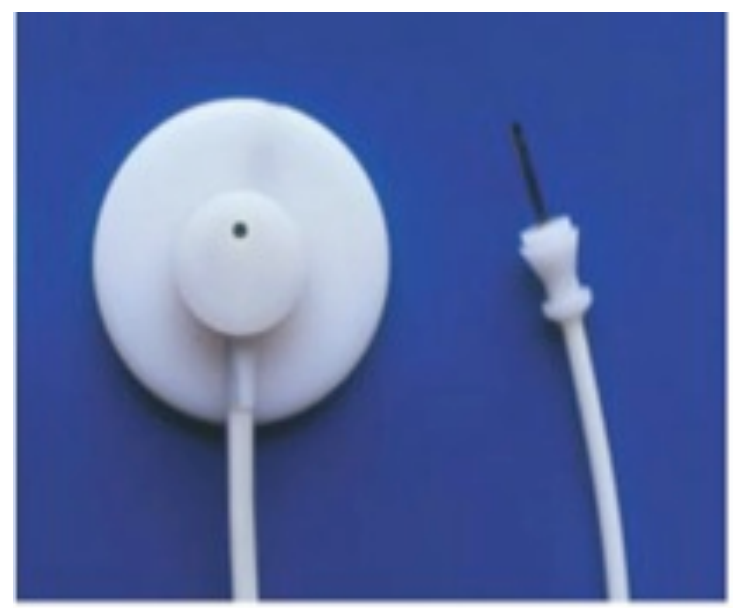

Figura 4.2: Disco de suportee elemento da aquecer (esquerda) e sonda óptica (direita), Moor Instruments, Moorlab (Axmminster,UK).

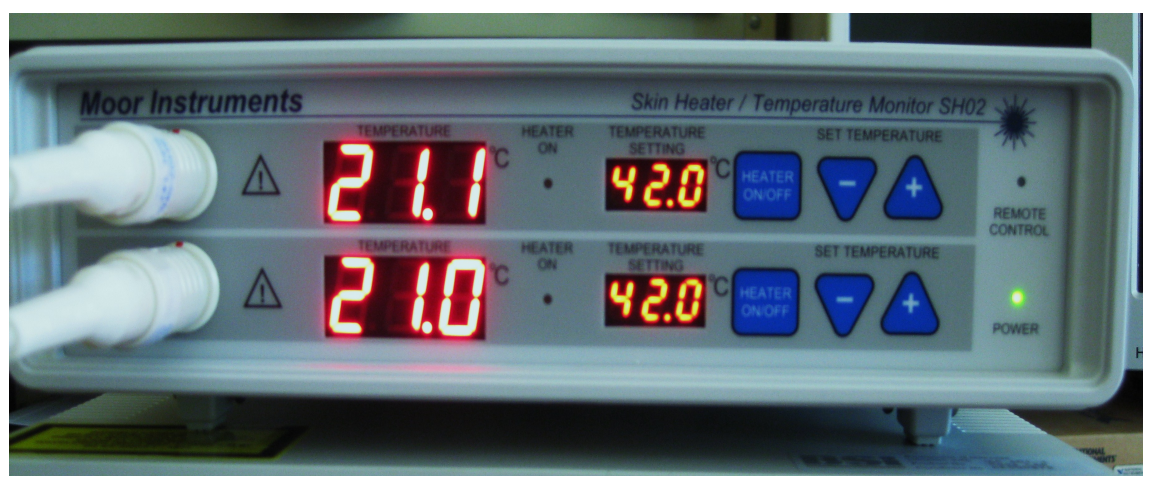

Figura 4.3: Unidade de aquecimento de pele, modelo SH02, Moor Instruments, Moorlab (Axmminster,UK). 


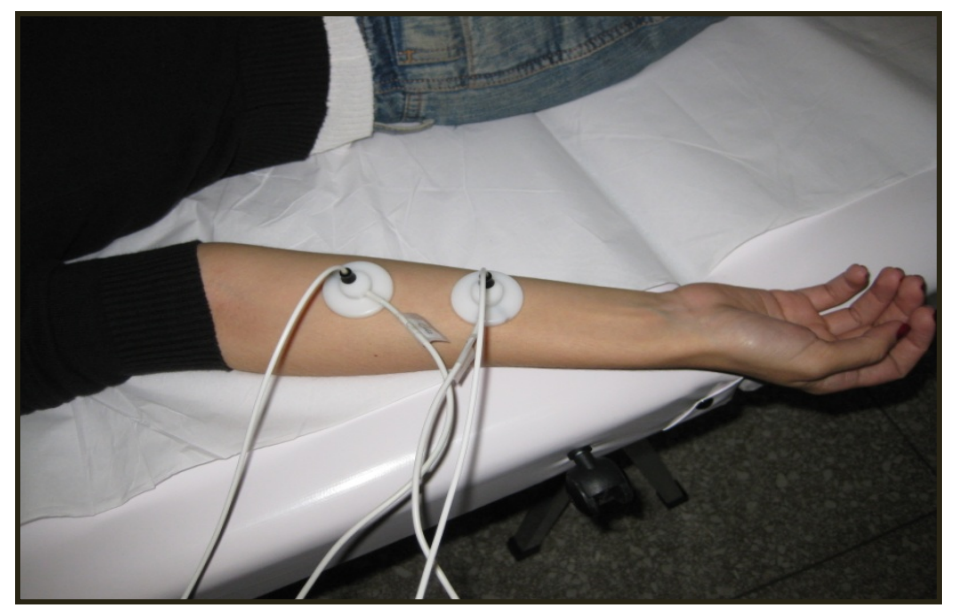

Figura 4.4.: Posicionamento das sondas nos dois sítios próximos estudados.

\subsection{Aquisição e processamento dos dados}

Os sinais (registros) de fluxo dos dois sítios estudados (R1 e R2) foram digitalizados (16 bits) a uma taxa de $100 \mathrm{~Hz}$ (amostras/s) e armazenados em um computador, usando um conversor analógico-digital NU USB 6210 National Instruments (EUA).

Filtros digitais que preservam a fase e a amplitude dos sinais foram utilizados para separar os sinais de fluxo em sete regiões ou bandas espectrais, mostradas na Tab. 4.1, adaptados de Folgosi-Correa ${ }^{64}$ et al. . Foram usados cinco filtros passa-faixas, significando que componentes do sinal de registro com frequências superiores e inferiores a cada banda são fortemente suprimidos (filtros Butterworth de ordem 12). Dois filtros passa-baixas também foram usados, significando que componentes do sinal com frequências superiores ao limite superior de cada faixa $(0,005 \mathrm{~Hz}$ e $0,0095 \mathrm{~Hz})$ são fortemente suprimidos (filtro Butterworth de ordem 12). O diagrama em blocos da FIG. 4.5 mostra o arranjo de filtros usado. Os registros de fluxo amostrados com taxa de $100 \mathrm{~Hz}$ foram decimados para $4 \mathrm{~Hz}$, e filtrados. O sinal na faixa B1 é a diferença entre dois sinais passa-baixas. É, portanto, passa-faixas entre $0,005 \mathrm{~Hz}$ a 0,0095 Hz.

Os sinais filtrados, em cada banda, foram designados SB0, SB1, SB2 SB3, SB4, SB5 e SB6, ou simplesmente referido como sinal na banda 
B0...B6, correspondendo a sete bandas mostradas na Tab. 4.1. Os sinais filtrados podem ser expressos como

$$
F=S B 0+S B 1+S B 2+S B 3+S B 4+S B 5+S B 6+\text { erro }
$$

onde $\mathrm{F}$ é o sinal de fluxo. Experimentalmente foi verificado que, para um sinal com potência média igual a $1 \mathrm{~W}$, a potência do erro é menor que $0.01 \mathrm{~W}$. Note-se que apenas o sinal na faixa B0 tem valor médio diferente de zero (sua faixa de frequência inclui a origem do espectro: $f=0$ ), enquanto que os sinais nas bandas B1 a B6 possuem valores médios iguais a zero (pois suas faixas não incluem a origem do espectro).

Tabela 4.1. Faixas de frequências correspondentes a cada banda passante dos filtros usados.

\begin{tabular}{ccc}
\hline Banda & Intervalo de frequência $(\mathrm{Hz})$ & Origem \\
\hline B0 & 0 a 0,005 & \\
B1 & 0,005 a 0,0095 & Endotelial No-independente \\
B2 & 0,0095 a 0,02 & Endotelial No-dependente \\
B3 & 0,02 a 0,06 & Neurogênica \\
B4 & 0,06 a 0,16 & Miogênica \\
B5 & 0,16 a 0,4 & Respiratória \\
B6 & 0,4 a 1,6 & Cardíaca \\
\hline
\end{tabular}




\subsection{Quantificação do fluxo e das parcelas flutuantes do fluxo}

Os sinais nas bandas $\mathrm{B} 0$ a $\mathrm{B} 6$, correspondentes ao sinal de fluxo (B0) e das parcelas flutuantes de fluxo nas faixas espectrais B1 a B6, foram armazenados em um computador para análises posteriores. Cada sinal continha um conjunto de amostras, digitalizados e processados usando a taxa de 4 amostras/s. Em cada sinal, intervalos temporais de aproximadamente 20 minutos foram selecionados. Assim, cada sinal nas bandas B0 a B6 tinha aproximadamente 4800 amostras, igualmente espaçadas no tempo, sendo portanto séries temporais, aqui também denominadas sinais nas bandas B0 a B6.

Os valores médios de fluxo e dos sinais na banda BO foram calculados efetuando a média aritmética das amostras de cada série temporal, e suas variâncias computadas. Uma vez que os sinais nas bandas B1 a B6 possuem valores médios iguais a zero, valores médios de seus valores absolutos foram calculados, conforme ilustra o gráfico da FIG. 4.6, e suas variâncias computadas.

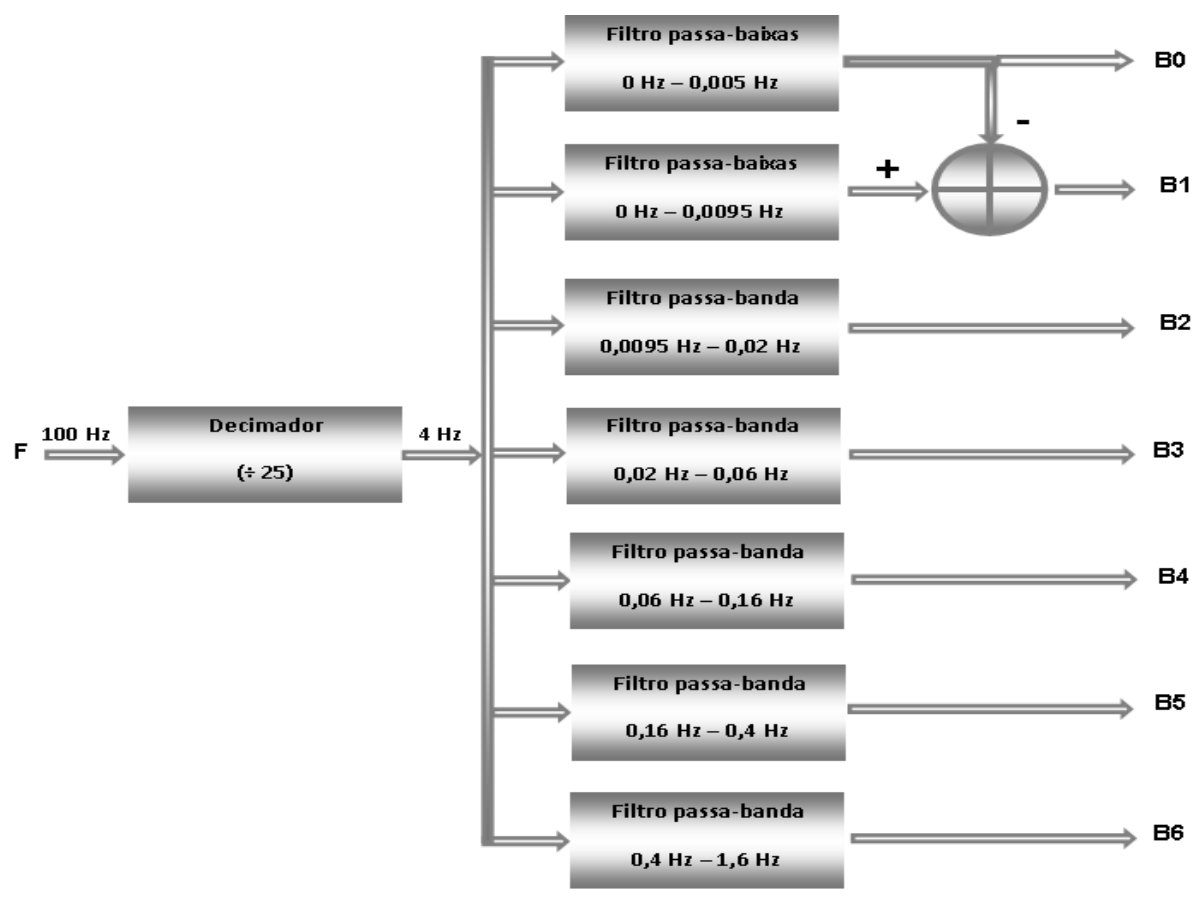

Figura 4.5: Diagrama em blocos do banco de filtros digitais usados para separar sinais de registros de fluxo em sete faixas espectrais, segundo a TAB. 4.1. 
Para medir a variabilidade temporal e espacial, foi usado o coeficiente de variação. Uma vez que a variância muda em função da escala de um sinal, uma medida de variabilidade independente da escala é o coeficiente de variação (CV). O coeficiente de variação é uma medida de dispersão usada na comparação de distribuições diferentes, definido como a razão entre o valor médio de um sinal $(m)$ e seu desvio-padrão $(D P): C V=D P / m$. O CV não depende da escala do sinal.

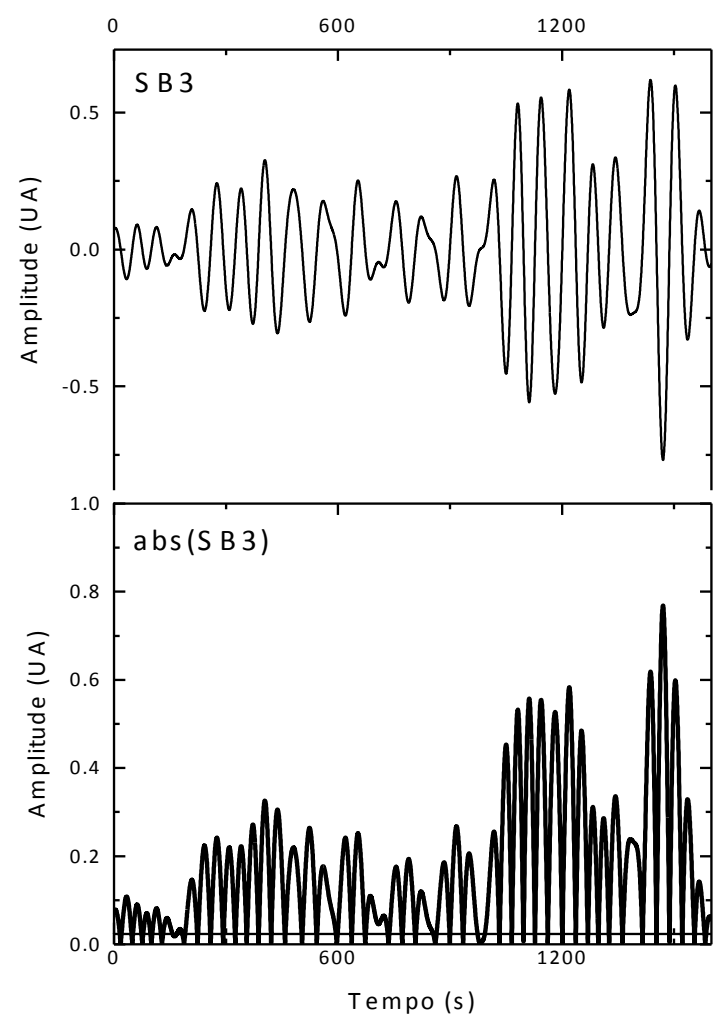

Figura 4.6: Gráfico de um registro de fluxo filtrado na banda B3 (superior) e de seu valor absoluto (inferior).

\subsection{Análise da correlação espaço-temporal}

Com o objetivo de verificar possíveis relações lineares de sinais nas bandas B0 a B6 de duas regiões próximas dos antebraços de voluntários, a 
análise da correlação cruzada com atraso zero (Pearson product-moment correlation) foi utilizada ${ }^{65}$.

Há uma variedade de métodos destinados à quantificação de interrelações, medindo o grau de correlação ou coerência entre duas ou mais variáveis 66, 67. Cada método tem suas limitações e qualidades, mas essencialmente apresentam resultados similares ${ }^{68}$.

O método aqui usado é uma adaptação do método descrito por Corsi-Cabrera ${ }^{65}$, permitindo estimar o coeficiente de correlação $r$ em janelas temporais com duração $T$. O coeficiente de correlação $(r)$ pode variar entre 1 a -1 , onde 1 significa elevada correlação direta (as amplitudes de ambos os sinais aumentam ou diminuem juntas), -1 significa elevada correlação reversa (enquanto a amplitude de um sinal aumenta a do outro diminui) e zero significa nenhuma correlação. Significados e restrições sobre a correlação de Pearson podem ser obtidos em artigos específicos ${ }^{69,70}$.

Janelas temporais móveis, com durações $T$ iguais a $600 \mathrm{~s}, 200 \mathrm{~s}$, $100 \mathrm{~s}, 50 \mathrm{~s}, 17 \mathrm{~s}, 7 \mathrm{~s}$ e $2,5 \mathrm{~s}$ (bandas B0 a B6, respectivamente) foram usadas nas estimativas das correlações entre sinais nas bandas B0 a B6. Assim, para cada sinal contendo $N$ amostras $(n=1,2,3, \ldots \mathrm{N}), n$ amostras corresponde a uma janela temporal com largura $T=n / 4$ segundos. Para cada par de sinal, valores de $r$ foram computados em janelas temporais móveis com duração $T$ iniciando em $n=1, n=2$ até $n=N-T$. Desta forma, para cada par de sinais, os valores de $r$ foram computados em janelas temporais com larguras fixas varrendo toda extensão dos sinais. Assim, os coeficientes de correção variaram em função do tempo. Para as estimativas de $r$ com $p>0,05$ foram atribuídos valores $r=0$. Para as estimativas que resultaram $r<0$ foram atribuídos valores $r=0$ (rejeitando correlações espúrias). Para facilitar a exposição dos resultados, valores médios de $r$ foram calculados. Também foram calculadas as percentagens de tempo em que os pares de sinais permaneceram sincronizados durante os períodos analisados. 


\subsection{Análise da variabilidade espacial}

A verificação de correlações lineares das amplitudes médias de sinais nas bandas B0 a B6 entre as duas regiões estudadas ( $R 1$ e R2) foi efetuada usando a correlação de Pearson ( $r$ ). Coeficientes $r>0,5$ foram considerados indicadores de fortes correlações ${ }^{71}$. A repetibilidade das medições entre as duas regiões foi avaliada usando o coeficiente de correlação intraclasse ( $C C /$ ). Valores de $C C l<0,4$ significam baixa repetibilidade, valores $0,4<C C l<0,75$ significam entre média e boa, e $C C l>0,75$ excelente. ${ }^{72}$

\subsection{Análise estatística dos dados}

A avaliação de diferenças entre os grupos foi efetuada usando ANOVA. Para este propósito, nas comparações entre coeficientes de correlação, a transformação de Fisher foi usada (e a normalidade dos dados transformados foi verificada). Comparações múltiplas foram realizadas usando o método de Tukey. Comparações entre pares de grupos foram efetuadas usando o teste-t de Student. Valores $p<0,05$ foram considerados significantes. 


\section{RESULTADOS E DISCUSSÕES}

Médias temporais do fluxo e das amplitudes das flutuações do fluxo têm sido usadas como parâmetros indicadores da função microvascular. Mas ainda são pouco conhecidas as variações temporais dos sinais de fluxo e desconhecidas as variações temporais das flutuações do fluxo. Portanto, são desconhecidos os intervalos mínimos requeridos para calcular os valores médios destas quantidades e este será o primeiro tópico deste capítulo. Na sequência este capítulo apresentará os valores experimentais da variabilidade temporal de sinais de fluxo e de suas flutuações em sete faixas espectrais, pois o intervalo mínimo requerido para estimar médias de fluxo e de suas flutuações depende da variabilidade temporal dos sinais. Com os resultados obtidos, será apresentada a quantificação dos valores médios de fluxo e de suas flutuações, incluindo a análise da variabilidade espacial destas quantidades. Por fim, a análise da correlação espaço-temporal dos sinais de fluxo e de suas flutuações será apresentada, suprindo outra lacuna na literatura e abrindo a possibilidade do uso de outros parâmetros indicadores da função microvascular que apresentam menor variabilidade.

\subsection{Quantificação do fluxo médio}

Neste estudo, o registro de fluxo foi separado em faixas de frequências, usando filtros digitais, conforme descrito no capitulo anterior. A título de exemplo, no gráfico da FIG. 5.1 mostra um sinal de fluxo basal sem qualquer filtragem e as parcelas (filtradas) deste sinal nas faixas $\mathrm{B} 0$ a B6, onde podem ser verificadas ondas com frequências muito baixas (B0) até as mais elevadas (B6).

A inspeção visual de um gráfico de registro de fluxo (sem filtragem), como o exemplificado na FIG. 5.1, não revela com clareza as amplitudes das flutuações mais lentas, que estão somadas às mais rápidas. A separação do sinal de fluxo em faixas espectrais permite facilmente visualizar as amplitudes de suas 
parcelas oscilantes nas bandas B0 a B6, e que suas amplitudes também flutuam largamente. Este fato (de as amplitudes flutuarem largamente) foi verificado em todos os 80 registros analisados. A FIG. 5.2 mostra um exemplo de um sinal na faixa B3 onde uma envoltória foi traçada para facilitar a visualização das flutuações da amplitude. Em todos os sinais nas bandas B1 a B6 foram observadas flutuações intensas e variações mais lentas que os períodos das oscilações características de cada faixa.

Enquanto medir experimentalmente a amplitude média de uma senóide requer um intervalo de tempo de apenas um período (ou meio), medir a amplitude média de um sinal oscilante que tem sua amplitude variável requer outros critérios. Sem recorrer a ferramentas matemáticas mais complexas, que sai fora do escopo deste trabalho, seria necessário conhecer o comportamento dos sinais nas bandas B0 a B6 durante intervalos superiores de tempo. Este fato suscita uma questão importante: qual é o intervalo mínimo de tempo necessário para medir a amplitude média de cada sinal nestas bandas? Esta questão será tratada na sequência. 


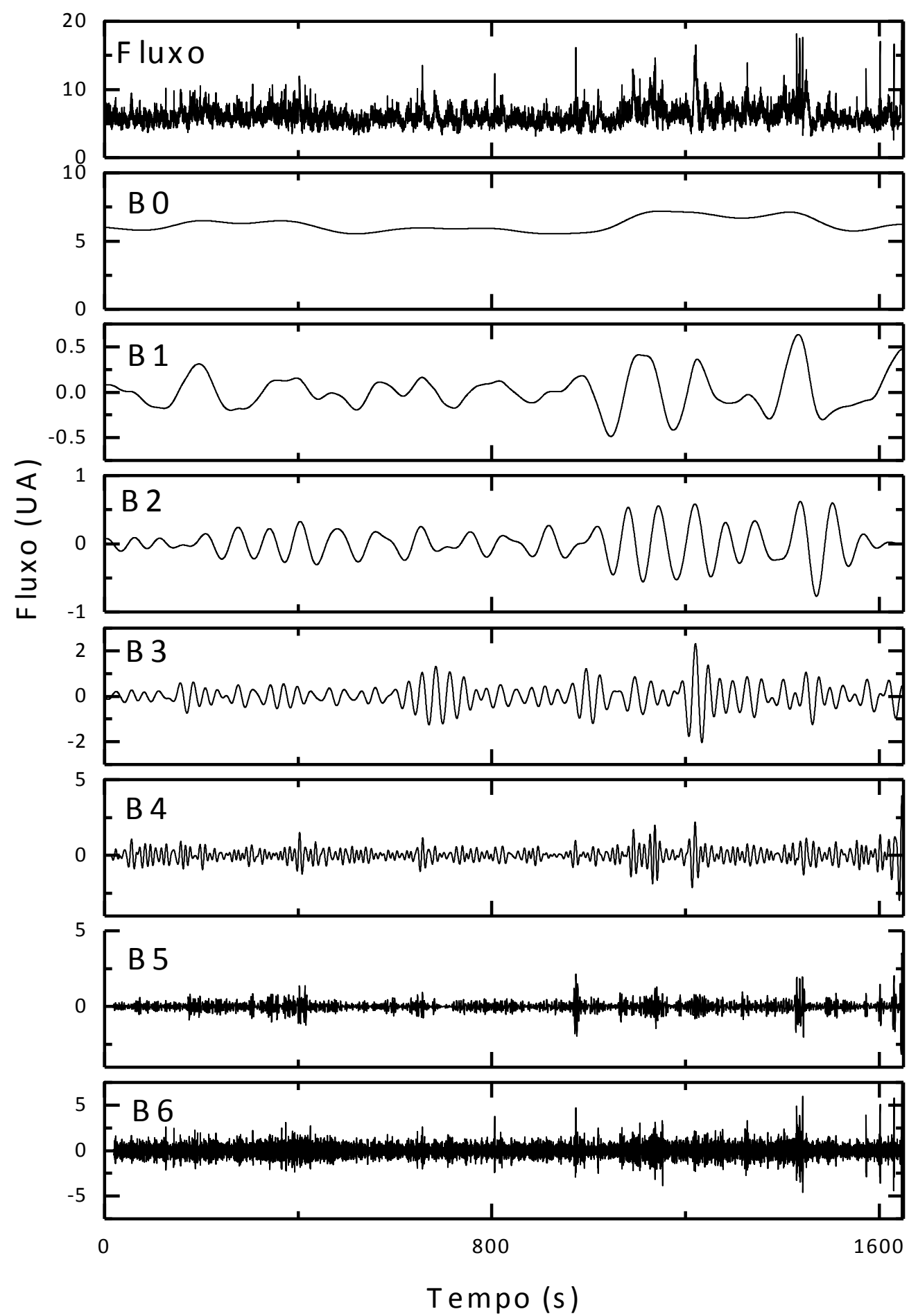

Figura 5.1: Gráficos representativo de um registro de fluxo durante a temperatura basal e de suas parcelas oscilantes, nas bandas B0 a B6. 


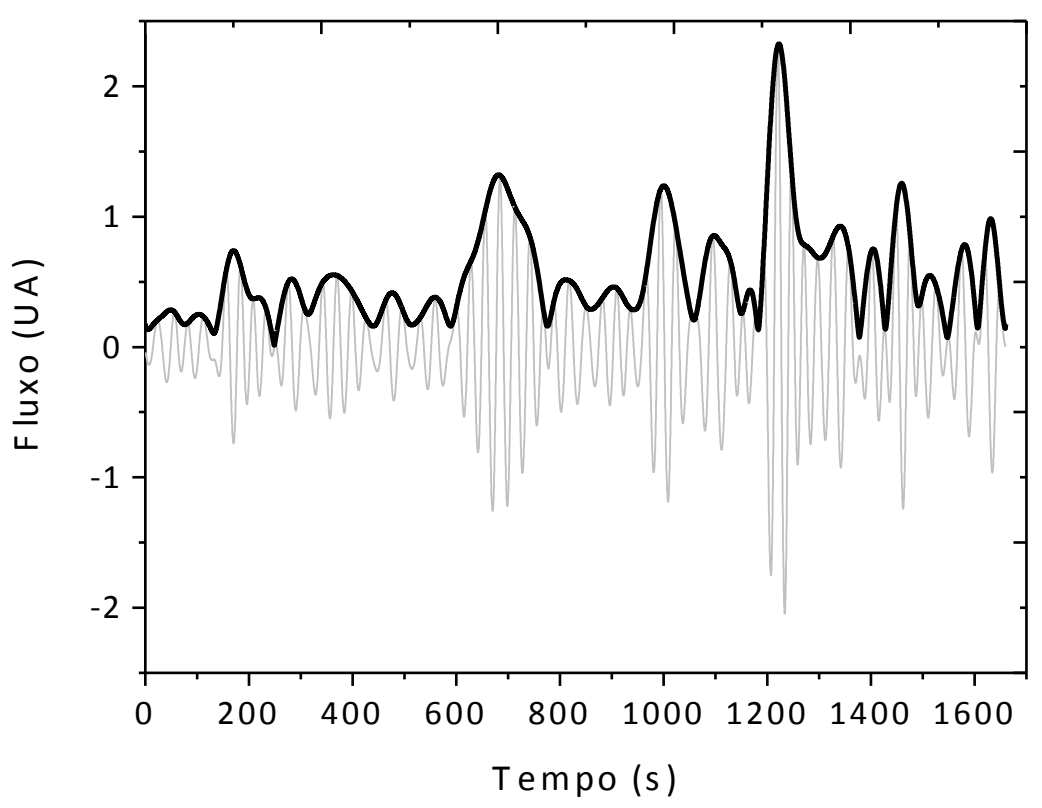

Figura 5.2: Gráfico de um sinal de fluxo filtrado na banda B3 e sua envoltória onde podem ser verificadas elevadas variações de amplitude. A envoltória varia mais lentamente que o sinal.

Antes, porém, um exemplo de registro de fluxo durante um processo de estímulo térmico é mostrado no gráfico da Fig. 5.3. No mesmo gráfico é mostrado a curva do sinal filtrado, com frequências abaixo de $0,005 \mathrm{~Hz}$, onde as flutuações com frequências superiores são suprimidas. Neste exemplo, o fluxo basal é registrado durante aproximadamente 8 minutos, após este lapso temporal inicia-se o aquecimento local. Após aproximadamente 10 minutos de registro ocorre o primeiro pico máximo, seguido de um pequeno vale, uma nova curva ascendente e depois de alguns minutos, a estabilização em um patamar.

Segundo Minson et al. ${ }^{10}$ (2001), a vasodilatação no aquecimento local na pele humana pode ser divido em duas fases. A primeira fase é o pico inicial, que é rápida e ocorre dentro dos primeiros minutos do aquecimento local - sendo 
que neste estudo, o referido pico deu-se nos primeiros dois minutos de aquecimento - e corresponde a aproximadamente $80 \%$ da vasodilatação máxima. Durante esta fase acredita-se que esteja ocorrendo um mecanismo de controle pelos nervos sensoriais, através de liberação local de neuropeptídios vasodilatadores ${ }^{10}$. A segunda fase da vasodilatação é mais lenta e correlacionada à liberação de NO, ou seja, é dependente do NO endotelial ${ }^{10}$. Nessa fase, geralmente em 20 a 30 minutos de aquecimento, ocorre um patamar ${ }^{10,} 73$.

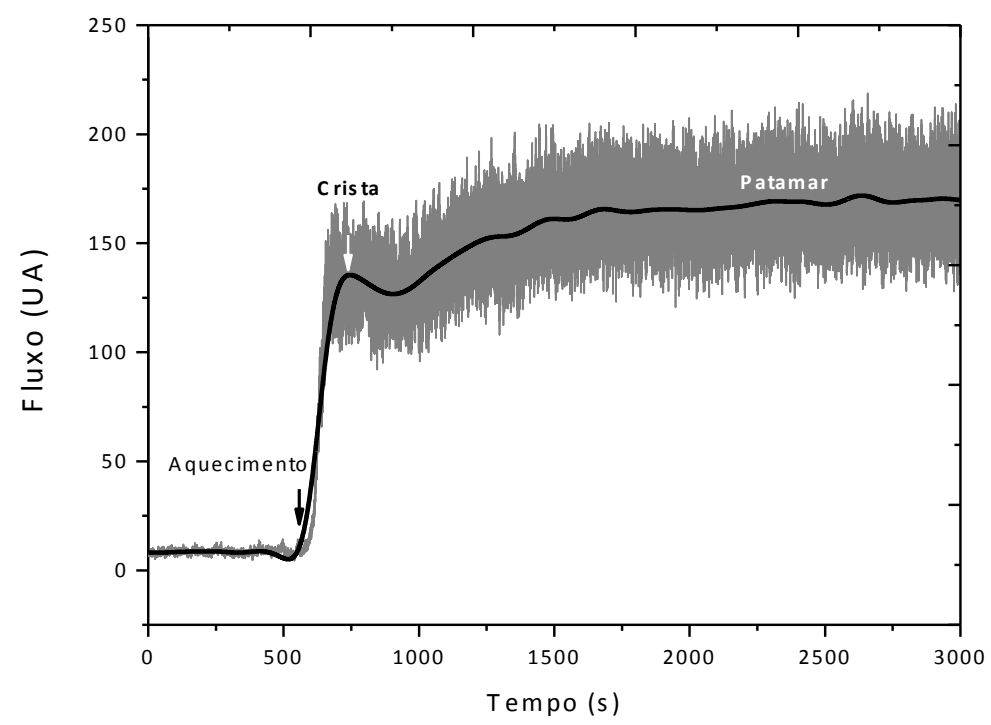

Figura 5.3: Sinal de fluxo representativo durante um estimulo térmico sem filtragem (traçado cinza) e filtrado (traçado preto, banda B0), suprimindo todas as frequências superiores a $0,005 \mathrm{~Hz}$.

A figura 5.4 apresenta os gráficos de um registro de fluxo sem filtragem e de suas parcelas nas bandas B0 a B6, onde pode ser notado que durante o intervalo de tempo em que a temperatura aumentava há pronunciado aumento nas amplitudes das ondas nas bandas B1 e B2, depois retornando a níveis menores. Este aumento transitório de energia nas bandas B1 e B2 reflete somente o rápido aumento de fluxo em resposta ao estresse térmico, nestas faixas espectrais. Ou seja, somando estes sinais ao da banda B0 
(SB0+SB1+SB2) a diferença entre o sinal não filtrado e o sinal na banda B0 na rampa ascendente (figura. 5.3) diminui significativamente.

Durante o patamar, as flutuações nas bandas B0 a B6 podem ser facilmente visualizadas (figura 5.4), onde pode ser notado que suas amplitudes também flutuaram largamente. Este comportamento (largas flutuações dos sinais nas bandas B1 a B6) foi observado nos 40 registros analisados. 


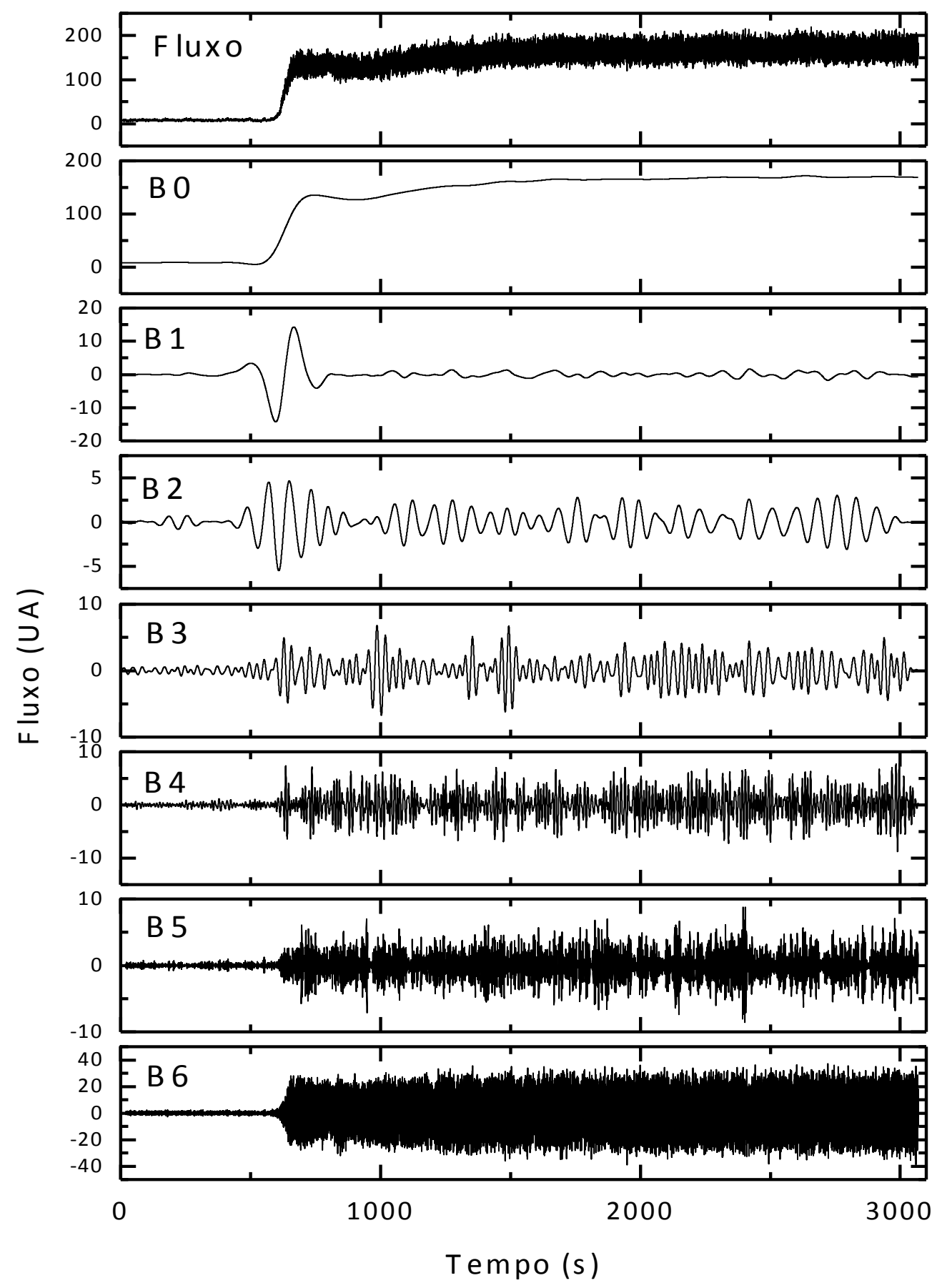

Figura 5.4: Gráficos representativos de um registro de fluxo e de suas parcelas oscilantes nas bandas B0 a B6 de um sinal de fluxo que sofreu um estimulo térmico 


\subsubsection{Quantificação do erro na estimação do fluxo médio e de suas parcelas flutuantes}

Um registro de fluxo possui informações sobre o fluxo microvascular. Uma forma frequente de extrair informações do registro de fluxo é computar seu valor médio (média temporal). A razão entre valores médios de fluxo antes e depois de um estresse térmico é um exemplo de teste de indicação da capacidade de dilatação microvascular ${ }^{13}$

As parcelas flutuantes do fluxo também carreiam informações sobre o fluxo microvascular, conforme já apontado nos Capítulos 3 e 4 . A forma mais comum de extrair informações das parcelas flutuantes é medir seus valores médios (media temporal) de suas amplitudes ou de suas potências ou de suas energias. Assim, valores médios do fluxo e das amplitudes ou das potências ou das energias de suas flutuações em faixas espectrais conforme a TAB. 4.1 são parâmetros comumente usados para avaliar o estado funcional microvascular.

Quando o parâmetro em análise é o fluxo $(F)$ basal, o procedimento usual para quantificar o fluxo basal é calcular seu valor médio em um intervalo de tempo arbitrariamente escolhido; 30 segundos $^{39}, 1$ minuto ${ }^{37}, 3$ minutos $^{74}$ e 5 minutos $^{75}$. Durante um estresse térmico, o mesmo procedimento é repetido para calcular o fluxo médio no patamar, mas em um intervalo de tempo onde o patamar está estabelecido (geralmente no fim do registro) em intervalos de tempo arbitrariamente escolhidos: 30 segundos ${ }^{39}, 1$ minuto ${ }^{37}, 3$ minutos ${ }^{74}$ e 5 minutos 75. Ou seja, não existe um critério para estabelecer o intervalo de tempo que se deve considerar para obter o fluxo médio.

Com o objetivo de saber qual a diferença entre valores médios do fluxo e das amplitudes e das potências de suas oscilações, quando calculadas em intervalos diferentes de tempo, diferentes médias foram efetuadas, considerando intervalos de tempo de 1 minuto e 20 minutos. Tomando como referência valores médios computados em intervalos de 20 minutos, o desvio do valor obtido, quando comparado aos respectivos valores calculados em intervalos de 1 minuto foi analisado, conforme segue. 
O fluxo médio foi obtido computando o valor médio do fluxo medido em um intervalo de tempo de 1 minuto e de 20 minutos Tomando como exemplo o registro ilustrado na FIG. 5.1, o fluxo médio é a média aritmética $(m)$ dos aproximadamente 4800 valores de fluxo medidos durante o registro (4 amostras/s, 1200 s). Caso o fluxo médio seja calculado em um intervalo de tempo menor, o valor médio pode ser outro $\left(m^{\prime}\right)$. Para quantificar o erro (desvio), foi usado o desvio absoluto percentual definido como $e=\left(\left|m-m^{\prime}\right| / m\right) \cdot 100$. Este mesmo procedimento foi usado para analisar os sinais nas bandas B0 a B6. No entanto, como o fluxo varia constantemente no tempo, o desvio depende do momento escolhido para calcular m'. Assim, objetivando simular todas as possibilidades de escolha de onde a média pode ser calculada, valores médios $\left(m^{\prime}\right)$ foram calculados em intervalos sucessivos de tempo de 1 minuto, desde o início do registro até o seu final. Desta forma, o desvio resultante também foi calculado desde o inicio até o final do registro. Como um exemplo, os gráficos da FIG. 5.5 apresentam valores de erro de um registro no estado basal, onde pode ser verificado um erro máximo de aproximadamente $23 \%$ na estimação do fluxo médio $(F)$ computado em 1 minuto, quando comparado ao fluxo médio calculado em 20 minutos. Note-se que quando a média foi efetuada na banda B0, o desvio máximo caiu para aproximadamente $16 \%$. Este comportamento foi comum em todos os 40 registros analisados (detalhes na sequência).

Na FIG. 5.5 pode ser verificado que os erros nas bandas B1 a B6 são maiores que os encontrados nas estimações dos valores médios do fluxo (F) e do fluxo filtrado na banda B0. Este fato era esperado, pois a análise visual dos sinais revelava largas flutuações em suas amplitudes, conforme ilustrado na FIG. 5.2. Este comportamento foi observado em todos os 40 registros analisados. 


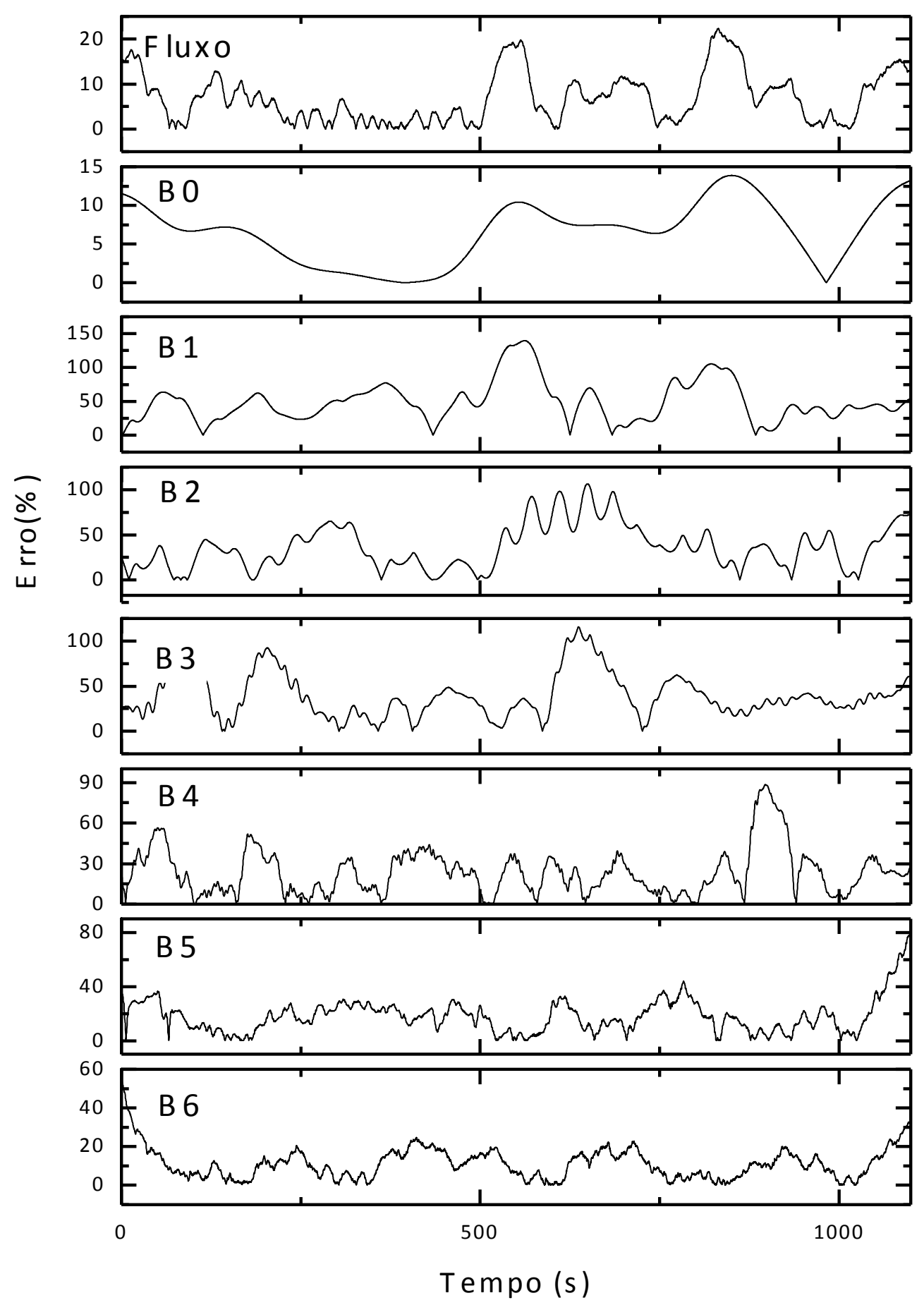

Figura 5.5: Erro percentual (absoluto) de valores médios de fluxo e suas parcelas flutuantes nas bandas B0 a B6 calculadas durante intervalos de 1 minuto quando comparados aos respectivos valores médios calculados durante 20 minutos 
Em todas as análises que seguem, durante o estresse térmico, somente o patamar foi considerado. Os patamares considerados iniciaram 600s depois das primeiras cristas, conforme mostrado na FIG. 5.3, e perduraram até o final do registro.

Durante a análise de cada um dos 40 registros de uma das regiões estudadas (R1) foi encontrado um valor máximo de erro. A TAB. B1 (ANEXO B1) mostra os erros máximos encontrados nos 20 registros de fluxo durante o estresse térmico e nos 20 registros durante o estado basal em uma das regiões estudadas (R1).

Analisando a TAB. B1 - ANEXO B1, pode ser verificado que os erros dos valores de fluxo calculados sem filtragem são significativamente maiores que os erros encontrados quando os registros são filtrados (banda B0), durante a temperatura basal e durante o estresse térmico, conforme mostra o diagrama de barras na FIG. 5.6. A diminuição do erro na banda B0 é facilmente compreendida, como segue.

O registro de fluxo (sem filtragem) apresenta flutuações em todas as bandas (B0 a $\mathrm{B} 6$ ). Embora os valores médios das parcelas flutuantes serem zero, isto somente ocorre em um intervalo infinito de tempo. Quando o intervalo de tempo é finito, que é o caso, seus valores médios podem ser diferentes de zero. Sem recorrer a ferramentas matemáticas complexas, este fato pode ser compreendido quando tomamos uma senóide definida em tempo infinito. A amplitude média da senóide é zero, assim como valor médio tomado em um período é zero. Mas não é zero quando a média é calculada em intervalos de tempo diferentes de um período (ou de múltiplos de um período) da senóide. Exemplificando, os gráficos da FIG. 5.7 mostram valores médios de duas senóides com frequências de $0,1 \mathrm{~Hz}$ e $1 \mathrm{~Hz}$ e amplitudes unitárias cujas médias foram efetuadas em intervalos progressivos de tempo $T$, onde pode ser observado que o valor médio diminui quando T aumenta e que o decaimento aumenta com a 
frequência. Obviamente, o valor médio também depende da amplitude da senóide (são diretamente proporcionais). Assim, quando o sinal é filtrado, este tipo de erro na estimação do fluxo médio diminui, pois a porção flutuante diminui.

A diminuição do erro durante o estresse térmico, quando o sinal não foi filtrado, decorre principalmente do seguinte fato: durante o estresse térmico o fluxo médio aumenta mais que as flutuações nas bandas B1 a B5. Este fato será apresentado mais adiante.

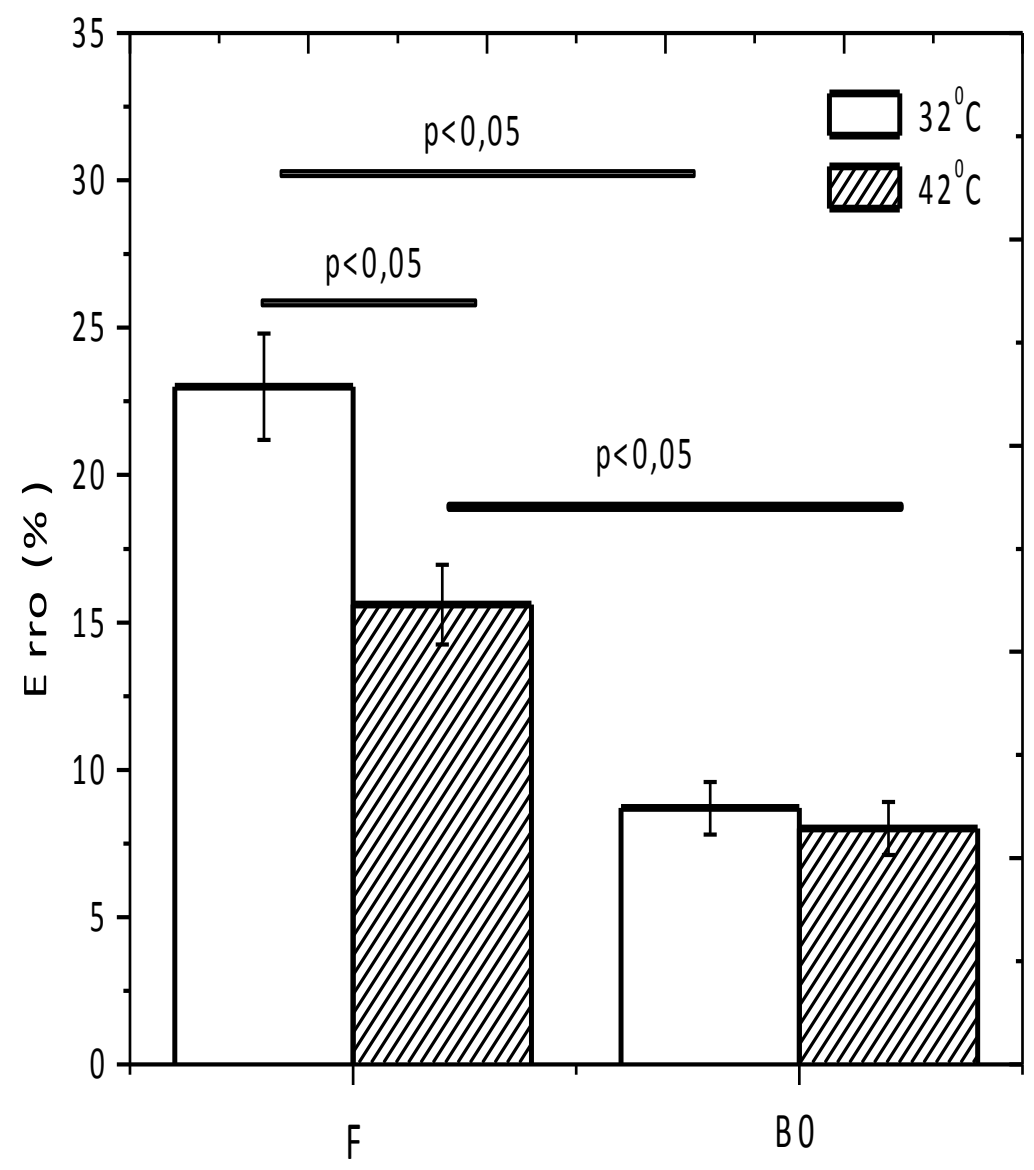

Figura 5.6: Erros percentuais dos valores médios de fluxo não filtrados (F) e filtrados (B0) calculados em um minuto tomando como referência os respectivos valores calculados em 20 minutos. Pares indicados por barras horizontais significam diferentes, ANOVA e Tukey , $p<0,05$. Barras verticais significam erros-padrão 


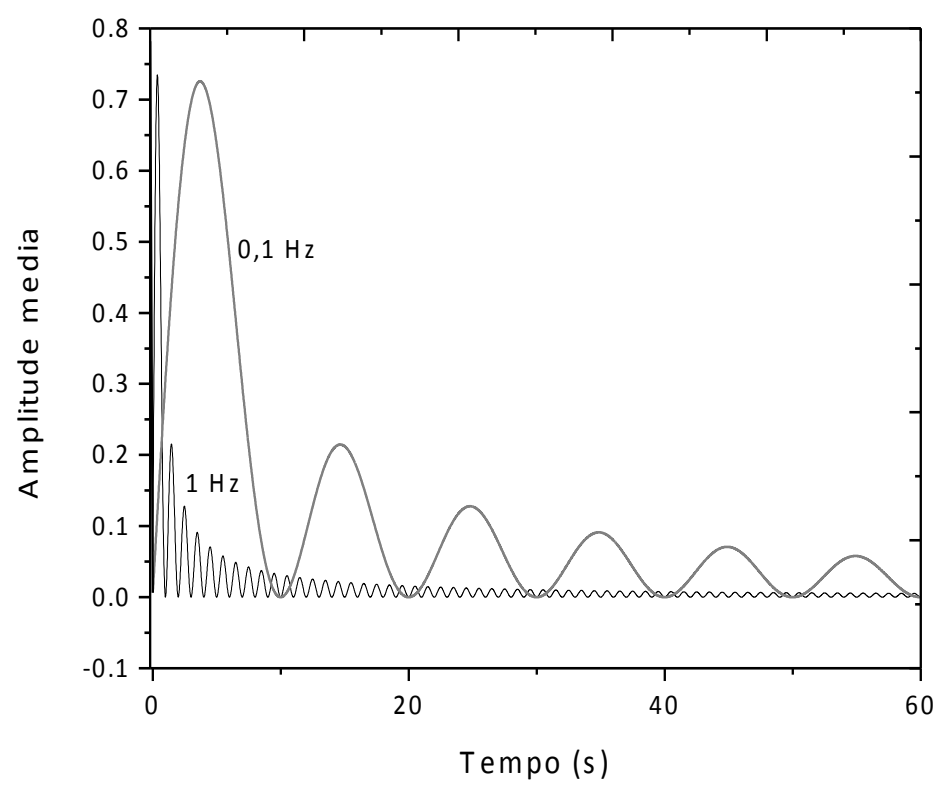

Figura 5.7: Valores médios de duas senóides com frequências $0,1 \mathrm{~Hz}$ e $1 \mathrm{~Hz}$ calculados em intervalos de tempo $\mathrm{T}$

De forma similar à anteriormente descrita, também foram analisados os erros (desvios) nas estimativas dos valores médios das amplitudes (A) e potências $(P)$ dos sinais nas bandas B1 a B6 no estado basal. Contudo, uma vez que os sinais nas bandas B1 a B6 possuem valores médios iguais a zero, foram computados valores médios de seus valores absolutos (foram considerados os módulos das amplitudes dos sinais nas bandas B1 a B6).

A TAB. B2 (ANEXO B2) apresenta os erros obtidos nos sinais das bandas $\mathrm{B} 1$ a B6 de 20 registros colhidos na região $\mathrm{R} 1$ durante o fluxo basal.

Analisando a TAB. B2 (ANEXO B2), foi verificado que, em todas as bandas, os erros nas estimações das amplitudes foram significativamente menores quando comparados aos correspondentes erros nas estimações da potência, conforme mostra a FIG. 5.8. Este fato era esperado, pois as largas flutuações dos sinais nas bandas B1 a B6 resultam flutuações intensificadas de potências (quadrado das amplitudes). Assim, embora seja comum a literatura quantificar a potência dos sinais nas bandas B1 a B6, doravante somente as amplitudes absolutas serão consideradas, pois resultam menores erros. 
Comparando somente os erros das amplitudes (excluindo potências) nas bandas B1 a B6 (TAB. B2- ANEXO B2) foi possível encontrar que o erro na banda B6 é significativamente menor que os demais (FIG. 5.8). De fato, foi observado que as variações nas amplitudes dos sinais nesta banda são menores que as variações encontradas nos sinais das demais bandas comparadas. Este fato será confirmado mais adiante, na análise da variância das amplitudes. Contudo, os erros encontrados nas estimações das amplitudes dos sinais basais nas faixas B1 a B6 foram elevados e significativamente maiores que os obtidos para o fluxo médio $(F)$ e amplitude média na banda $B 0(p<0,05$, teste de Tukey depois de ANOVA, comparando os valores correspondentes encontrados na TAB. B1 - ANEXO B1).

Assim, durante a temperatura basal, os erros (desvios) encontrados nas estimações de valores médios das amplitudes das oscilações nas bandas B1 a B6 foram significativamente maiores que os encontrados na estimação do valor médio do fluxo com ou sem filtragem, durante o estado basal, quando o intervalo de tempo usado foi um minuto.

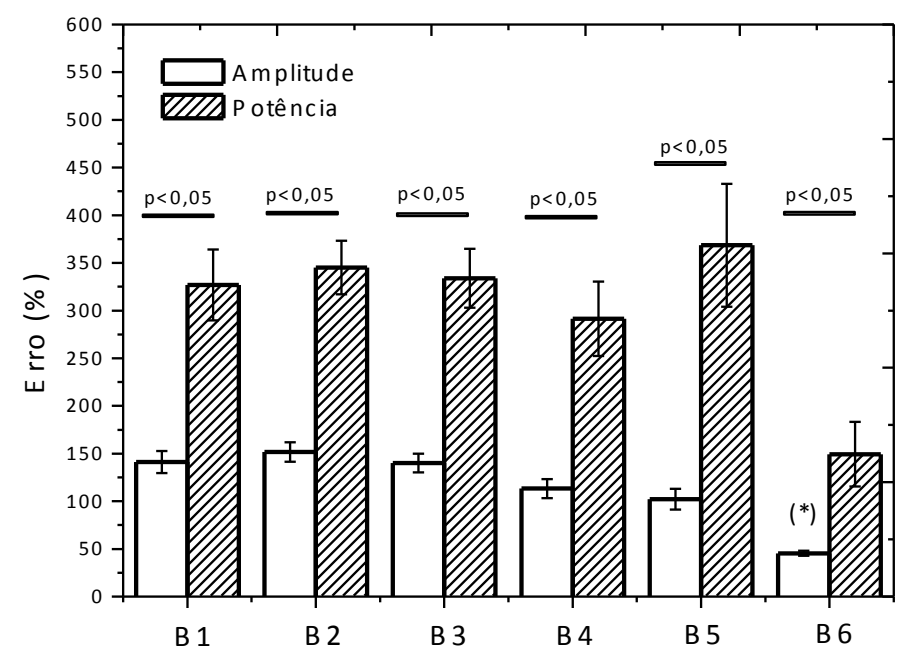

Figura 5.8: Erro percentual dos valores médios das amplitudes e das potências de sinais basais nas bandas B1 a B6. Barras horizontais significam diferença entre pares (teste-t) e (*) significa diferente de todos os grupos, ANOVA e Tukey, $p<0,05$. Barras verticais significam erros-padrão. 
De forma similar à analise imediatamente anterior, os erros encontrados nas estimações dos valores médios das amplitudes das oscilações durante o estresse térmico também são mostrados na TAB. B1.- ANEXO B1. Neste estado, os erros nas faixas B5 e B6 foram significativamente menores que os dos demais grupos, mas não foi encontrada diferença entre B5 e B6, conforme mostra a FIG. 5.9. Similarmente ao já comentado para o fluxo basal, era esperado menor erro na faixa B6, pois foi observado visualmente que as flutuações de amplitude dos sinais nesta faixa eram menores.

Comparando os erros nas estimações das amplitudes de sinais nas bandas B1 a B6 nos dois estados (basal e estresse térmico) entre pares (ex., pares de B1 na TAB. B1- ANEXO B1), foram encontras evidências suficientes indicando que os erros no estado basal são significativamente maiores em todas as faixas, teste-t de Student pareado, $p<0,05$.

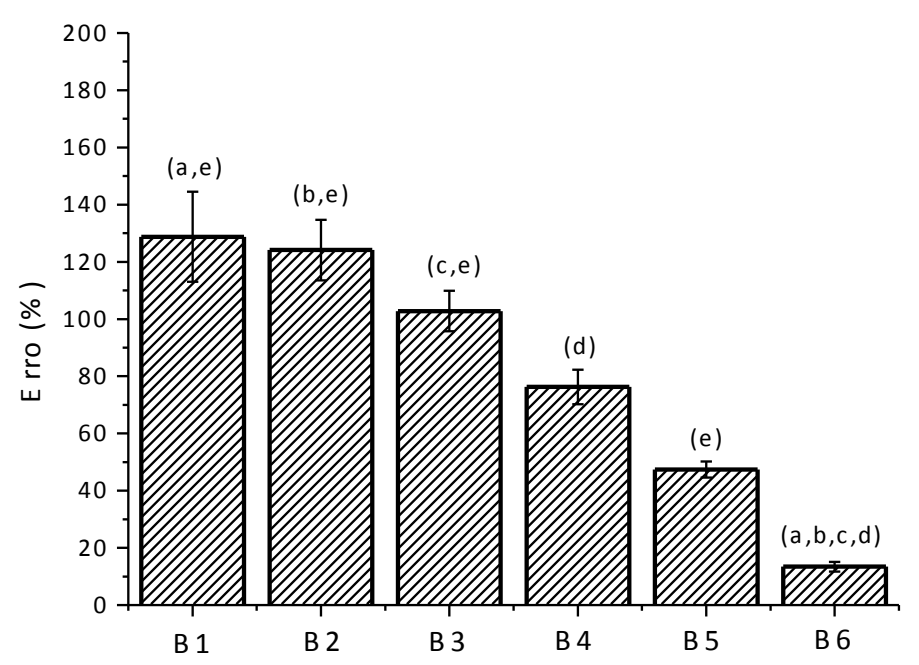

Figura 5.9: Erros percentuais dos valores médios das amplitudes de sinais no patamar durante estresse térmico nas bandas B1 a B6, estimados em um minuto, quando comparados aos valores estimados em 20 minutos. Pares (a, b, c, d, e) significam diferenças (ANOVA, Tukey, p<0,05). Barras verticais significam erros-padrão. 
Sumarizando, os resultados obtidos demonstram que estimações das amplitudes médias das oscilações quando calculadas durante um minuto desviam largamente de seus respectivos valores médios quando calculados durante 20 minutos. Os resultados também demonstram que estimativas de fluxo médio, quando calculados em um minuto, resultam erros menores quando o registro de fluxo é filtrado (banda B0).

Os resultados obtidos demonstram que os erros nas estimações dos valores médios, quando calculados em 1 minuto, do fluxo $(F)$ e das amplitudes de suas parcelas flutuantes são menores durante o estresse térmico, comparados aos respectivos erros quando a temperatura era basal. Contudo, os erros nas estimações das amplitudes das oscilações do fluxo nas faixas B1 a B6 são significativamente maiores que os observados nas estimações de fluxos médios (entre $76 \pm 25 \%$ a $131 \pm 67 \%$ contra $8 \pm 4 \%$ a $9 \pm 4 \%$, respectivamente).

Note-se que o erro encontrado na estimação do valor médio do fluxo na banda B0 foi $16 \%$ e $8 \%$ quando a temperatura era a basal e durante o aquecimento.

Medições do fluxo médio em intervalos curtos de tempo são necessários quando é desejável medir o valor da primeira crista durante um estresse térmico (ver FIG. 5.2). Neste caso, um intervalo curto de tempo é necessariamente usado, pois o evento tem curta duração. Contudo, os resultados obtidos indicam que as medições, quando realizadas na faixa B0 resultam erros toleráveis. Medições diretas nos registros de fluxo (sem filtragem) resultam erros consideravelmente maiores (23\%) no estado basal e devem ser evitadas.

Enquanto estimar valores médios de fluxo em um intervalo temporal igual a um minuto pode ser aceitável, o mesmo intervalo temporal é inadequado para estimar valores médios das flutuações do fluxo.

Retornando à questão sobre o intervalo de tempo mínimo requerido na estimação de valores médios de fluxo e de suas flutuações, recorrendo aos resultados obtidos, algumas conclusões podem ser traçadas. 
Pode-se inferir que registros mais longos (superiores a 20 minutos) resultariam erros menores. Contudo, enquanto períodos mais longos podem ser desejáveis quando o fluxo é basal, longos períodos podem não ser possíveis durante um estresse térmico.

Braverman et al. ${ }^{6}$ (2000) observaram que, quando uma única região arteriolar é continuamente monitorada em um intervalo entre 1 e 2 horas, o fluxo sanguíneo basal apresentava mudanças entre o mínimo e máximo e viceversa em um intervalo de tempo entre 12 a 90 minutos. Dessa forma, considerando o maior intervalo, registros de 90 ou mais minutos seriam necessários. Contudo, os autores observaram as flutuações sem qualquer processamento do sinal de registro e não informaram as amplitudes e frequências das oscilações. Assim, considerando os erros relativamente pequenos encontrados nas estimativas de fluxos médios quando da banda B0, intervalos de tempo na ordem de 1 minuto são toleráveis. No entanto, estimações das amplitudes das flutuações requerem intervalos consideravelmente maiores. Entretanto, é conhecido que durante um estresse térmico, o fluxo aumenta e permanece estável (região de patamar) durante um tempo variável de aproximadamente 50 minutos. Mas, depois deste período, o fluxo decresce novamente, talvez pela indisponibilidade de $\mathrm{NO}^{10}$. Assim, embora tenha sido aqui verificado que as amplitudes das oscilações flutuam largamente e lentamente, requerendo longos períodos para calcular seus valores médios, não é possível obter patamares muito longos durante um estresse térmico. E, embora este trabalho não tenha contemplado o estudo do erro considerando períodos superiores a aproximadamente 20 minutos, é aqui sugerido períodos longos, contudo menores que 50 minutos.

\subsubsection{Quantificação da variabilidade temporal do fluxo e de suas parcelas flutuantes}

O fluxo medido via FLD apresenta flutuações temporais, apresentando padrões rítmicos em faixas espectrais distintas segundo suas origens (TAB. 4.1). 
Caso as amplitudes das oscilações fossem constantes, suas amplitudes médias seriam constantes. Contudo, no tópico anterior foi demonstrado que as oscilações em cada uma das faixas estudadas (B0 a B6) apresentam amplitudes também variantes no tempo. Este comportamento, exemplificado na FIG. 5.2, foi observado em todos os registros analisados. Assim é desejável conhecer a variabilidade temporal dos sinais nas bandas $\mathrm{B} 0$ a $\mathrm{B} 6$.

Os registros de fluxo foram amostrados e armazenados com taxa de 4 $\mathrm{Hz} / \mathrm{s}$. Assim cada registro de fluxo ou das parcelas filtradas tem aproximadamente 4800 amostras, formando séries temporais (amostras de quantidades igualmente espaçadas no tempo). A média aritmética de cada série temporal resulta um valor médio. Buscando analisar a dispersão dos valores de cada série temporal, foi usado como indicador de variabilidade: o coeficiente de variação (CV). Mas, notese que aqui o CV mede variabilidade temporal do fluxo ou de suas parcelas flutuantes.

O CV temporal do parâmetro fluxo médio $(F)$ é a razão entre o desviopadrão do registro de fluxo e seu valor médio. Ou seja, basta calcular o desviopadrão e o valor médio das aproximadamente 4800 amostras de cada série. 0 mesmo procedimento é aplicável ao registro de fluxo filtrado na banda B0, pois ambos possuem médias diferentes de zero. No cálculo do CV das oscilações, o mesmo procedimento foi usado, exceto o cálculo de seus valores médios: foram calculadas médias dos valores absolutos, pois estas séries têm valores médios iguais a zero.

Os valores médios de fluxo, computados de 20 registros de voluntários na temperatura basal e de 20 registros durante um estresse térmico colhidos na região R1 são apresentados na TAB. B3 (ANEXO B3). Os respectivos desviospadrão são apresentados na TAB. B7 - ANEXO B7 . Recorrendo às TAB. B3 ANEXO B3 e B7 ANEXO B7, os coeficientes médios de variação calculados são mostrados na FIG. 5.10, onde pode ser verificado que os CVs nos sinais nas bandas B1 a B6 são significativamente maiores que os encontrados nos sinais na banda B0 e para $F$ (ANOVA e Tukey, $p<0,05$ ). Também foi verificado que o CV 
diminui significativamente durante o estresse térmico nos sinais de fluxo e nas bandas B0, B2, B3, B4, B5 e B6 (teste-t pareado, $p<0,05$ ).

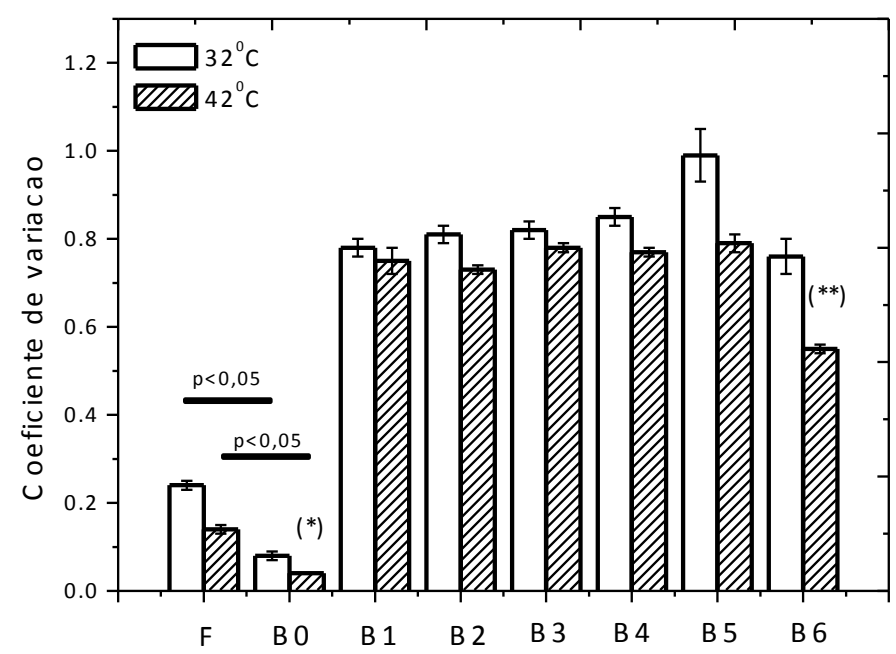

Figura 5.10: Coeficientes médios de variações temporais de 20 registros de fluxo basal $(F)$ e de seus respectivos sinais filtrados nas bandas $\mathrm{B} 0$ a $\mathrm{B} 6$ e de 20 registros de fluxo durante o estresse térmico. Barras horizontais significam diferenças entre pares (teste-t). $\left({ }^{*}\right)$ significa diferente dos grupos $F .\left(^{* \star}\right)$ significa diferente dos demais grupos B1 a B6. ANOVA e teste de Tukey, $p<0,05$. Barras verticais significam erros-padrão

Um coeficiente de variação temporal diferente de zero significa que há dispersão de valores na série temporal. Mas não há valores CV temporais acima dos quais são inaceitáveis. Um elevado CV temporal pode significar a necessidade de médias temporais durante um intervalo longo de tempo.

CVs temporais significativamente maiores nas bandas B1 a B6, quando comparados aos obtidos na banda $\mathrm{B} 0$ e $\mathrm{F}$, refletem o fato de que são sinais cujas amplitudes se distanciam largamente em torno de seus valores médios, no tempo, enquanto $\mathrm{F}$ e $\mathrm{B} 0$ se distanciam menos. Estes resultados, associados aos obtidos no tópico imediatamente anterior, confirmam a necessidade de mediar os sinais nas bandas B1 a B6 em intervalos mais longos de tempo, quando comparados ao sinal na banda B0 e o sinal de fluxo.

Os CVs temporais diminuíram significativamente durante o estresse térmico nos registros de fluxo $(F)$, e nos sinais nas bandas $B 0, B 2, B 3, B 4, B 5$ e 
B6. O CV temporal também diminuiu significativamente na banda B0 comparado ao obtido para F. Este último fato reflete somente a supressão das oscilações nas bandas superiores (B1 a B6), diminuindo a variabilidade temporal na banda B0, confirmando o resultado obtido no tópico anterior. Assim, sempre que as variações de fluxo forem lentas (como o caso da resposta ao estresse térmico), a filtragem na banda B0 é recomendada.

\subsubsection{Quantificação do fluxo e de suas parcelas flutuantes}

A FIG. 5.11 mostra os valores médios dos fluxos basais e durante os estresses térmicos, medidos em 20 voluntários na região R1 (valores da TAB. B3 - ANEXO B3 e B5 ANEXO- B5). O valor médio basal obtido foi 5,7 UA e durante o estresse térmico 124,6 UA.

A FIG. 5.12 mostra os valores médios das flutuações dos fluxos medidos na mesma região e nas mesmas condições (TAB. B3 - ANEXO 3 e B5 ANEXO B5). As oscilações apresentaram amplitudes entre 0,12 UA (banda B1) a 0,49 UA (B6) durante o fluxo basal e entre 0,64 UA (B1) a 12,3 UA (B6) durante o estresse térmico.

Lembrando que os filtros usados para separar os sinais nas bandas B0 a B6 preservam suas amplitudes, os dados aqui apresentados mostram, sem distorções, as proporções entre as amplitudes dos fluxos médios (banda B0) e de suas flutuações (B1 a B6) em ambos os estados (basal e estresse térmico). termo "sem distorções" será discutido na sequência.

Os primeiros resultados sobre as oscilações do fluxo microvascular basal de antebraços, efetuados com a transformada de wavelet, mostravam que a energia na banda B6 era menor que nas demais (B2 a B5) ${ }^{53,76}$. Contudo, é fácil verificar em um registro de fluxo, sem qualquer processamento, que as amplitudes das oscilações seguindo o ritmo cardíaco são claramente maiores que as flutuações do fluxo com frequências mais baixas. Este fato é evidente no registro mostrado na FIG. 5.1. Assim, seria esperado que a amplitude, a energia e a 
potência na banda B6 fossem maiores que as encontradas nas demais bandas (B1 a B5), que é o resultado obtido. Somente recentemente foi evidenciado o seguinte fato: há a necessidade de normalizar os coeficientes de wavelet (obtidos da transformada de wavelet) em cada região espectral ${ }^{77}$. Assim, trabalhos anteriores apresentavam proporções distorcidas de amplitudes, energias ou potências entre as bandas. Mesmo corrigindo as distorções, Sheppard et al. ${ }^{77}$ apresentaram valores de energia das oscilações durante um intervalo de tempo não informado, não sendo assim possível comparar os resultados. A ausência de distorções nas amplitudes (energias e potências) é importante quando comparações são efetuadas entre diferentes bandas.

Em cada banda (B0 a B6), comparando pares, foi possível verificar que as amplitudes aumentaram significativamente durante o estresse térmico (student-t, $p<0,05)$.

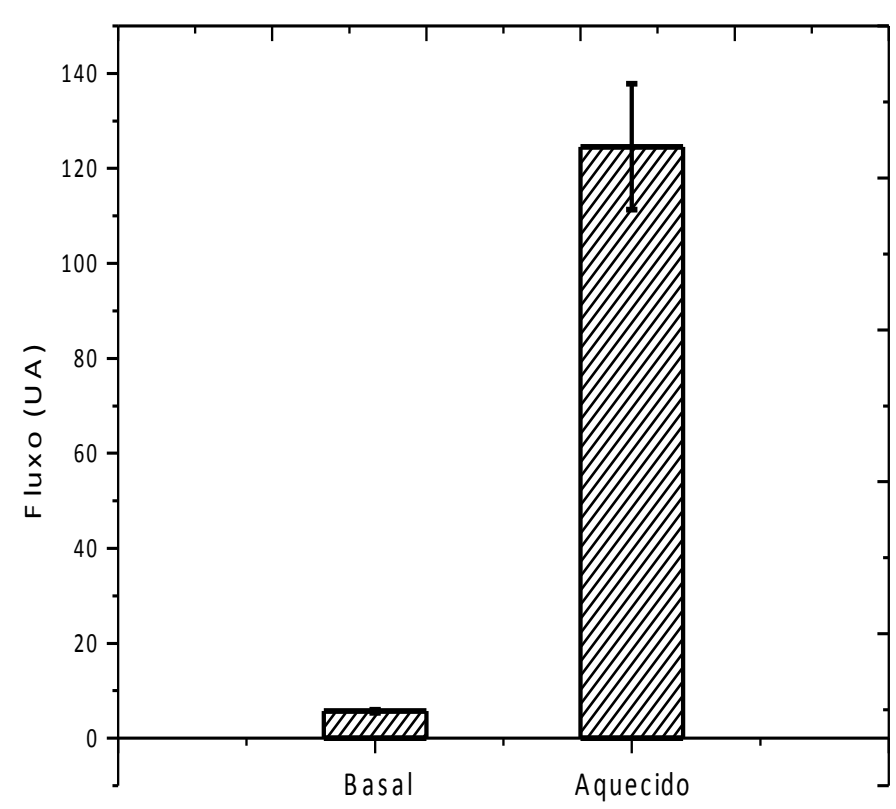

Figura 5.11: Fluxo médio de 20 registros durante a temperatura basal e de 20 registros durante o estresse térmico. Barras verticais significam erros-padrão 


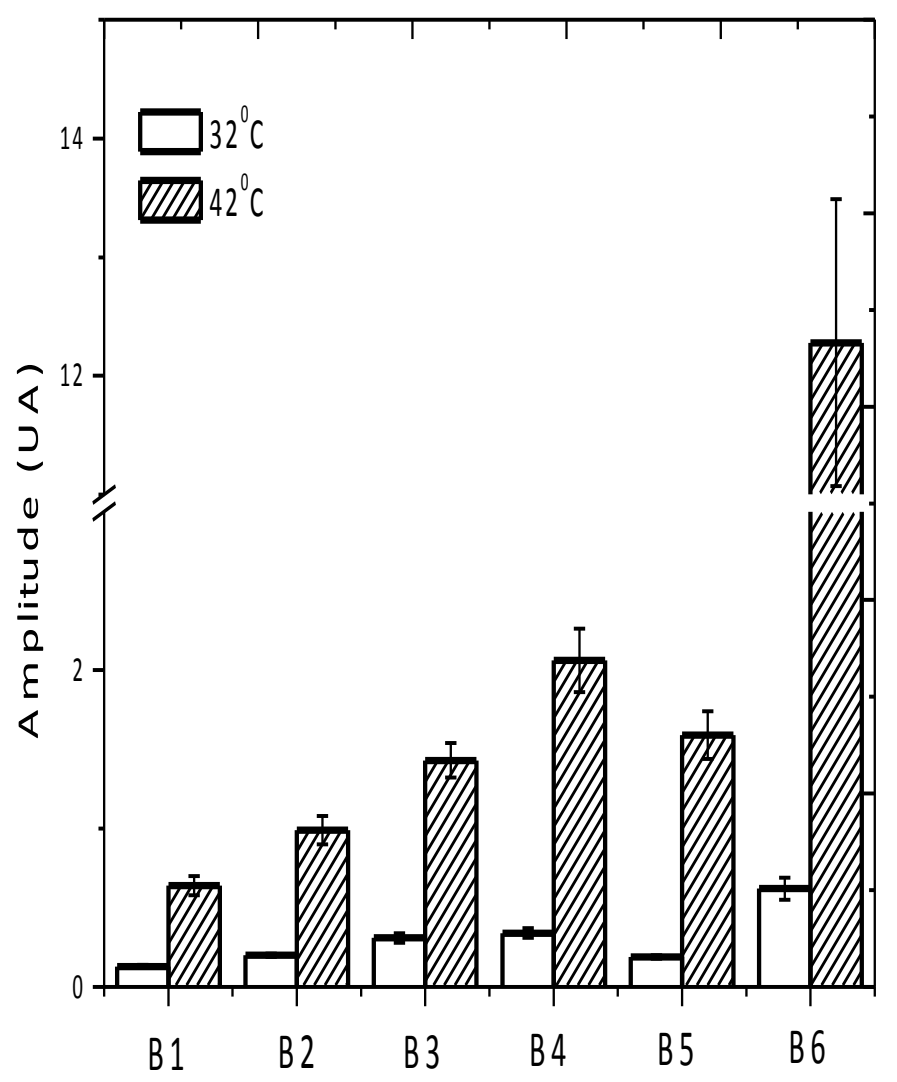

Figura 5.12: Amplitudes médias das oscilações (bandas B1 a B6) de 20 registros de fluxo durante a temperatura basal e 20 registros durante o estresse térmico. Barras verticais significam erros-padrão. Note-se que o eixo das ordenadas foi truncado para evidenciar as diferenças de amplitudes nas bandas B1 a B5

As razões entre as amplitudes médias das flutuações durante 0 estresse térmico e durante a temperatura basal nas faixas B0 a B6 são apresentadas na TAB. 5.1. Cada razão reflete a alteração de fluxo nesta faixa, decorrente da alteração da resistência vascular. Note-se que a variação de fluxo na banda B0 foi consideravelmente superior às das faixas B1 a B5, significando que o fluxo aumentou em uma proporção muito superior às das oscilações nas faixas B1 a B5. Este fato explica a razão da diminuição do erro na estimação do fluxo médio e da diminuição da variabilidade temporal de sinais na banda B0 durante o estresse térmico, quando o sinal de fluxo não foi filtrado, comentado anteriormente. 
Tabela 5.1: Valores médios de fluxo basal $\left(32^{\circ} \mathrm{C}\right)$ e durante 0 estresse térmico $\left(42^{\circ} \mathrm{C}\right)$ nas faixas $\mathrm{BO}$ a $\mathrm{B} 6 \mathrm{em}$ unidades arbitrárias (UA); e razão das variações de fluxo entre os dois estados (adimensional).

\begin{tabular}{cccc}
\hline & Fluxo $\left(\mathbf{4 2}{ }^{\circ} \mathrm{C}\right)$ & Fluxo $\left(32^{\circ} \mathrm{C}\right)$ & Fluxo $\left(\mathbf{4 2}{ }^{\circ} \mathrm{C}\right) /$ Fluxo $\left(32^{\circ} \mathrm{C}\right)$ \\
\hline B0 & 124,57 & 5,71 & 21,82 \\
B1 & 0,64 & 0,13 & 4,92 \\
B2 & 0,99 & 0,19 & 5,21 \\
B2 & 1,43 & 0,31 & 4,61 \\
B4 & 2,06 & 0,34 & 6,06 \\
B5 & 1,59 & 0,19 & 8,37 \\
B6 & 12,28 & 0,62 & 19,81 \\
\hline
\end{tabular}

\subsection{Variabilidade espacial do fluxo e de suas parcelas flutuantes}

O diagrama de barras na FIG. 5.13 apresenta os valores médios dos sinais nas bandas B0 a B6 das duas regiões estudadas (R1 e R2), durante as medições de fluxo basal. Diferenças estatisticamente significantes foram verificadas nas bandas B0, B4 e B6. Contudo, as diferenças não são quantitativamente significantes, principalmente nas bandas B4 e B6.

Durante o estresse térmico, em todas as bandas, não foram encontradas diferenças significantes entre pares de sinais das duas regiões (FIG. 5.14). 


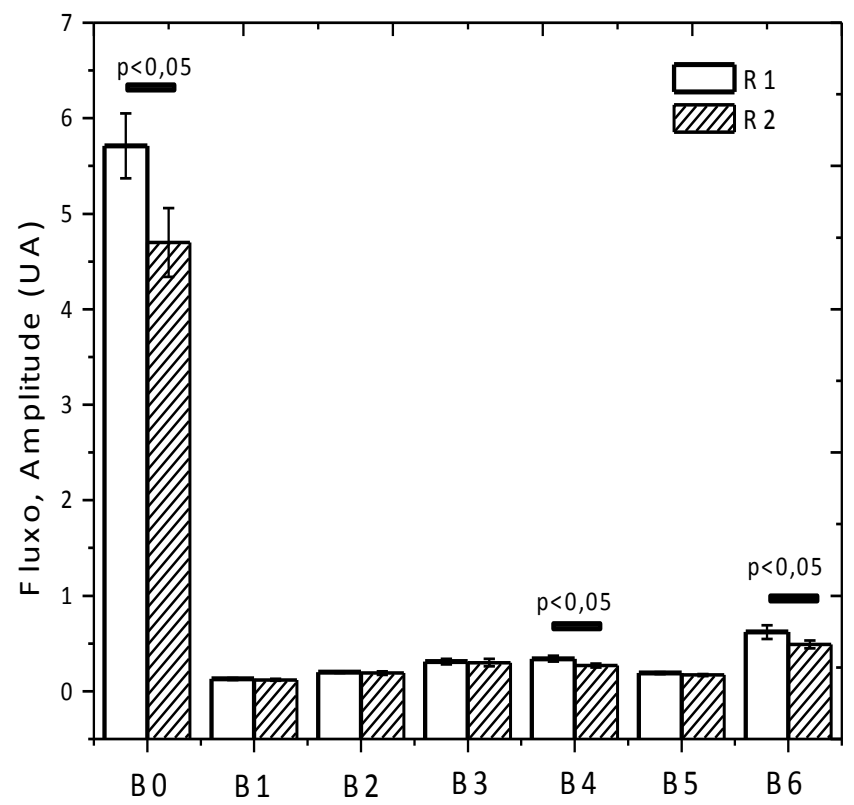

Figura 5.13: Valores médios de fluxo basal e de suas parcelas flutuantes nas duas regiões estudadas (R1 e R2). Barras verticais significam erros-padrão

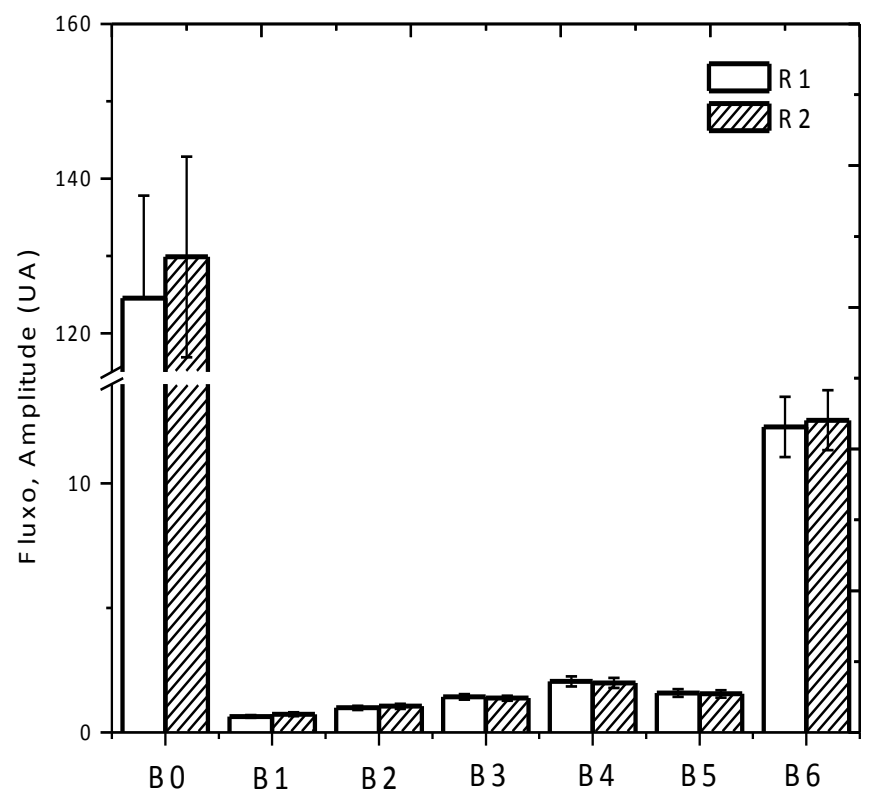

Figura 5.14: Valores médios de fluxo e de suas parcelas flutuantes nas duas regiões estudadas (R1 e R2), durante o estresse térmico. Barras verticais significam erros-padrão. Note-se que o eixo das ordenadas foi truncado para evidenciar as diferenças de amplitudes nas bandas B1 a B5 
A TAB. 5.2 apresenta os valores dos coeficientes de correlação intraclasse $(C C l)$ e de Perason $(r)$ computados dos vinte valores médios de fluxo (B0) e de suas flutuações (B1 a B6) medidos em duas regiões distintas (R1 e R2) durante temperatura basal (dados nas TAB. B3 e B4 (ANEXOS B3 e B4), relativos a R1 e R2 e durante o estresse térmico (dados nas TAB. B5 ANEXO B5 e B6 ANEXO B6). Durante o fluxo basal foram verificados moderados valores de $\mathrm{CCl}$ nas bandas B0, B3, B5 e B6 indicando repetibilidades médias, e baixas nas demais. Durante o estresse térmico, o aquecimento resultou aumento de repetibilidade (especialmente nas bandas B1, B2 e B4), exceto na Banda B3, onde ocorreu diminuição, e exceto na banda B5, que permaneceu inalterada.

Roustit et al. ${ }^{78}$ avaliando a variabilidade espacial de valores de condutância (fluxo/pressão) medidos em duas regiões próximas de antebraços durante um estresse térmico $\left(42^{\circ} \mathrm{C}\right)$ encontraram um valor de $\mathrm{CCl}=0,57$. Portanto, próximo ao valor encontrado para a banda B0. Roustit et al. ${ }^{78}$ não estudaram a repetibilidade durante a temperatura basal e também não analisaram outras bandas além da B0.

Sumarizando, não foram encontradas diferenças significantes (estatística ou quantitativa) entre os valores médios dos sinais nas bandas B0 a B6 tomados em duas regiões próximas tanto na temperatura basal quanto durante o estresse térmico. Contudo, note-se que foram comparados valores médios de cada grupo, significando que não foram encontradas diferenças coletivas, embora a variabilidade dos dados (individuais) tenha sido elevada em alguns casos. De fato, comparações entre pares de medições em um mesmo indivíduo mostraram baixas repetibilidades nas bandas B1, B2 e B4 quando a temperatura era basal. A variabilidade espacial é importante quando se deseja discriminar indivíduos, que é o caso de testes diagnósticos. A repetibilidade aumentou com o estresse térmico nas bandas B0, B1, B2, B4 e B6, sugerindo menor variabilidade espacial nesta condição. Contudo, o aquecimento aumentou a variabilidade espacial na 
banda B3, cuja origem é neurogênica. Este último fato pode significar que respostas neurogênicas podem não ser detectadas quando o estímulo é o estresse térmico e o parâmetro discriminante é a amplitude do registro na faixa B3.

Tabela 5.2: Coeficientes de correlação intraclasse $(C C l)$ e de correlação de Pearson ( $r$ ) entre valores médios de fluxo (B0) e de suas flutuações (B1 a B6) medidos em duas regiões distintas durante a temperatura basal $\left(32^{\circ} \mathrm{C}\right)$ e durante o estresse térmico $\left(42^{\circ} \mathrm{C}\right)$.

\begin{tabular}{cccccccccc}
\hline & & B0 & B1 & B2 & B3 & B4 & B5 & B6 \\
\hline Basal & $C C l$ & 0.42 & 0.08 & 0.06 & 0.6 & 0.3 & 0.55 & $\mathbf{0 . 4 8}$ \\
$\left(32^{\circ} \mathrm{C}\right), \mathbf{n}=\mathbf{2 0}$ & & & 0.51 & 0.09 & 0.06 & 0.6 & 0.36 & 0.58 & $\mathbf{0 . 6 3}$ \\
& & & & & & & & \\
Aquecida & $C C l$ & 0.59 & 0.56 & 0.42 & 0.13 & 0.58 & 0.55 & $\mathbf{0 . 5 9}$ \\
$\left(\mathbf{4 2}{ }^{\circ} \mathrm{C}\right), \mathbf{n}=\mathbf{2 0}$ & & & 0.59 & 0.6 & 0.43 & 0.13 & 0.58 & 0.58 & $\mathbf{0 . 5 9}$ \\
& & & & & & & & \\
\hline
\end{tabular}

A menor variabilidade espacial verificada durante o estresse térmico (exceto na banda B3) pode ser decorrente dos seguintes fatos: aproximadamente apenas $5 \%$ dos capilares estão ativos em uma região em um dado intervalo de tempo ${ }^{79}$. Assim o plexo microvascular ativo não é homogêneo em uma região ${ }^{6}$. Mas o aumento da temperatura resulta o recrutamento de mais capilares, aumentando a fração de vasos ativos na região ${ }^{32}$. Deste modo é esperado que a variabilidade espacial diminua com o aumento da temperatura.

\subsection{Variabilidade intragrupo}


Os coeficientes de variação (CV) calculados usando os valores médios e desvios-padrão (DP) dos sinais basais nas bandas B0 a B6 colhidos na região R1 (médias e DP nas colunas da TAB. B3 ANEXO B3) e durante o estresse térmico na região R1 (medias e DP nas colunas da TAB. B5 ANEXO 5) são apresentados no diagrama em barras na FIG 5.15. Agora um CV significa a variabilidade intragrupo. Ou seja, é uma medida da dispersão dos valores médios em cada grupo.

Não há um valor de corte acima do qual um CV seja considerado excessivo. Mas a capacidade de um parâmetro detectar diferenças entre grupos ou de discriminar indivíduos aumenta quando o CV deste parâmetro diminui. Neste sentido, CV do fluxo médio foi acentuadamente menor durante a temperatura basal $(\mathrm{CV}=0,26)$ enquanto os $\mathrm{CVs}$ das amplitudes médias das flutuações do fluxo foram maiores e sem acentuadas diferenças entre o estado basal e aquecido, oscilando entre 0,3 e 0,48. Contudo, note-se que enquanto o estresse térmico diminuiu as variabilidades temporal e espacial na banda B0 (FIG. 5.10 e TAB. 5.2), aumentou acentuadamente a variabilidade entre indivíduos nesta banda. Este fato pode significar diferenças acentuadas de respostas entre indivíduos. Assim, sempre que viável, um indivíduo deve ser seu próprio controle. Mas, embora o CV intragrupo basal na banda B0 seja menor que os demais (FIG. 5.15), note-se que o valor médio do fluxo na banda B0 não deve ser tomado como referência, pois nesta faixa a variabilidade espacial é elevada (TAB. 5.2). Neste caso, a referência deve ser outra. Uma possibilidade é usar como referência o fluxo médio em um patamar quando a temperatura é elevada a $44^{\circ} \mathrm{C}$, conforme sugere Roustit et $a^{78}$. 


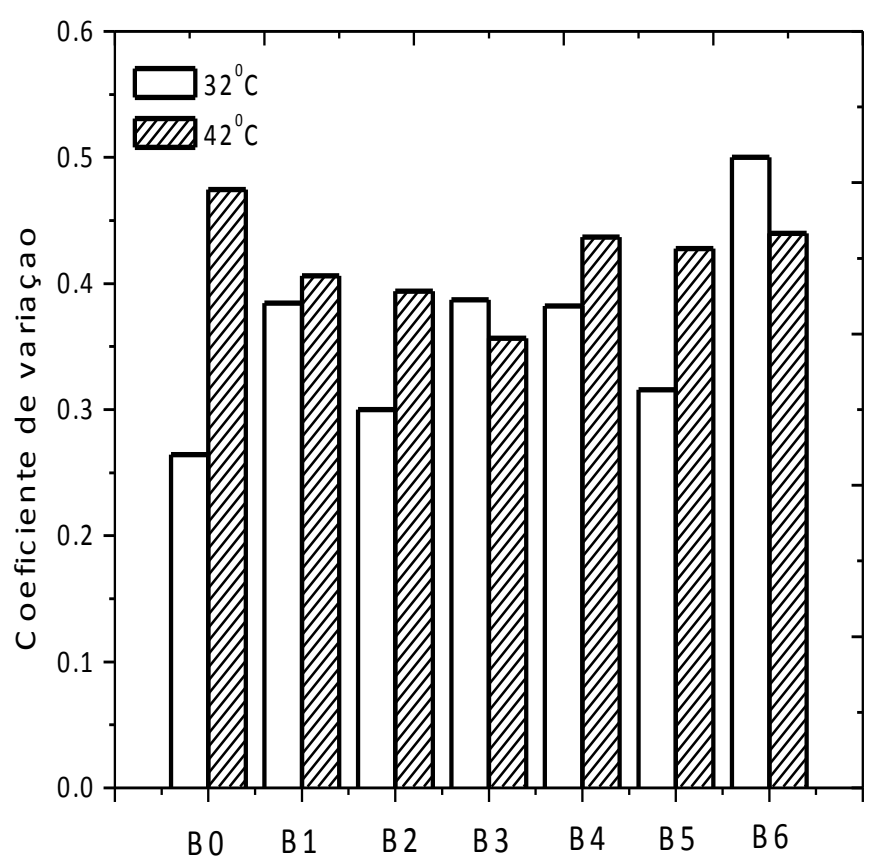

Figura 5.15: Coeficientes de variação intragrupos nas bandas B0 a B6

Note-se ainda que enquanto $o$ aquecimento diminuiu as variabilidades temporais (exceto na banda B1, FIG. 5.10) e espaciais (exceto nas bandas B3 e B5, TAB. 5.2) das amplitudes das flutuações do fluxo, aumentou discretamente as variabilidades intragrupos, exceto nas bandas B3 e B6 (onde houve discreta diminuição). Este fato sugere que a diversidade de respostas entre indivíduos também aumenta quando os parâmetros são as amplitudes das flutuações, exceto nas bandas B3 e B6. Desta forma, novamente, a normalização dos valores das amplitudes das flutuações, tomando o mesmo indivíduo como controle, provavelmente diminuirá a variabilidade dos dados.

\subsection{Correlação espaço-temporal}

Os sinais de um registro de fluxo decomposto nas sete bandas espectrais estudadas (B0 a B6) de duas regiões próximas colhidas no antebraço de um voluntário durante o patamar de um processo de estresse térmico são 
apresentados na FIG. 5.16. A simples inspeção visual revela que há sincronismo intermitente entre todos os pares de sinais (de duas regiões próximas) nas sete bandas espectrais durante longos intervalos de tempo, incluindo a banda B0. A FIG 5.17 evidencia segmentos de sinais na banda B0 das duas regiões de outro voluntário (durante o patamar) onde podem ser observados sincronismos entre as variações lentas e rápidas de fluxo nesta faixa espectral. O intervalo de tempo em que foi observado sincronismo contínuo entre cada par de sinais foi variável: variou entre indivíduos e entre as sete bandas espectrais estudadas. O mesmo padrão (sincronismo intermitente) foi observado em todos os registros estudados. O intervalo de tempo em que cada par de sinais estava em sincronismo foi longo (centenas de segundos), exceto na banda B5 (respiratória), onde o tempo que permaneceram em sincronismo foi menor (dezenas de segundos). Durante longos intervalos temporais, as flutuações entre pares de sinais ocorreram em sincronismo, embora suas amplitudes diferissem. 

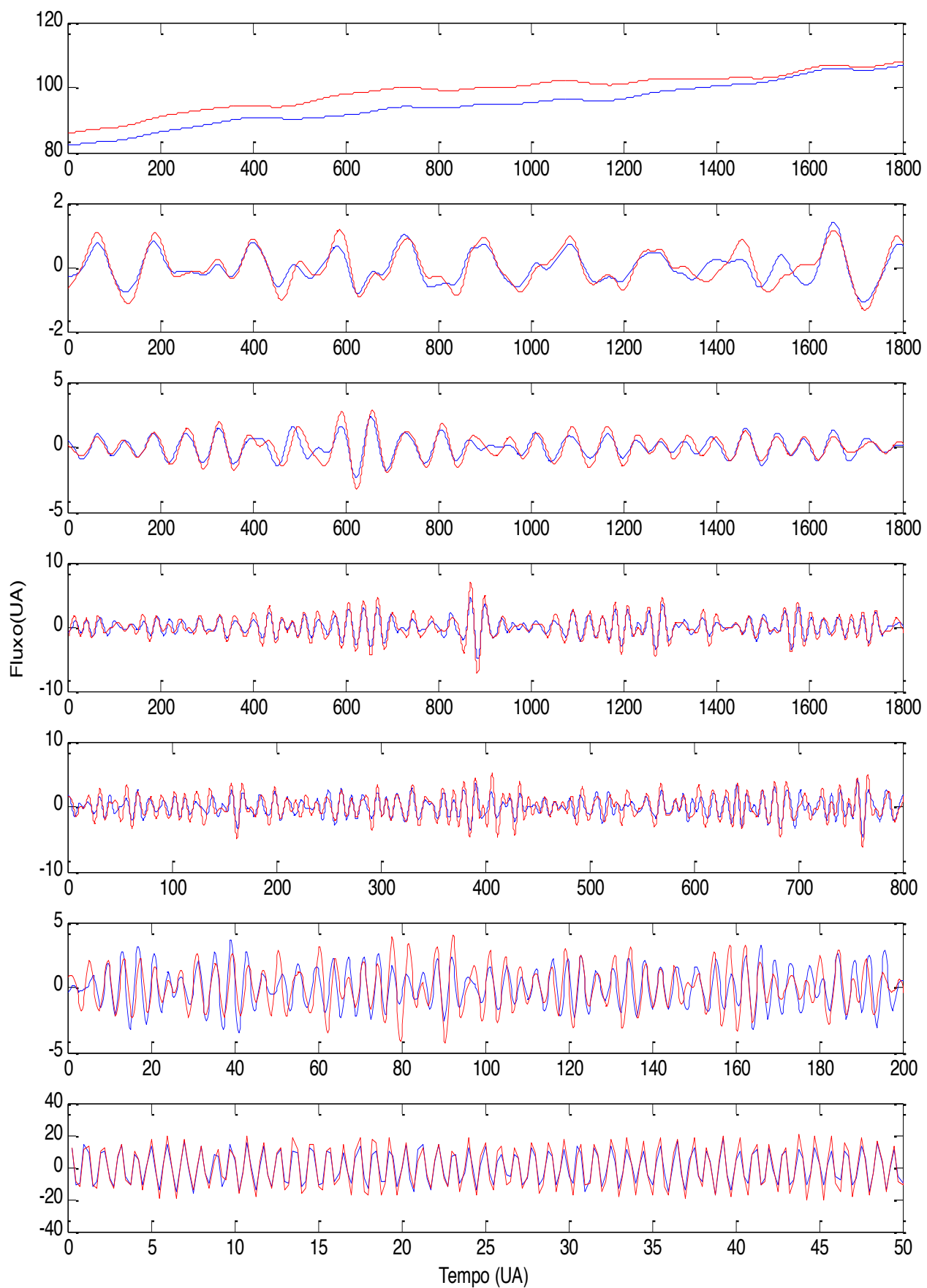

Figura 5.16: Segmentos de sinais de fluxo na região do patamar, durante um procedimento de estresse térmico, decomposto nas sete bandas espectrais estudadas (B0 a B6, de cima para baixo). Os sinais foram colhidos em duas regiões próximas ( $\mathrm{R} 1$, em azul e $\mathrm{R} 2$ em vermelho) 


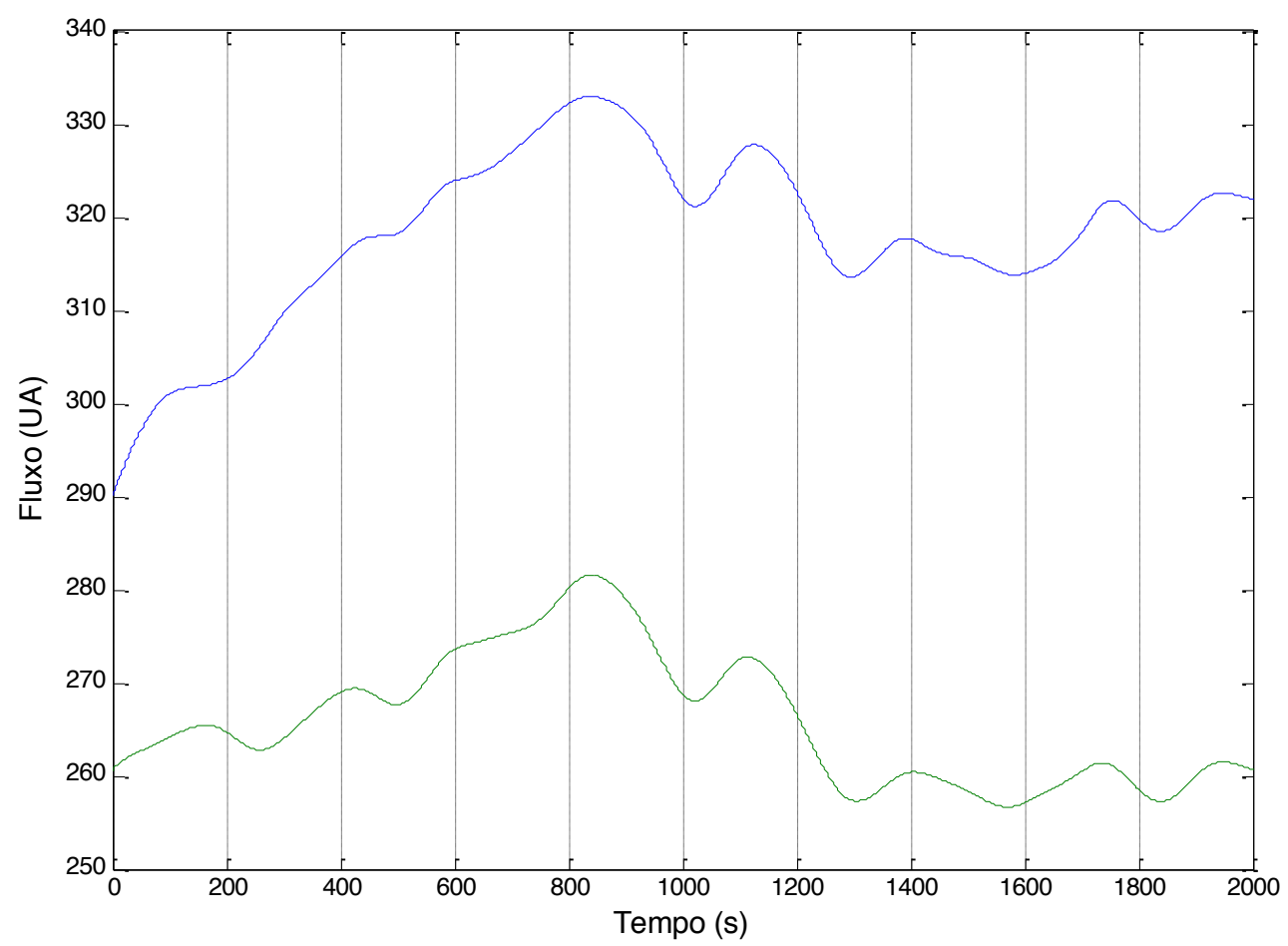

Figura 5.17: Segmentos de sinais de fluxo colhidos em duas regiões próximas de um voluntário, durante um procedimento de estresse térmico, decomposto na banda espectral B0, onde pode ser observado sincronismo entre as variações lentas e rápidas observadas nesta faixa espectral $(0$ a $0,005 \mathrm{~Hz})$

Embora os pares de sinais nas bandas B0 a B6 não tenham permanecido síncronos durante todo patamar, as perdas de sincronismo foram momentâneas, retornando ao sincronismo. A percentagem de tempo em que cada par de sinais permaneceu síncrono ao logo de cada patamar, está representada na TAB. B9 (ANEXO B9) e os coeficientes de correlação na TAB. B10 (ANEXO B10).

Pares de sinais basais em todas as bandas $\mathrm{B} 0$ a $\mathrm{B} 6$, entre duas regiões próximas, semelhante ao já descrito durante o estresse térmico, também apresentaram sincronismo. Contudo, o tempo que permaneceram em sincronismo foi menor. Quantificando, a TAB. B11 (ANEXO B11) apresenta as percentagens de tempo que cada par permaneceu em sincronismo e a TAB. B12 (ANEXO B12) 
os coeficientes de correlação dos sinais estudados nas bandas B0 a B6 para os sinais basais.

O diagrama de barras da FIG. 5.18 mostra os valores médios das percentagens de tempo em que pares de sinais permaneceram síncronos em ambos os regimes (basal e estresse térmico). $O$ incremento da temperatura aumentou significativamente a percentagem de tempo de sincronismo em todas as bandas, exceto nas bandas B1 e B5 (FiG. 5.18). Durante o estresse térmico, a percentagem de tempo de sincronismo na banda B5 foi significativamente menor que as observados nas demais bandas (TAB. B9 - ANEXO B9). Durante o fluxo basal, o tempo de sincronismo na banda B5 foi significativamente menor que nas bandas B0 e B1. Não foram encontradas diferenças significantes nas percentagens de tempo entre as demais bandas (TAB. B11- ANEXO B11).

O diagrama de barras da FIG. 5.19 apresenta os valores médios dos coeficientes de correlação entre pares de sinais durante a temperatura basal e durante o estresse térmico, onde podem ser verificadas as mesmas diferenças entre as diferentes temperaturas que as encontradas para a percentagem de tempo. Ou seja, semelhante à percentagem de tempo, o incremento da temperatura aumentou significativamente a correlação entre pares em todas as bandas exceto nas bandas B1 e B5 (FIG. 5.19). Durante o estresse térmico, a correlação entre pares em todas as bandas, exceto na B5, foram significativamente maiores que 0,5 (teste-t). Na banda B5 a correlação foi significativamente menor que as encontradas nas demais bandas (ANOVA e Tukey). Na temperatura basal, a correlação entre pares na banda B5 foi menor que nas bandas $\mathrm{B} 0$ e B1.

O diagrama em barras da FIG. 5.20 apresenta os coeficientes de variação intragrupos das percentagens de tempo em que os pares de sinais permaneceram correlacionados (PC), calculados usando os dados nas TAB. B9 (ANEXO B9) e B11 (ANEXO B11), onde pode ser observado que ocorreu acentuada diminuição da variabilidade dos valores de percentagens de tempo com o aumento da temperatura. 
Note-se que os CVs intragrupos das PCs são menores que os observados quando os parâmetros eram amplitudes dos sinais nas bandas B1 a B6 (FIG. 5.15). Ou seja, a variabilidade entre indivíduos deste último parâmetro é menor que a encontrada para a amplitude. Este fato indica que este parâmetro (PC) pode ser um parâmetro mais sensível a alterações em cada uma das faixas. Este tópico é uma sugestão de estudos futuros.

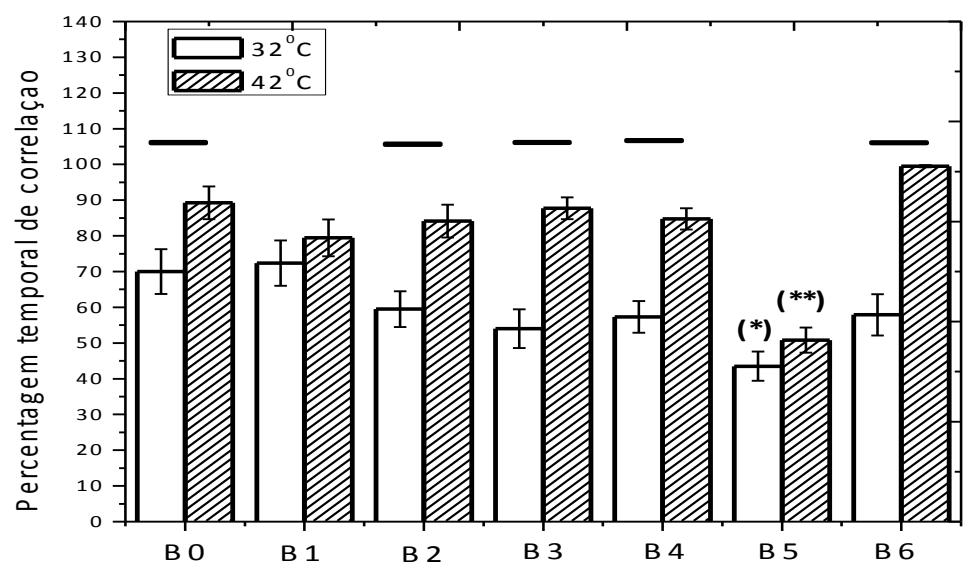

Figura 5.18: Valores médios da percentagem de tempo em que vinte pares de sinais nas bandas B0 a B6 permaneceram síncronos. $\left({ }^{*}\right)$ significa diferente das bandas B0 e B1 basais. $\left({ }^{* *}\right)$ significa diferente das demais bandas. ANOVA e teste de Tukey, $p<0,05$. Barras verticais significam diferentes, teste-t. Barras verticais significam erros-padrão

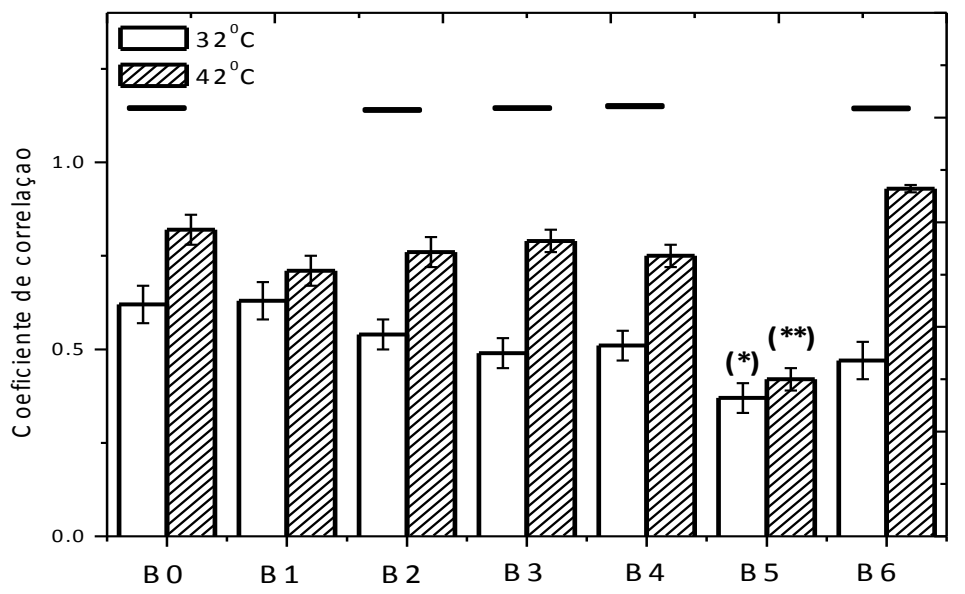

Figura 5.19: Valores médios dos coeficientes de correlação de Pearson entre vinte pares de sinais nas bandas B0 a B6. $\left(^{\star}\right)$ significa diferente das bandas B0 e B1 basais. $\left(^{* *}\right)$ significa diferente das demais bandas. ANOVA e teste de Tukey, $p<0,05$. Barras verticais significam diferentes, teste-t. Barras verticais significam erros-padrão. 


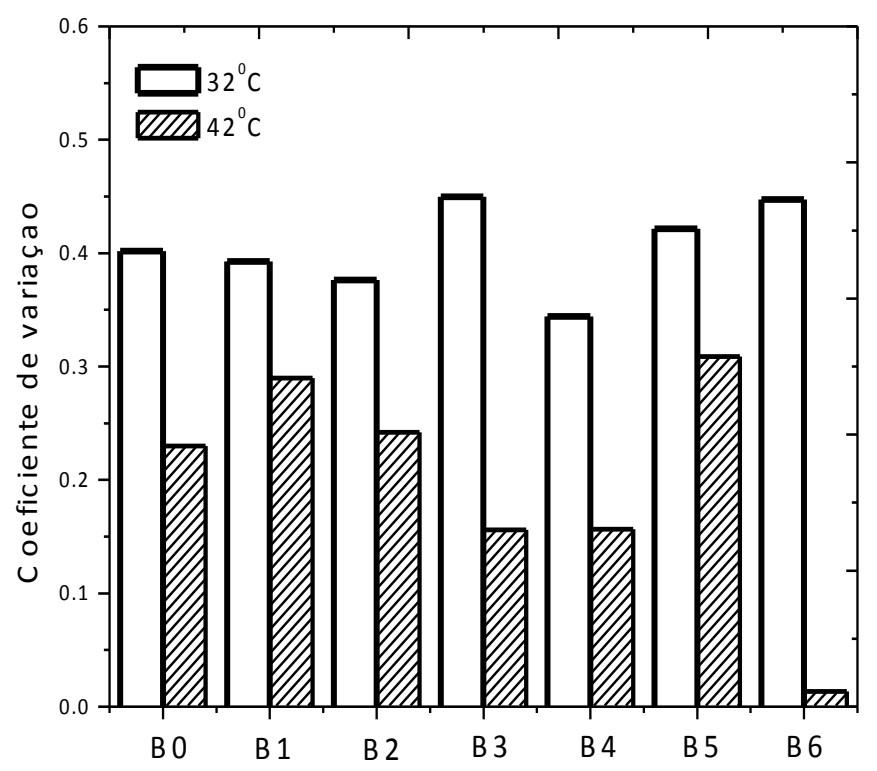

Figura 5.20: Valores médios dos coeficientes de variação das percentagens de tempo em que vinte pares de sinais nas bandas $\mathrm{B} 0$ a $\mathrm{B} 6$, permaneceram síncronos

Foi verificado que as variações de sinais de fluxo medidos em duas regiões próximas no antebraço de voluntários saudáveis estavam sincronizadas durante intervalos variáveis de tempo, dependendo da faixa espectral. Este fato foi verificado tanto nos registros de fluxo basal quanto durante o estresse térmico, mas durante esta última condição, permaneceram síncronos mais tempo.

Estudos da relação (correlação ou coerência) de sinais de fluxo com outros sinais cardiovasculares (ECG e pressão sanguínea) são abundantes na literatura, pois a existência de correlação ou coerência sugere uma origem comum ou relações de dependências entre sinais. Como exemplo, a existência de flutuações de fluxo microvascular em $1 \mathrm{~Hz}$ e a frequência cardíaca em um ECG igual a $1 \mathrm{~Hz}$ sugerem que a origem das flutuações do fluxo nesta frequência seja cardíaca. Contudo, os dois sistemas (coração e microcirculação) podem eventualmente oscilar na mesma frequência e não estarem relacionados. A existência de correlação ou de coerência entre os sinais não é suficiente para 
assumir causalidade (relação entre causa e efeito). Mas é pouco provável que dois sinais de fluxo permaneçam síncronos durante longos intervalos de tempo e não estejam relacionados. Assim, dada a importância desta ferramenta, estudos da relação entre sinais de fluxo de grandes artérias com sinais cardiovasculares são abundantes, enquanto que os que correlacionam sinais de fluxos microvasculares com sinais cardiovasculares são mais raros. Mais especificamente, somente foi encontrado na literatura um estudo sobre a relação de fluxos microvasculares entre duas regiões distintas em um mesmo indivíduo (entre dois indicadores em um mesmo indivíduo) ${ }^{80}$. Neste estudo, a região estudada foi a polpa digital, que é uma região termoregulatória, rica em shunts artério-venulares, diferindo funcionalmente da região estudada neste trabalho, que foi a região volar do antebraço, que é uma região nutritiva, onde shunts artériovenulares são raros ${ }^{6}$. Desta forma, por ser este um estudo sem precedentes, a comparação direta dos resultados obtidos com outros na literatura não foi possível, e os resultados de Bernardi et al. ${ }^{80}$ são aqui comparados, sempre que possível.

Note-se que não foi um objetivo deste trabalho estudar as origens das flutuações síncronas dos sinais de fluxo de duas regiões próximas. Contudo, as flutuações síncronas encontradas podem ser úteis e os possíveis significados e as possíveis consequências destes achados também serão discutidos na sequência, segundo suas origens sugeridas na literatura.

\subsubsection{Origem cardíaca - Banda B6}

No sistema cardiovascular, o coração é uma bomba cuja pressão de saída é pulsátil, resultando pressão pulsátil em todo o circuito circulatório. Logo, a frequência cardíaca é evidente em todo o circuito cardiovascular. A frequência cardíaca de indivíduos normais é aproximadamente $1 \mathrm{~Hz}$. A presença de flutuações de fluxo medido via FLD em torno de $1 \mathrm{~Hz}$, comparadas com outros sinais cardiovasculares (ECG e pressão sanguínea) obtidos simultaneamente, tem 
sido considerada evidência direta da origem deste tipo de flutuação no registro de fluxo via FLD ${ }^{81}$.

Foi verificado neste trabalho que, na região B6 do espectro, as flutuações dos fluxos microvasculares medidos via FLD em duas regiões próximas nas regiões volares de antebraços de voluntários saudáveis são síncronos durante a quase totalidade dos experimentos, tanto nas temperaturas basais quanto durante o estresse térmico. Não foi encontrado outro estudo similar na literatura para comparação com os resultados obtidos nesta faixa do espectro. Contudo, admitindo a inquestionável origem deste sinal (SB6) ser cardíaca ${ }^{82}$, este resultado é concordante com o esperado, pois a velocidade da onda de pressão braquial é da ordem de $18 \mathrm{~m} / \mathrm{s}^{83}$. Considerando que o espaçamento entre as duas regiões estudadas foi da ordem de $10 \mathrm{~cm}$, atrasos na ordem de 5 ms são esperados. Portando, era esperado que os dois sinais de fluxo fossem praticamente síncronos nesta faixa do espectro.

\subsubsection{Origem respiratória - Banda B5}

Nesta faixa de frequência, os coeficientes de correlação entre os dois sinais foram significativamente menores que $0,5 \mathrm{em}$ ambas as temperaturas, TAB. B10 (ANEXO B10) e B12 (ANEXO B12). Portanto, não foi encontrada correlação significativa entre pares de sinais nesta banda espectral.

Segundo o estudo de Bernardi et $a l .^{80}$, os índices de coerência encontrados entre sinais, nesta faixa de frequência, das polpas de dois indicadores de um mesmo indivíduo foram maiores que $0,5 \mathrm{em}$ todos os 10 indivíduos estudados. Neste estudo, o índice de coerência variava entre zero (não coerente) e um (coerente). Os autores consideraram coerências significantes quando os índices de coerência eram maiores que 0,5. O método usado pelos autores permitiu estimar o atraso entre os dois sinais: o atraso encontrado foi próximo a zero. Assim, segundo este estudo, os sinais eram síncronos. Os resultados do presente trabalho são discordantes dos obtidos por Bernardi et al. ${ }^{80}$ 
No trabalho de Bernardi et al. ${ }^{80}$, a respiração ou foi ativamente controlada em $0,25 \mathrm{~Hz}$ ou foi mantida espontaneamente na faixa entre $0,2 \mathrm{~Hz}$ a $0,26 \mathrm{~Hz}$.

No presente trabalho, a respiração foi espontânea. Mas foi observado que os tempos elevados dos experimentos (entre 30 minutos a 90 minutos), a posição e a temperatura controlada da sala contribuíram tal que quase invariavelmente o nível de vigília dos voluntários diminuía, suas frequências respiratórias diminuíam e suas amplitudes aumentavam. Ainda, em muitos casos, os voluntários falaram durante os experimentos, modificando drasticamente a frequência respiratória.

A manutenção da frequência respiratória é importante quando o espectro do sinal é analisado (que é o caso da quase totalidade dos estudos similares encontrados na literatura), pois quando a frequência muda ao longo do registro, a energia dispersa no espectro. Contudo, o método usado neste trabalho não é sensível às alterações de frequência, pois o método de análise usado (correlação temporal) é insensível a mudanças de frequência.

Segundo a literatura, a origem das flutuações do fluxo microvascular nesta faixa do espectro (B5) tem sido atribuída à arritmia sinusal respiratória82, que é uma flutuação rítmica dos intervalos temporais entre batimentos cardíacos (intervalo R-R de um ECG), caracterizada pela diminuição ou aumento do intervalo R-R durante a inspiração e expiração, respectivamente.

É conhecido que a arritmia sinusal respiratória é evidente em crianças, mas é menos evidente em adultos. Também é conhecido que padrões respiratórios lentos e profundos potencializam a arritmia sinusal respiratória ${ }^{84}$. Assim, o padrão respiratório ativamente controlado usado no trabalho de Bernardi et al. ${ }^{80}$ pode ter potencializado a arritmia sinusal respiratória, resultando flutuações de fluxo na banda B5 mais intensas; enquanto que a respiração espontânea usada no experimento deste trabalho pode ter resultado arritmia menos evidente ou ausente, resultando influências respiratórias na banda B5 menores ou ausentes. Esta possibilidade explicaria a divergência entre os 
resultados, lembrando ainda que outra razão seria o fato de as duas regiões comparadas serem funcionalmente diferentes (nutritiva e termorregulatória).

\subsubsection{Origem miogênica - Banda B4}

Segundo Shiogai et al. ${ }^{82}$, Stefanovska et al. ${ }^{53}$, Jan et al ${ }^{19}$, Rossi et al. ${ }^{15}$, Geyer, et al. ${ }^{13}$ tem sido sugerido que as flutuações de fluxo nesta faixa do espectro correspondem à atividade miogênica. Não há evidências diretas sobre a origem dessas oscilações. Contudo, têm sido observadas atividades espontâneas na musculatura lisa de microvasos com frequências próximas a $0,1 \mathrm{~Hz}{ }^{82}$ e este fato tem sido o fundamento para a associação.

Embora a atividade miogênica seja largamente estudada, ainda não há um entendimento abrangente sobre sua origem e efeitos. Contudo tem sido observado que a musculatura lisa nos vasos pré-capilares possui um tônus que pode ser modulado por vários fatores, incluindo a pressão transmural ${ }^{79}$. De fato, tem sido observado que um aumento de pressão transmural resulta contração da musculatura (diminuição do diâmetro vascular) e a diminuição da pressão transmural resulta a relaxação (aumento do diâmetro).

O coração bombeia o sangue pelo sistema vascular em uma forma pulsátil, e as flutuações de pressão são presentes em praticamente todo sistema circulatório. A pressão sanguínea apresenta um valor máximo sistólico e um valor mínimo diastólico. Durante cada ciclo cardíaco a pressão sistêmica tem um valor médio e pode variar entre batimentos. A variação da pressão sistêmica média, quando calculada em ciclos cardíacos consecutivos, tem sido denominada variabilidade da pressão sanguínea (VPS). Tem sido observado que a VPS apresenta flutuações rítmicas nas faixas B1 a B5 ${ }^{82}$, incluindo a faixa B4 onde a energia é mais elevada (miogênica). Assim, tem sido sugerido que a atividade miogênica microvascular atua no controle da pressão ${ }^{82}$.

Uma vez que a atividade miogênica nesta faixa do espectro é uma resposta às variações sistêmicas de pressão, seria esperado que as flutuações de fluxo em duas regiões distintas em um mesmo indivíduo apresentassem elevada 
correlação e que o atraso entre as flutuações no presente experimento fosse pequeno, pelas mesmas razões já apontadas no tópico imediatamente anterior.

No trabalho de Bernardi et al. ${ }^{80}$ (descrito no tópico anterior), foi encontrada elevada coerência entre o fluxo medido (polpa de um indicador) e a pressão sanguínea em seis de dez indivíduos, nesta faixa do espectro. No trabalho de Bernardi et al. ${ }^{80}$ também foram encontradas elevadas coerências entre os fluxos medidos nas polpas de indicadores (de um mesmo indivíduo), em dez de dez voluntários.

A correlação média, encontrada neste trabalho, dos sinais na faixa B4 de duas regiões próximas durante o estresse térmico, foi significativamente maior que 0,5, TAB. B10, ANEXO B10. Não foi possível saber se a correlação média durante a temperatura basal foi significativamente diferente de 0,5 , TAB . B12, ANEXO B12. Assumindo ser aproximadamente igual a 0,5, o resultado obtido quando a temperatura era basal está em concordância com o obtido por Bernardi et al.80, lembrando que as regiões estudadas são funcionalmente diferentes (nutritiva e termorregulatória). Não foram encontrados estudos similares na literatura para comparar os resultados obtidos durante o estresse térmico.

\subsubsection{Origem neurogênica - Banda B3}

O coração, os pulmões e todos os vasos sanguíneos (exceto os capilares) são inervados. O sistema nervoso autônomo atua continuamente em todos estes sistemas.

Em regiões glabras (sem pêlos) da pele (palmas das mãos, solas dos pés, lábios) os vasos são somente inervados por nervos simpáticos noradrenérgicos. Em regiões não glabras (membros, tronco e cabeça), nervos simpáticos noradrenérgicos vasoconstritores e colinérgicos vasodilatadores modulam o tônus vascular. Há evidências que mostra que a inervação vascular participa do controle da pressão sanguínea sistêmica ${ }^{85}$, do processo termoregulatório ${ }^{16}$, e de respostas locais via reflexo antidrômico (ex., aquecimento local, $\left.{ }^{16}\right)$. Contudo, não há evidências diretas sobre a origem das flutuações do 
fluxo microvascular nesta faixa do espectro. Mas há elevado corpo de evidências indiretas sugerindo que as oscilações nesta faixa do espectro são reações neurogênicas.

Söderström et al. ${ }^{86}$ demonstraram que as amplitudes das oscilações nesta faixa do espectro são significativamente menores em peles transplantadas, quando comparadas a áreas sadias em regiões próximas. Uma vez que as inervações são totalmente seccionadas neste procedimento, a associação foi sugerida.

Wilson et al. ${ }^{87}$ efetuaram registros de fluxos em antebraços de indivíduos saudáveis em três condições: i) basais; ii) bloqueio ganglionar, administrando trimetafano e iii) trimetafano mais oscilações de pressão negativas em membros inferiores (para regenerar flutuações na pressão sanguínea que foi abolida pelo bloqueio). Nestas condições foi observado que as amplitudes das flutuações diminuíram significativamente durante o bloqueio e aumentaram quando pressões negativas oscilantes foram aplicadas nos membros inferiores, demonstrando indiretamente a associação entre as flutuações do fluxo microvascular nesta faixa de frequências e o sistema autônomo.

Nesta faixa do espectro (B3), a correlação média observada foi $r=$ 0,49, mas não foi possível saber se a correlação média durante as temperaturas basais foi significativamente diferente de 0,5 . Contudo houve aumento significativo durante o estresse térmico, quando os sinais permaneceram síncronos durante $88 \%$ do tempo experimental e o coeficiente de correlação médio obtido foi $r=$ 0,79 .

Considerando ser o sistema autônomo responsável pelas flutuações nesta faixa do espectro, e considerando que a velocidade de condução e resposta nervosa é elevada (ordem de $1 \mathrm{~m} / \mathrm{s}^{88}$ ), era esperado que os sinais na faixa B3 fossem síncronos, concordando com os resultados obtidos. Não foi encontrado um estudo similar, na literatura, nesta faixa do espectro. 


\subsubsection{Origem endotelial NO dependente - Banda B2}

Trocas gasosas $\left(\mathrm{CO}_{2}\right.$ e $\left.\mathrm{O}_{2}\right)$ e outras substâncias relacionadas com o metabolismo tecidual ocorrem no plexo microvascular. Assim o fluxo microvascular é ajustado em função das necessidades metabólicas.

Tem sido sugerido que o endotélio participa no processo de regulagem do fluxo microvascular em função das necessidades metabólicas, via ajuste da concentração de várias substâncias. Dentre outras, o oxido nítrico (NO) é conhecidamente um potente vasodilatador, cuja disponibilidade e síntese está relacionada ao endotélio ${ }^{89}$.

Stewart et al. ${ }^{90}$, realizaram experimentos em humanos (pele), usando acetilcolina, um vasodilatador dependente do endotélio e nitro-L-arginina, um inibidor da síntese de NO, ambos administrados via micro-diálise. Segundo este estudo, as amplitudes das oscilações em todas as faixas do espectro eram maiores quando sob efeito da acetilcolina, mas diminuía significativamente e seletivamente, na faixa B2, quando nitro-L-arginina foi administrada. Segundo os autores, estes resultados sugerem que as oscilações do sinal de fluxo nesta faixa do espectro são NO dependentes. Vários outros estudos confirmam a relação entre a amplitude das oscilações nesta faixa e a disponibilidade de NO endotelia| ${ }^{82}$.

Quando a temperatura era basal, nesta faixa (B2), os sinais de duas regiões próximas permaneceram $59,5 \%$ do tempo experimental sincronizados e o coeficiente de correlação médio encontrado foi $r=0,54$. No entanto, quando as regiões foram aquecidas houve um aumento significativo tanto do tempo em que os sinais permaneceram síncronos (84\%) como do coeficiente de correlação médio $(r=0,76)$.

Não foram encontrados, na literatura, estudos similares para comparação. Contudo, tanto a elevada correlação como o elevado tempo de sincronismo encontrados entre os sinais durante o estresse térmico suscitam uma questão: se a disponibilidade de NO depende de sua síntese no endotélio seria um processo local de controle do fluxo microvascular. Sendo este um processo 
local, não seria esperado sincronismo de fluxo entre as duas regiões ensaiadas. Este fato sugere que a origem das oscilações nesta banda requer mais estudos.

Segundo comentários de Stewart et al. ${ }^{90}$ (experimento acima descrito), enquanto têm sido encontradas oscilações do sinal de fluxo com frequências abaixo de $0,021 \mathrm{~Hz}$, as contrapartes não têm sido encontradas: i) nos sinais de pressão sanguínea, ii) nos sinais de variações do ritmo cardíaco e; iil) em atividades nervosas simpáticas de músculos. Assim, apontam os autores que tais oscilações de fluxo não estariam relacionadas às atividades neurogênicas central ou periférica, levando inferir que os mecanismos que resultam tais oscilações são locais e provavelmente mediadas pelo endotélio. Contudo, Stewart et al. ${ }^{90}$ usaram a transformada de Fourier nas análises dos sinais, que não possui resolução espectral adequada em baixas frequências. De fato, usando a transformada de wavelet, recentemente foram encontradas oscilações de pressão arterial nesta faixa do espectro ${ }^{82}$. Oscilações sistêmicas da pressão arterial podem explicar o sincronismo observado.

\subsubsection{Origem endotelial NO- não dependente - Banda B1}

Existem evidências indiretas sugerindo que oscilações de fluxo na faixa entre $0,005 \mathrm{~Hz}$ a $0,0095 \mathrm{~Hz}$ dependem do endotélio, mas não dependem da disponibilidade de NO.

Kvandal et al. ${ }^{14}$ provocaram vasodilatação em humanos usando acetilcolina e nitroprussiato de sódio, um vasodilatador independente do endotélio, localmente administrados via iontoforese. Os autores também testaram a inibição da síntese de NO usando NG - monometil-L-arginina, infundido na artéria braquial, e a inibição da síntese da prostaglandina (vasodilatador), infundindo aspirina endovenosamente. A acetilcolina induziu maior aumento nas oscilações nas duas faixas (B1 e B2) quando comparado ao aumento induzido pelo nitroprussiato de sódio. A inibição da síntese de NO via NG - monometil-L-arginina não afetou a diferença de resposta à acetilcolina versus nitroprussiato de sódio na faixa B1 mas aboliu a diferença das respostas na faixa B2. A aspirina não alterou as respostas 
à acetilcolina e nitroprussiato de sódio. Fundamentados nesses resultados, os autores sugeriram que outro mecanismo (exceto o NO) deveria estar envolvido nas oscilações na faixa B1. Os autores sugerem o envolvimento do fator hiperpolarizante derivado do endotélio.

$\mathrm{Na}$ faixa $\mathrm{B} 1$ os pares de sinais permaneceram síncronos durante $72 \%$ e $80 \%$ do tempo experimental e os coeficientes de correlação obtidos foram 0,6 e 0,7 durante a temperatura basal e o estresse térmico, respectivamente. Portanto os sinais apresentaram elevados índices de sincronismo.

Não foram encontrados, na literatura, estudos sobre a coerência ou correlação entre flutuações de sinais de fluxo em regiões distintas na pele, nesta faixa do espectro. Contudo, é conhecido que as células endoteliais estão normalmente sujeitas a dois tipos de forças: uma axial, decorrente da pressão transmural (diferença de pressões do interior e exterior dos vasos) e outra, longitudinal, resultante da força de ficção gerado pelo fluxo sanguíneo. A força axial resulta contrações da musculatura lisa dos vasos e este é um mecanismo conhecido de regulagem do fluxo vascular, já discutido (faixa B4). Em resposta aos aumentos da força longitudinal, o endotélio libera vários vasodilatadores, incluindo o $\mathrm{NO}$ e prostaciclina. $\mathrm{Na}$ microvasculatura humana, a inibição combinada da síntese de $\mathrm{NO}$ e da ciclooxigenase (síntese da prostaglandina) não inibe totalmente a vasodilatação, e tem sido sugerido que a dilatação residual é dependente da ação de um fator hiperpolarizante derivado do endotélio ${ }^{91}$. Caso esta hipótese esteja correta, as ondas na faixa B1 poderiam ser dependentes de alterações de fluxo. Ou seja, um aumento de fluxo localizado induziria vasodilatação coordenada nos vasos que irrigam esta região. Esta possibilidade explicaria o elevado sincronismo encontrado nas oscilações do fluxo microvascular nesta faixa do espectro.

\subsubsection{Banda BO}

Flutuações na banda B0, que inclui frequências inferiores a 0,005 $\mathrm{Hz}$, não têm sido estudadas, talvez pelas seguintes razões: os métodos espectrais 
normalmente usados na análise das oscilações são a transforma da Fourier truncada ou a transformada de wavelet. A transforma da Fourier não possui resolução espectral ou resolução temporal suficiente. Por outro lado, longos intervalos de tempo são necessariamente descartados no início e no final da transformada de wavelets, onde ocorrem distorções ${ }^{77}$. Assim longos intervalos de tempo seriam necessários para estudar frequências inferiores a $0,005 \mathrm{~Hz}$, dificultando procedimentos experimentais.

Também não foram encontrados estudos sobre oscilações com frequências inferiores a $0,005 \mathrm{~Hz}$ nos sinais de pressão sanguínea e variações do ritmo cardíaco, talvez pelas mesmas razões acima apontadas. Assim, novamente não foi possível comparar os resultados obtidos com estudos semelhantes.

As flutuações entre pares de sinais de fluxo provenientes de duas regiões próximas nesta faixa do espectro (abaixo de $0,005 \mathrm{~Hz}$ ) foram surpreendentemente síncronas durante $89 \%$ e $70 \%$ do tempo em que foram realizados os experimentos, e os coeficientes de correlação foram 0,82 e 0,62, durante o estresse térmico e temperatura basal, respectivamente, sugerindo ou um controle central ou um comportamento regional coletivo. 


\section{CONCLUSÃO}

Os sinais das sete faixas foram temporalmente, espacialmente e espaço-temporalmente caracterizados e quantificados.

Os resultados obtidos permitiram concluir que as variabilidades temporais de sinais na faixa BO são significativamente menores que as observadas em registros de fluxo. Este resultado sugere que valores médios de fluxo, quando calculados em intervalos curtos de tempo (aproximadamente 1 minuto), devem ser calculados na faixa B0. Os resultados obtidos também permitiram observar que a variabilidade entre medições de fluxo em duas regiões próximas em um mesmo indivíduo (variabilidade espacial) diminui quando as regiões são localmente aquecidas $\left(42^{\circ} \mathrm{C}\right)$, mas nesta condição a variabilidade intragrupo aumenta.

Os resultados obtidos mostraram que as variabilidades temporais de sinais nas faixas B1 a B6 são significativamente maiores que a encontrada na faixa B0. Este resultado sugere a necessidade de calcular as médias temporais de sinais nestas faixas usando períodos mais longos que o acima sugerido para o fluxo. Nesta condição foi observado que as variabilidades espaciais dos valores médios dos sinais nas faixas B1 a B6 diminuem com o aquecimento local, exceto nas faixa B3 e B5. Mas o aquecimento aumentou discretamente as variabilidades intragrupos, exceto nas bandas B3 e B6, onde houve discreta diminuição.

A caracterização espaço-temporal revelou elevadas correlações temporais entre os sinais de regiões próximas quando localmente aquecidas, em todas as faixas, exceto na faixa B5. Nesta condição, as variabilidades intragrupos das quantidades $P C$ (percentagem de tempo em que os sinais permaneceram correlacionados) foram menores que as variabilidades intragrupos das amplitudes 
médias dos sinais nas faixas $\mathrm{B} 1$ a $\mathrm{B} 6$. Este resultado indica que o parâmetro $P C$ é promissor para o estudo e análise de funções microvasculares. 
ANEXO A1

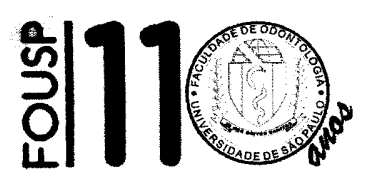

\author{
UNIVERSIDADE DE SÃO PAULO \\ FACULDADE DE ODONTOLOGIA \\ COMtê de Ética Em Pesquisa
}

\author{
PARECER DE APROVAÇÃO \\ FR368328 \\ Protocolo 166/10
}

Com base em parecer de relator, o Comitê de Ética em Pesquisa APROVOU o protocolo de pesquisa "Caracterização das flutuaçóes do sinal laser Doppler do fluxo microvascular", de responsabilidade do(a) Pesquisador(a) Melissa S. Folgosi-Corrêa sob orientação do(a) Prof.(a) Dr.(a) Gesse Eduardo Calvo Nogueira.

Tendo em vista a legislação vigente, devem ser encaminhados a este Comitê relatórios anuais referentes ao andamento da pesquisa e ao término cópia do trabalho em "cd". Qualquer emenda do projeto original deve ser apresentada a este CEP para apreciação, de forma clara e sucinta, identificando a parte do a ser modificada e suas justificativas.

São Paulo, 19 de abril de 2011.

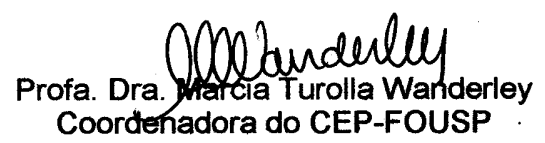

Av. Prof. Lineu Prestes, 2227 - Cidade Universitária "Armando de Salles Oliveira". São Paulo - SP - CEP 05508-900 - Tel. (0XX11) 3091-7960 


\section{Anexo A2}

\section{TERMO DE CONSENTIMENTO LIVRE E ESCLARECIDO}

(Obrigatório para pesquisas científicas em seres humanos - Resolução CNS $n^{\circ} 1$ de 13.6.98)

\section{Dados de identificação}

Título do Projeto: Caracterização das flutuações do sinal laser Doppler do fluxo microvascular

Pesquisador Responsável: Gesse Eduardo Calvo Nogueira

Instituição a que pertence o Pesquisador Responsável: Instituto de Pesquisas Energéticas e Nucleares (IPEN)_

Telefones para contato: (11) 31339188 - (11) 31339255

Nome

voluntário:

Idade: anos

R.G.

\section{INFORMAÇÕES GERAIS SOBRE A PESQUISA A QUAL SEREI SUBMETIDO:}

Logo abaixo da pele há pequenos vasos sanguíneos chamados microvasos onde ocorre a microcirculação sanguínea. O diabetes, o uso crônico do fumo, certas doenças que afetam o sistema nervoso e até a idade avançada podem causar problemas na microcirculação. Nestes casos a microcirculação também não é normal. Atualmente há vários métodos de examinar o funcionamento da microcirculação usando o laser. Estes métodos são interessantes, pois não necessitam a coleta de sangue ou de tecidos, não são 
perigosos para o paciente e são fáceis de efetuar. Mas os métodos existentes ainda precisam ser melhorados, pois os registros de fluxo microvascular obtidos com o laser ainda ocorrem muitas variações entre indivíduos mesmo quando saudáveis, e estas variações ainda não são totalmente conhecidas.

O projeto de pesquisa "Caracterização das flutuações do sinal laser Doppler do fluxo microvascular", sob responsabilidade do(a) pesquisador(a) Gesse Eduardo Calvo Nogueira e Melissa Santos Folgosi-Corrêa, tem como objetivo colher e registrar informações sobre o fluxo sanguíneo da pele na região do antebraço para caracterizar as variações dos registros de fluxo microvascular. Não há benefícios diretos aos participantes desta pesquisa. Contudo a caracterização dos registros de fluxo permitirá conhecer as flutuações do fluxo medido, minimizar as variações indesejáveis, aumentando a sensibilidade do método, que é frequentemente usado no estudo da microcirculação. O estudo da microcirculação é útil não somente ao entendimento de disfunções microvasculares, comuns em diabéticos, como já dito, mas também é útil para diagnosticar a vitalidade da polpa de dentes e o estado de outros órgãos. Assim, é esperado que o resultado deste trabalho seja útil a todos os voluntários e para sociedade sempre que ocorrer uma suspeita de doença microvascular.

Os registros de fluxo serão obtidos usando um fluxômetro laser Doppler. O fluxômetro laser Doppler é um instrumento que mede o fluxo microvascular usando um laser operando em baixa intensidade, não oferecendo riscos de danos à pele ou olhos. A medição do fluxo microvascular é efetuada fixando na pele uma sonda, por intermédio de fita adesiva facilmente removível. A sonda é uma fibra óptica que conduz radiação laser em seu interior, terminando em um pequeno disco de plástico que somente toca a pele. Assim a sonda emite radiação laser, em baixa intensidade, e recebe a radiação que é espalhada pela pele. A radiação espalhada é coletada pela sonda e volta ao fluxômetro, que analisa a radiação laser espalhada e indica o fluxo microvascular na região onde a sonda é fixada. $\mathrm{O}$ registro de fluxo é a leitura do fluxo durante o tempo em que o instrumento está medindo o fluxo. 
O material que será colhido do voluntário serão registros de fluxo, que serão armazenados em um computador e também podem ser impressos em papel. Os registros de fluxo serão usados exclusivamente para os propósitos desta pesquisa. A identidade de cada voluntário não será divulgada, exceto se legalmente solicitados por órgãos competentes para finalidades administrativas ou judiciais. Também é assegurado aos voluntários que não haverá qualquer custo monetário.

A pesquisa envolve voluntários saudáveis, com idades entre 18 a 60 anos, de ambos os sexos. A cada voluntário será solicitado comparecer em 03 (três) sessões.

Antes do inicio de cada sessão de medição o voluntário permanecerá deitado em repouso em uma sala climatizada a $23^{\circ} \mathrm{C}$ durante 30 (trinta) minutos. Serão fixadas duas sondas no antebraço, usando uma fita adesiva. Na primeira sessão o fluxo será registrado durante aproximadamente 30 (trinta) minutos. Numa segunda sessão, em outro dia, com duração igual à primeira, os suportes das sondas do fluxômetro serão aquecidos até $42^{\circ} \mathrm{C}$ (quarenta e dois graus Celsius), usando um equipamento de aquecimento de pele. Na terceira sessão, com duração igual às duas sessões anteriores, os suportes das sondas serão aquecidos até $42^{\circ} \mathrm{C}$ numa região previamente tratada com lidocaína ou EMLA. A aplicação da lidocaína ou EMLA será efetuada uma hora antes do início dos registros. Lidocaína ou EMLA são drogas, aplicadas na pele em forma de creme, que anestesiam o local onde são aplicadas. O local onde a lidocaína ou EMLA será aplicada é uma pequena região (aproximadamente $2 \times 2$ centímetros) onde a sonda do fluxômetro será fixada. O equipamento de aquecimento usa uma pequena resistência elétrica que aquece o local onde a sonda irá medir o fluxo (pequena região de aproximadamente $2 \times 2 \mathrm{~cm}$ ). O aquecimento é controlado e a taxa de aquecimento é tão pequena que geralmente não causa desconforto. Ou seja, geralmente o voluntário não percebe que a sonda está sendo aquecida.

Os voluntários serão convidados a participar das três sessões acima descritas. Mas é assegurado aos voluntários desistir de qualquer sessão e mesmo 
durante qualquer sessão. Contudo o registro de qualquer sessão isolada é de interesse e valor na execução deste trabalho.

\section{RISCOS E BENEFÍCIOS}

O laser que será usado não é perigoso. Não produz danos aos olhos ou pele. A sonda de medição do fluxo é uma fibra óptica terminada em um disco de plástico que somente encosta na pele e não causa desconforto. O sistema de aquecimento da pele é controlado e a velocidade de aquecimento é controlada para propositalmente não causar desconforto. Contudo pode ser desconfortável permanecer durante as sessões de registros com mobilidade restrita (o voluntário deverá permanecer deitado e será solicitado ao voluntário não mexer os braços para não interferir nos registros) e o aquecimento da pele pode eventualmente resultar leve desconforto inicial. As drogas anestésicas poderão eventualmente causar reações alérgicas no local onde será aplicada. Neste caso a sessão será interrompida e o voluntário será encaminhado ao Hospital Universitário da USP. Mas deve estar claro que em qualquer momento o voluntário poderá desistir e neste caso a sessão será interrompida e o voluntário estará dispensado sem qualquer prejuízo.

\section{DECLARAÇÃO DE CONSENTIMENTO:}

Declaro para todos os efeitos jurídicos, presentes e futuros, que o efeito e natureza do procedimento acima relatado foram perfeitamente explicados e compreendidos. E, por conseguinte, declaro ter ciência que terei assistência integral do pesquisador, durante e após a realização das sessões, para o esclarecimento de quaisquer dúvidas que por ventura surjam durante a realização da referida pesquisa. Razão pela qual expressamente reconheço que antes da minha submissão à referida pesquisa tive oportunidade de esclarecer todas e quaisquer dúvidas possíveis quanto ao procedimento ao qual serei submetido(a). Afirmo, ainda, ter ciência de que os dados a serem obtidos nessa pesquisa serão mantidos em sigilo, mantendo-se preservada minha privacidade, de que nenhuma 
das informações seja requerida pelos órgãos competentes por meio do devido processo administrativo ou judicial necessário à obtenção das respectivas informações. Por fim, declaro que, ao assinar o presente termo de consentimento, recebi uma cópia desse termo, com igual teor. Sabendo que poderei abandonar a pesquisa em qualquer etapa, sem que a mim sejam aplicadas penas ou multas, conscientemente, autorizo, por minha livre iniciativa, a realização dos trabalhos acima relatados.

$\mathrm{Eu}$, RG $\mathrm{n}^{0}$ declaro ter sido informado e concordo em participar, como voluntário, do projeto de pesquisa acima descrito.

São Paulo, de de

Gesse Eduardo Calvo Nogueira

Nome e assinatura do voluntário Melissa Santos Folgosi-Corrêa 


\section{ANEXO B1}

Tabela B1: Erros percentuais dos valores médios de fluxo não filtrados $(F)$ e das amplitudes dos sinais filtrados nas bandas B0 a B6 calculados em 1 minuto tomando como referência os respectivos valores calculados em 20 minutos, de registros de fluxo durante um estresse térmico e basal. DP (desvio-padrão)

\begin{tabular}{|c|c|c|c|c|c|c|c|c|c|c|c|c|c|c|c|c|}
\hline & \multicolumn{8}{|c|}{ Erro (\%) - Temperatura basal } & \multicolumn{8}{|c|}{ Erro (\%) - Estresse térmico } \\
\hline Indivíduo & $\mathrm{F}$ & B0 & B1 & B2 & B3 & B4 & B5 & B6 & $\mathrm{F}$ & B0 & B1 & B2 & B3 & B4 & B5 & B6 \\
\hline 1 & 22 & 14 & 140 & 107 & 116 & 88 & 78 & 54 & 4 & 5 & 70 & 87 & 96 & 49 & 37 & 25 \\
\hline 2 & 14 & 10 & 86 & 97 & 116 & 76 & 68 & 37 & 7 & 7 & 96 & 104 & 134 & 72 & 74 & 10 \\
\hline 3 & 25 & 23 & 154 & 93 & 125 & 85 & 94 & 37 & 3 & 2 & 68 & 82 & 66 & 61 & 28 & 10 \\
\hline 4 & 27 & 19 & 144 & 126 & 93 & 130 & 109 & 65 & 8 & 7 & 140 & 93 & 146 & 97 & 36 & 8 \\
\hline 5 & 29 & 16 & 180 & 189 & 221 & 209 & 127 & 58 & 6 & 5 & 107 & 80 & 79 & 61 & 47 & 9 \\
\hline 6 & 46 & 33 & 124 & 108 & 124 & 63 & 122 & 53 & 16 & 15 & 335 & 246 & 117 & 66 & 45 & 37 \\
\hline 7 & 23 & 11 & 123 & 183 & 79 & 98 & 78 & 28 & 16 & 14 & 126 & 165 & 164 & 105 & 49 & 15 \\
\hline 8 & 24 & 14 & 104 & 161 & 169 & 116 & 53 & 58 & 6 & 5 & 85 & 94 & 69 & 69 & 50 & 12 \\
\hline 9 & 25 & 18 & 91 & 133 & 202 & 75 & 53 & 46 & 8 & 8 & 125 & 97 & 93 & 69 & 37 & 13 \\
\hline 10 & 32 & 19 & 290 & 206 & 156 & 169 & 205 & 55 & 9 & 8 & 124 & 107 & 80 & 107 & 53 & 9 \\
\hline 11 & 20 & 16 & 135 & 153 & 108 & 126 & 79 & 39 & 14 & 13 & 136 & 166 & 153 & 67 & 46 & 16 \\
\hline 12 & 19 & 14 & 118 & 217 & 109 & 196 & 193 & 60 & 3 & 3 & 128 & 103 & 78 & 101 & 72 & 19 \\
\hline 13 & 29 & 19 & 107 & 115 & 172 & 116 & 107 & 48 & 7 & 7 & 102 & 129 & 78 & 50 & 48 & 6 \\
\hline 14 & 11 & 6 & 156 & 140 & 141 & 171 & 54 & 31 & 13 & 13 & 289 & 168 & 92 & 104 & 54 & 12 \\
\hline 15 & 22 & 15 & 87 & 117 & 103 & 67 & 85 & 34 & 14 & 15 & 118 & 81 & 109 & 145 & 42 & 18 \\
\hline 16 & 8 & 5 & 176 & 174 & 87 & 68 & 114 & 44 & 7 & 7 & 102 & 130 & 78 & 50 & 48 & 6 \\
\hline 17 & 20 & 15 & 132 & 144 & 105 & 149 & 196 & 25 & 6 & 3 & 90 & 108 & 95 & 66 & 29 & 8 \\
\hline 18 & 18 & 13 & 117 & 126 & 191 & 92 & 57 & 37 & 10 & 10 & 77 & 111 & 83 & 49 & 62 & 11 \\
\hline 19 & 21 & 13 & 250 & 265 & 212 & 65 & 51 & 59 & 9 & 6 & 128 & 207 & 143 & 61 & 43 & 11 \\
\hline 20 & 25 & 19 & 110 & 180 & 175 & 107 & 120 & 39 & 8 & 7 & 171 & 142 & 229 & 76 & 39 & 8 \\
\hline Média & 23 & 16 & 141 & 152 & 140 & 113 & 102 & 45 & 9 & 8 & 131 & 125 & 109 & 76 & 47 & 13 \\
\hline DP & 8 & 6 & 52 & 45 & 44 & 45 & 48 & 12 & 4 & 4 & 67 & 45 & 41 & 25 & 12 & 7 \\
\hline
\end{tabular}




\section{ANEXO B2}

Tabela B2: Erro percentual dos valores médios das amplitudes $(A)$ e das potências $(P)$ de sinais basais nas bandas $\mathrm{B} 1$ a $\mathrm{B} 6$, calculados em 1 minuto tomando como referência os respectivos valores calculados em 20 minutos.

\begin{tabular}{|c|c|c|c|c|c|c|c|c|c|c|c|c|}
\hline \multirow[t]{2}{*}{ Individuo/banda } & \multicolumn{2}{|c|}{ B1 } & \multicolumn{2}{|c|}{ B2 } & \multicolumn{2}{|c|}{ B3 } & \multicolumn{2}{|c|}{ B4 } & \multicolumn{2}{|c|}{ B5 } & \multicolumn{2}{|c|}{ B6 } \\
\hline & $A$ & $P$ & $A$ & $P$ & $A$ & $P$ & $A$ & $P$ & $A$ & $P$ & $A$ & $P$ \\
\hline 1 & 140 & 319 & 107 & 218 & 116 & 239 & 88 & 246 & 78 & 168 & 54 & 68 \\
\hline 2 & 86 & 148 & 97 & 191 & 116 & 274 & 76 & 160 & 68 & 167 & 37 & 66 \\
\hline 3 & 154 & 371 & 93 & 198 & 125 & 260 & 85 & 168 & 94 & 401 & 37 & 154 \\
\hline 4 & 144 & 382 & 126 & 278 & 93 & 195 & 130 & 306 & 109 & 306 & 65 & 97 \\
\hline 5 & 180 & 436 & 189 & 440 & 221 & 632 & 209 & 683 & 127 & 489 & 58 & 359 \\
\hline 6 & 124 & 285 & 108 & 202 & 124 & 263 & 63 & 139 & 122 & 415 & 53 & 134 \\
\hline 7 & 123 & 263 & 183 & 413 & 79 & 163 & 98 & 223 & 78 & 189 & 28 & 37 \\
\hline 8 & 104 & 221 & 161 & 370 & 169 & 443 & 116 & 242 & 53 & 88 & 58 & 73 \\
\hline 9 & 91 & 182 & 133 & 266 & 202 & 465 & 75 & 149 & 53 & 115 & 46 & 67 \\
\hline 10 & 290 & 792 & 206 & 498 & 156 & 347 & 169 & 607 & 205 & 955 & 55 & 578 \\
\hline 11 & 135 & 249 & 153 & 346 & 108 & 224 & 126 & 282 & 79 & 177 & 39 & 78 \\
\hline 12 & 118 & 250 & 217 & 560 & 109 & 255 & 196 & 584 & 193 & 855 & 60 & 453 \\
\hline 13 & 107 & 221 & 115 & 239 & 172 & 398 & 116 & 253 & 107 & 270 & 48 & 91 \\
\hline 14 & 156 & 344 & 140 & 329 & 141 & 356 & 171 & 449 & 54 & 134 & 31 & 35 \\
\hline 15 & 87 & 158 & 117 & 254 & 103 & 203 & 67 & 92 & 85 & 329 & 34 & 38 \\
\hline 16 & 176 & 458 & 174 & 420 & 87 & 204 & 68 & 157 & 114 & 479 & 44 & 135 \\
\hline 17 & 132 & 266 & 144 & 331 & 105 & 217 & 149 & 476 & 196 & 1071 & 25 & 54 \\
\hline 18 & 117 & 254 & 126 & 277 & 191 & 481 & 92 & 202 & 57 & 164 & 37 & 51 \\
\hline 19 & 250 & 698 & 265 & 632 & 212 & 589 & 65 & 138 & 51 & 131 & 59 & 126 \\
\hline 20 & 110 & 238 & 180 & 439 & 175 & 469 & 107 & 272 & 120 & 467 & 39 & 293 \\
\hline Média & 141 & 327 & 152 & 345 & 140 & 334 & 113 & 291 & 102 & 369 & 45 & 149 \\
\hline DP & 52 & 167 & 45 & 125 & 44 & 139 & 45 & 174 & 48 & 288 & 12 & 151 \\
\hline
\end{tabular}




\section{ANEXO B3}

Tabela B3: Valores de fluxos basais e respectivas amplitudes das oscilações de fluxo nas bandas B0 a B6, em unidades arbitrárias (UA), colhidos na região R1.

\begin{tabular}{|c|c|c|c|c|c|c|c|c|}
\hline Individuo/banda & Fluxo & BO & B1 & B2 & B3 & B4 & B5 & B6 \\
\hline 1 & 4,95 & 4,96 & 0,12 & 0,24 & 0,38 & 0,24 & 0,18 & 0,63 \\
\hline 2 & 8,94 & 8,94 & 0,17 & 0,2 & 0,48 & 0,44 & 0,23 & 0,67 \\
\hline 3 & 5,87 & 5,87 & 0,1 & 0,16 & 0,2 & 0,21 & 0,12 & 0,58 \\
\hline 4 & 3,97 & 3,97 & 0,1 & 0,23 & 0,28 & 0,39 & 0,28 & 0,49 \\
\hline 5 & 6,2 & 6,2 & 0,15 & 0,17 & 0,36 & 0,35 & 0,23 & 0,58 \\
\hline 6 & 3,74 & 3,74 & 0,16 & 0,18 & 0,16 & 0,4 & 0,16 & 0,32 \\
\hline 7 & 4,41 & 4,42 & 0,15 & 0,23 & 0,24 & 0,21 & 0,15 & 0,56 \\
\hline 8 & 6,34 & 6,33 & 0,2 & 0,17 & 0,58 & 0,49 & 0,2 & 0,89 \\
\hline 9 & 6,04 & 6,03 & 0,16 & 0,26 & 0,25 & 0,24 & 0,13 & 0,31 \\
\hline 10 & 4,01 & 4,01 & 0,1 & 0,17 & 0,29 & 0,19 & 0,17 & 0,31 \\
\hline 11 & 6,02 & 6,02 & 0,06 & 0,1 & 0,13 & 0,14 & 0,13 & 0,94 \\
\hline 12 & 5,61 & 5,61 & 0,12 & 0,18 & 0,43 & 0,36 & 0,19 & 0,66 \\
\hline 13 & 4,92 & 4,93 & 0,18 & 0,17 & 0,31 & 0,6 & 0,15 & 0,39 \\
\hline 14 & 3,82 & 3,82 & 0,05 & 0,1 & 0,23 & 0,23 & 0,1 & 0,37 \\
\hline 15 & 8,44 & 8,45 & 0,19 & 0,25 & 0,44 & 0,48 & 0,23 & 1,48 \\
\hline 16 & 8,12 & 8,11 & 0,09 & 0,17 & 0,37 & 0,46 & 0,29 & 0,97 \\
\hline 17 & 5,92 & 5,93 & 0,15 & 0,29 & 0,37 & 0,47 & 0,16 & 0,67 \\
\hline 18 & 4,86 & 4,86 & 0,07 & 0,11 & 0,17 & 0,27 & 0,16 & 0,34 \\
\hline 19 & 6,84 & 6,84 & 0,2 & 0,3 & 0,36 & 0,34 & 0,29 & 0,99 \\
\hline 20 & 5,16 & 5,16 & 0,12 & 0,22 & 0,24 & 0,26 & 0,16 & 0,3 \\
\hline Média & 5,71 & 5,71 & 0,13 & 0,19 & 0,31 & 0,34 & 0,19 & 0,62 \\
\hline DP & 1,51 & 1,51 & 0,04 & 0,06 & 0,12 & 0,13 & 0,06 & 0,31 \\
\hline CV & 0,26 & 0,26 & 0,31 & 0,32 & 0,39 & 0,38 & 0,32 & 0,49 \\
\hline
\end{tabular}




\section{ANEXO B4}

Tabela B4: Valores de fluxos basais e respectivas amplitudes das oscilações de fluxo nas bandas B0 a B6, em unidades arbitrárias (UA), colhidos na região R2.

\begin{tabular}{|c|c|c|c|c|c|c|c|c|}
\hline Individuo/banda & Fluxo & BO & B1 & B2 & B3 & B4 & B5 & B6 \\
\hline 1 & 4,1 & 4,11 & 0,13 & 0,2 & 0,33 & 0,21 & 0,2 & 0,69 \\
\hline 2 & 9,35 & 9,37 & 0,17 & 0,36 & 0,8 & 0,55 & 0,31 & 0,71 \\
\hline 3 & 4,85 & 4,85 & 0,1 & 0,16 & 0,24 & 0,17 & 0,11 & 0,39 \\
\hline 4 & 5,59 & 5,59 & 0,18 & 0,32 & 0,35 & 0,43 & 0,27 & 0,51 \\
\hline 5 & 4,85 & 4,86 & 0,09 & 0,11 & 0,24 & 0,24 & 0,14 & 0,37 \\
\hline 6 & 3,25 & 3,24 & 0,17 & 0,23 & 0,16 & 0,3 & 0,1 & 0,28 \\
\hline 7 & 2,47 & 2,47 & 0,09 & 0,24 & 0,24 & 0,21 & 0,11 & 0,28 \\
\hline 8 & 4,34 & 4,33 & 0,12 & 0,14 & 0,45 & 0,32 & 0,17 & 0,51 \\
\hline 9 & 5,62 & 5,62 & 0,06 & 0,14 & 0,19 & 0,35 & 0,19 & 0,39 \\
\hline 10 & 2,75 & 2,76 & 0,12 & 0,18 & 0,31 & 0,2 & 0,16 & 0,38 \\
\hline 11 & 3,39 & 3,39 & 0,06 & 0,08 & 0,14 & 0,16 & 0,11 & 0,72 \\
\hline 12 & 5,51 & 5,51 & 0,18 & 0,36 & 0,58 & 0,42 & 0,26 & 0,6 \\
\hline 13 & 4,1 & 4,1 & 0,15 & 0,21 & 0,4 & 0,33 & 0,11 & 0,38 \\
\hline 14 & 5,34 & 5,35 & 0,1 & 0,17 & 0,18 & 0,23 & 0,12 & 0,54 \\
\hline 15 & 4,91 & 4,91 & 0,08 & 0,11 & 0,13 & 0,18 & 0,12 & 0,85 \\
\hline 16 & 6,3 & 6,31 & 0,1 & 0,19 & 0,27 & 0,24 & 0,22 & 0,78 \\
\hline 17 & 3,29 & 3,29 & 0,05 & 0,1 & 0,28 & 0,17 & 0,08 & 0,24 \\
\hline 18 & 4,21 & 4,21 & 0,06 & 0,11 & 0,15 & 0,26 & 0,14 & 0,32 \\
\hline 19 & 3,09 & 3,09 & 0,09 & 0,12 & 0,25 & 0,21 & 0,2 & 0,36 \\
\hline 20 & 6,62 & 6,62 & 0,21 & 0,26 & 0,22 & 0,31 & 0,2 & 0,45 \\
\hline Média & 4,7 & 4,7 & 0,12 & 0,19 & 0,29 & 0,27 & 0,17 & 0,49 \\
\hline DP & 1,6 & 1,61 & 0,05 & 0,08 & 0,16 & 0,1 & 0,06 & 0,18 \\
\hline CV & 0,34 & 0,34 & 0,42 & 0,42 & 0,55 & 0,37 & 0,35 & 0,37 \\
\hline
\end{tabular}




\section{ANEXO B5}

Tabela B5: Valores de fluxos durante um estresse térmico e respectivas amplitudes das oscilações de fluxo nas bandas $\mathrm{B} 0$ a B6, em unidades arbitrárias (UA), colhidos na região R1.

\begin{tabular}{|c|c|c|c|c|c|c|c|c|}
\hline Individuo/banda & Fluxo & BO & B1 & B2 & B3 & B4 & B5 & B6 \\
\hline 1 & 87,96 & 87,94 & 0,46 & 0,39 & 0,54 & 1 & 1,17 & 5,11 \\
\hline 2 & 166,5 & 166,5 & 0,55 & 1,07 & 1,58 & 2,22 & 1,74 & 15,91 \\
\hline 3 & 180,78 & 180,85 & 0,9 & 1,86 & 2,22 & 2,02 & 2,48 & 19,7 \\
\hline 4 & 319,18 & 319,23 & 1,37 & 1,59 & 2,22 & 3,4 & 3,47 & 29,11 \\
\hline 5 & 180,32 & 180,33 & 0,64 & 0,74 & 1,23 & 1,95 & 1,59 & 13,72 \\
\hline 6 & 105,5 & 105,43 & 1,04 & 1,28 & 1,3 & 1,25 & 1,31 & 7,5 \\
\hline 7 & 101,48 & 101,46 & 0,54 & 0,98 & 1,32 & 1,56 & 1,62 & 11,79 \\
\hline 8 & 191,16 & 191,21 & 0,66 & 1,8 & 1,86 & 3,04 & 2,72 & 16,32 \\
\hline 9 & 118,72 & 118,62 & 0,68 & 0,95 & 1,78 & 2,23 & 1,48 & 10,54 \\
\hline 10 & 116,01 & 116,01 & 0,41 & 0,68 & 1,25 & 2,18 & 1,53 & 11,99 \\
\hline 11 & 94,98 & 94,98 & 0,38 & 0,6 & 1 & 1,13 & 1,31 & 9,96 \\
\hline 12 & 87,38 & 87,36 & 0,33 & 0,78 & 1 & 1,28 & 1,08 & 7,42 \\
\hline 13 & 107,81 & 107,81 & 0,36 & 0,67 & 2,08 & 2,47 & 0,86 & 12,88 \\
\hline 14 & 98,57 & 98,59 & 0,63 & 0,94 & 1,76 & 2,51 & 1,67 & 14,24 \\
\hline 15 & 57,8 & 57,8 & 0,58 & 0,69 & 0,48 & 0,97 & 0,65 & 5,23 \\
\hline 16 & 107,78 & 107,79 & 0,36 & 0,67 & 2,07 & 2,46 & 0,86 & 12,88 \\
\hline 17 & 61,12 & 61,12 & 0,76 & 1,2 & 1,2 & 1,28 & 1,73 & 11,33 \\
\hline 18 & 113,01 & 113,01 & 0,67 & 1,02 & 1,4 & 4,62 & 2,13 & 8,01 \\
\hline 19 & 90,12 & 90,14 & 0,91 & 0,88 & 1,16 & 1,76 & 1,23 & 10,61 \\
\hline 20 & 105,38 & 105,31 & 0,62 & 1 & 1,17 & 1,78 & 1,09 & 11,27 \\
\hline Média & 124,58 & 124,57 & 0,64 & 0,99 & 1,43 & 2,06 & 1,59 & 12,28 \\
\hline DP & 59,09 & 59,11 & 0,26 & 0,39 & 0,51 & 0,9 & 0,68 & 5,4 \\
\hline CV & 0,47 & 0,47 & 0,41 & 0,39 & 0,36 & 0,44 & 0,43 & 0,44 \\
\hline
\end{tabular}




\section{ANEXO B6}

Tabela B6: Valor de fluxo durante um estresse térmico e respectivas amplitudes das oscilações de fluxo nas bandas $\mathrm{B} 0$ a B6, em unidades arbitrárias (UA), colhidos na região R2.

\begin{tabular}{|c|c|c|c|c|c|c|c|c|}
\hline Individuo/banda & Fluxo & BO & B1 & B2 & B3 & B4 & B5 & B6 \\
\hline 1 & 186,15 & 186,23 & 1,27 & 1,28 & 1,69 & 2,48 & 2,44 & 14,06 \\
\hline 2 & 92,93 & 92,92 & 0,37 & 0,53 & 0,68 & 0,99 & 0,97 & 7,96 \\
\hline 3 & 89,03 & 89,07 & 0,63 & 0,94 & 1,06 & 1,2 & 1,41 & 11,85 \\
\hline 4 & 266,01 & 266,04 & 1,19 & 1,44 & 2 & 3,32 & 3,07 & 26,78 \\
\hline 5 & 279,19 & 279,24 & 1,05 & 1,22 & 1,54 & 2,9 & 2,18 & 23,54 \\
\hline 6 & 101,95 & 101,81 & 1,47 & 1,85 & 1,44 & 1,33 & 1,1 & 8,68 \\
\hline 7 & 86,98 & 86,97 & 0,41 & 0,73 & 0,98 & 1,23 & 1,17 & 8,87 \\
\hline 8 & 165,04 & 165,13 & 0,88 & 1,88 & 1,92 & 3,16 & 2,54 & 15,93 \\
\hline 9 & 124,52 & 124,52 & 0,54 & 1 & 1,84 & 1,9 & 1,41 & 10,61 \\
\hline 10 & 94,27 & 94,25 & 0,49 & 0,76 & 1,08 & 2,02 & 1,29 & 11,68 \\
\hline 11 & 98,93 & 98,93 & 0,46 & 0,73 & 1,31 & 1,47 & 1,43 & 11,94 \\
\hline 12 & 104,69 & 104,6 & 0,46 & 0,68 & 0,96 & 1,2 & 1,15 & 8,54 \\
\hline 13 & 86,88 & 86,89 & 0,32 & 0,38 & 1,01 & 1,25 & 0,79 & 8,35 \\
\hline 14 & 163,38 & 163,41 & 0,87 & 1,53 & 2,67 & 3,64 & 2,44 & 20,08 \\
\hline 15 & 113,47 & 113,52 & 0,92 & 1,53 & 1,33 & 2,26 & 1,36 & 11,6 \\
\hline 16 & 86,85 & 86,86 & 0,32 & 0,38 & 1,01 & 1,25 & 0,79 & 8,35 \\
\hline 17 & 131,74 & 131,73 & 0,68 & 1,44 & 1,4 & 1,05 & 1,12 & 10,79 \\
\hline 18 & 96,79 & 96,85 & 0,83 & 0,64 & 1,18 & 3,56 & 2 & 7,76 \\
\hline 19 & 72,57 & 72,59 & 0,7 & 0,75 & 0,82 & 1,32 & 0,78 & 8,45 \\
\hline 20 & 156,27 & 156,19 & 0,82 & 1,34 & 1,59 & 2,27 & 1,52 & 15 \\
\hline Média & 129,88 & 129,89 & 0,73 & 1,05 & 1,37 & 1,99 & 1,55 & 12,54 \\
\hline DP & 58,01 & 58,03 & 0,33 & 0,47 & 0,48 & 0,9 & 0,67 & 5,38 \\
\hline$C V$ & 0,45 & 0,45 & 0,45 & 0,45 & 0,35 & 0,45 & 0,43 & 0,43 \\
\hline
\end{tabular}




\section{ANEXO B7}

Tabela B7: Desvio-padrão de registros de fluxo basal e das respectivas amplitudes das oscilações de fluxo nas bandas $\mathrm{B} 0$ a B6, em unidades arbitrárias (UA), colhidos na região R1.

\begin{tabular}{|c|c|c|c|c|c|c|c|c|}
\hline Individuo/banda & Fluxo & B0 & B1 & B2 & B3 & B4 & B5 & B6 \\
\hline 1 & 1,31 & 0,41 & 0,1 & 0,18 & 0,31 & 0,2 & 0,15 & 0,44 \\
\hline 2 & 1,55 & 0,35 & 0,11 & 0,15 & 0,34 & 0,35 & 0,2 & 0,47 \\
\hline 3 & 1,21 & 0,73 & 0,07 & 0,1 & 0,16 & 0,18 & 0,12 & 0,39 \\
\hline 4 & 1,22 & 0,3 & 0,08 & 0,17 & 0,2 & 0,33 & 0,24 & 0,37 \\
\hline 5 & 1,53 & 0,5 & 0,13 & 0,15 & 0,32 & 0,36 & 0,26 & 0,54 \\
\hline 6 & 1,1 & 0,56 & 0,12 & 0,14 & 0,13 & 0,29 & 0,17 & 0,28 \\
\hline 7 & 1,09 & 0,27 & 0,12 & 0,21 & 0,17 & 0,16 & 0,13 & 0,39 \\
\hline 8 & 1,75 & 0,39 & 0,14 & 0,14 & 0,47 & 0,42 & 0,15 & 0,55 \\
\hline 9 & 1,11 & 0,56 & 0,11 & 0,22 & 0,26 & 0,19 & 0,11 & 0,25 \\
\hline 10 & 1,04 & 0,25 & 0,11 & 0,15 & 0,26 & 0,2 & 0,29 & 0,41 \\
\hline 11 & 1,33 & 0,51 & 0,05 & 0,08 & 0,1 & 0,13 & 0,11 & 0,58 \\
\hline 12 & 1,51 & 0,37 & 0,09 & 0,16 & 0,33 & 0,35 & 0,24 & 0,58 \\
\hline 13 & 1,38 & 0,51 & 0,14 & 0,13 & 0,28 & 0,48 & 0,13 & 0,3 \\
\hline 14 & 0,77 & 0,13 & 0,05 & 0,07 & 0,18 & 0,2 & 0,08 & 0,26 \\
\hline 15 & 2,25 & 0,52 & 0,13 & 0,19 & 0,36 & 0,36 & 0,2 & 0,85 \\
\hline 16 & 1,81 & 0,21 & 0,08 & 0,14 & 0,26 & 0,36 & 0,38 & 0,76 \\
\hline 17 & 1,55 & 0,35 & 0,11 & 0,23 & 0,29 & 0,46 & 0,23 & 0,43 \\
\hline 18 & 0,85 & 0,28 & 0,05 & 0,08 & 0,15 & 0,21 & 0,13 & 0,24 \\
\hline 19 & 1,82 & 0,59 & 0,2 & 0,32 & 0,35 & 0,27 & 0,21 & 0,63 \\
\hline 20 & 1,04 & 0,51 & 0,08 & 0,18 & 0,2 & 0,23 & 0,16 & 0,27 \\
\hline
\end{tabular}




\section{ANEXO B8}

Tabela B8: Desvio-padrão de registros de fluxo durante um estresse térmico e das respectivas amplitudes das oscilações de fluxo nas bandas B0 a B6, em unidades arbitrárias (UA), colhidos na região R1.

\begin{tabular}{|c|c|c|c|c|c|c|c|c|}
\hline Individuo/banda & Fluxo & BO & B1 & B2 & B3 & B4 & B5 & B6 \\
\hline 1 & 8,16 & 2 & 0,26 & 0,26 & 0,44 & 0,75 & 0,92 & 3,32 \\
\hline 2 & 19,81 & 3,73 & 0,4 & 0,75 & 1,17 & 1,62 & 1,36 & 8,32 \\
\hline 3 & 24,2 & 1,96 & 0,56 & 1,23 & 1,54 & 1,47 & 1,8 & 10,47 \\
\hline 4 & 35,53 & 7,57 & 1 & 1,1 & 1,63 & 2,64 & 2,52 & 14,97 \\
\hline 5 & 17,92 & 5,89 & 0,44 & 0,54 & 0,88 & 1,56 & 1,26 & 7,38 \\
\hline 6 & 12,71 & 5,27 & 1,05 & 1,13 & 1,01 & 0,94 & 1,02 & 4,79 \\
\hline 7 & 15,2 & 4,02 & 0,35 & 0,7 & 1,16 & 1,31 & 1,28 & 6,33 \\
\hline 8 & 21,84 & 5,99 & 0,48 & 1,38 & 1,41 & 2,45 & 1,84 & 8,64 \\
\hline 9 & 14,35 & 4,84 & 0,55 & 0,65 & 1,51 & 1,58 & 1,19 & 5,91 \\
\hline 10 & 15,37 & 3,3 & 0,3 & 0,48 & 0,91 & 1,65 & 1,17 & 6,43 \\
\hline 11 & 13,64 & 6,74 & 0,27 & 0,45 & 0,79 & 0,9 & 0,94 & 5,17 \\
\hline 12 & 11,47 & 1,45 & 0,26 & 0,59 & 0,7 & 1,02 & 1,07 & 4,39 \\
\hline 13 & 15,75 & 2,42 & 0,25 & 0,46 & 1,47 & 1,74 & 0,69 & 6,42 \\
\hline 14 & 18,46 & 4,84 & 0,69 & 0,74 & 1,31 & 2,08 & 1,38 & 7,45 \\
\hline 15 & 8,07 & 4,51 & 0,42 & 0,46 & 0,38 & 0,84 & 0,51 & 2,85 \\
\hline 16 & 15,75 & 2,46 & 0,25 & 0,46 & 1,47 & 1,74 & 0,69 & 6,42 \\
\hline 17 & 14,61 & 1,21 & 0,52 & 0,91 & 1 & 0,97 & 1,31 & 7,13 \\
\hline 18 & 14,73 & 6,71 & 0,45 & 0,77 & 1,11 & 3,47 & 1,96 & 4,77 \\
\hline 19 & 13,44 & 3,26 & 0,66 & 0,79 & 1 & 1,27 & 0,94 & 5,67 \\
\hline 20 & 13,94 & 3,7 & 0,52 & 0,72 & 1,06 & 1,39 & 0,82 & 5,61 \\
\hline
\end{tabular}




\section{ANEXO B9}

Tabela B9: Percentagem de tempo em que pares de sinais nas bandas B0 a B6 permaneceram sincronizados durante a duração do patamar e valores médios do grupo. $\left(^{*}\right)$ Significativamente diferente dos demais grupos (ANOVA, Tukey, p<0,05). DP significa desvio-padrão.

\begin{tabular}{|c|c|c|c|c|c|c|c|}
\hline Indivíduo\banda & BO & B1 & B2 & B3 & B4 & B5 & B6 \\
\hline 1 & 99 & 79 & 23 & 40 & 44 & 47 & 97 \\
\hline 2 & 86 & 31 & 56 & 73 & 80 & 42 & 100 \\
\hline 3 & 100 & 100 & 100 & 100 & 72 & 70 & 100 \\
\hline 4 & 100 & 88 & 91 & 87 & 87 & 70 & 100 \\
\hline 5 & 100 & 100 & 79 & 80 & 90 & 36 & 100 \\
\hline 6 & 14 & 48 & 53 & 81 & 71 & 23 & 95 \\
\hline 7 & 99 & 87 & 92 & 88 & 72 & 44 & 100 \\
\hline 8 & 100 & 83 & 100 & 97 & 93 & 78 & 100 \\
\hline 9 & 100 & 27 & 100 & 81 & 88 & 48 & 100 \\
\hline 10 & 73 & 50 & 88 & 82 & 95 & 36 & 100 \\
\hline 11 & 100 & 91 & 92 & 97 & 83 & 68 & 100 \\
\hline 12 & 100 & 70 & 78 & 91 & 75 & 37 & 98 \\
\hline 13 & 77 & 90 & 73 & 97 & 95 & 44 & 100 \\
\hline 14 & 100 & 79 & 91 & 99 & 97 & 65 & 100 \\
\hline 15 & 100 & 100 & 100 & 85 & 94 & 53 & 100 \\
\hline 16 & 76 & 90 & 73 & 97 & 96 & 44 & 100 \\
\hline 17 & 100 & 100 & 100 & 97 & 79 & 41 & 100 \\
\hline 18 & 100 & 100 & 100 & 97 & 100 & 80 & 100 \\
\hline 19 & 88 & 100 & 95 & 91 & 93 & 40 & 100 \\
\hline 20 & 73 & 76 & 99 & 95 & 91 & 51 & 100 \\
\hline Média & 89 & 80 & 84 & 88 & 85 & $51^{*}$ & 99 \\
\hline DP & 20 & 23 & 20 & 14 & 13 & 16 & 1 \\
\hline
\end{tabular}




\section{ANEXO B10}

Tabela B10: Coeficiente de correlação de Pearson entre pares de sinais nas bandas B0 a B6 durante a duração do patamar e valor médio do grupo. $\left({ }^{*}\right)$ significativamente menor que 0,5 (teste t), $\left({ }^{* *}\right)$ Significativamente diferente dos demais grupos e $\left.{ }^{* * *}\right)$ significativamente diferente dos demais grupos exceto B0, (ANOVA, $p<0,05)$. DP significa desvio-padrão.

\begin{tabular}{|c|c|c|c|c|c|c|c|}
\hline Indivíduo/banda & B0 & B1 & B2 & B3 & B4 & B5 & B6 \\
\hline 1 & 0,83 & 0,64 & 0,23 & 0,36 & 0,41 & 0,39 & 0,85 \\
\hline 2 & 0,74 & 0,37 & 0,5 & 0,63 & 0,68 & 0,36 & 0,95 \\
\hline 3 & 0,92 & 0,84 & 0,92 & 0,94 & 0,64 & 0,56 & 0,96 \\
\hline 4 & 0,92 & 0,86 & 0,85 & 0,79 & 0,8 & 0,58 & 0,97 \\
\hline 5 & 0,98 & 0,85 & 0,69 & 0,72 & 0,78 & 0,3 & 0,95 \\
\hline 6 & 0,17 & 0,43 & 0,5 & 0,73 & 0,62 & 0,2 & 0,82 \\
\hline 7 & 0,93 & 0,77 & 0,84 & 0,81 & 0,64 & 0,37 & 0,93 \\
\hline 8 & 0,97 & 0,64 & 0,88 & 0,86 & 0,85 & 0,65 & 0,96 \\
\hline 9 & 0,96 & 0,24 & 0,84 & 0,73 & 0,79 & 0,39 & 0,93 \\
\hline 10 & 0,63 & 0,49 & 0,78 & 0,76 & 0,86 & 0,3 & 0,93 \\
\hline 11 & 0,93 & 0,86 & 0,86 & 0,87 & 0,73 & 0,58 & 0,97 \\
\hline 12 & 0,85 & 0,67 & 0,75 & 0,79 & 0,65 & 0,3 & 0,9 \\
\hline 13 & 0,69 & 0,75 & 0,61 & 0,89 & 0,87 & 0,36 & 0,96 \\
\hline 14 & 0,9 & 0,73 & 0,8 & 0,94 & 0,89 & 0,56 & 0,97 \\
\hline 15 & 0,96 & 0,88 & 0,95 & 0,74 & 0,85 & 0,44 & 0,96 \\
\hline 16 & 0,69 & 0,75 & 0,61 & 0,89 & 0,87 & 0,36 & 0,96 \\
\hline 17 & 0,94 & 0,9 & 0,91 & 0,82 & 0,54 & 0,29 & 0,86 \\
\hline 18 & 0,99 & 0,91 & 0,87 & 0,86 & 0,96 & 0,7 & 0,93 \\
\hline 19 & 0,8 & 0,89 & 0,88 & 0,82 & 0,82 & 0,33 & 0,95 \\
\hline 20 & 0,65 & 0,72 & 0,91 & 0,85 & 0,83 & 0,43 & 0,96 \\
\hline Média & 0,82 & 0,71 & 0,76 & 0,79 & 0,75 & $0,42(*)(* *)$ & $0,93(* * *)$ \\
\hline DP & 0,19 & 0,19 & 0,18 & 0,13 & 0,14 & 0,14 & 0,04 \\
\hline
\end{tabular}




\section{ANEXO B11}

Tabela B11: Percentagem de tempo em que pares de sinais basais nas bandas B0 a B6 permaneceram sincronizados e valor médio do grupo. (*) significa diferente das bandas B0 e B1 (ANOVA e Tukey, p<0,05). DP (desvio-padrão)

\begin{tabular}{|c|c|c|c|c|c|c|c|}
\hline Indivíduo\banda & BO & B1 & B2 & B3 & B4 & B5 & B6 \\
\hline 1 & 100 & 99 & 82 & 93 & 73 & 66 & 88 \\
\hline 2 & 100 & 89 & 69 & 75 & 78 & 49 & 60 \\
\hline 3 & 60 & 49 & 30 & 23 & 65 & 32 & 86 \\
\hline 4 & 79 & 83 & 78 & 69 & 80 & 84 & 45 \\
\hline 5 & 48 & 38 & 16 & 33 & 57 & 39 & 64 \\
\hline 6 & 78 & 95 & 82 & 82 & 31 & 26 & 51 \\
\hline 7 & 100 & 87 & 78 & 47 & 51 & 23 & 47 \\
\hline 8 & 100 & 93 & 62 & 84 & 83 & 69 & 93 \\
\hline 9 & 0 & 5 & 45 & 14 & 53 & 26 & 14 \\
\hline 10 & 69 & 66 & 67 & 57 & 61 & 34 & 36 \\
\hline 11 & 81 & 100 & 47 & 58 & 40 & 34 & 99 \\
\hline 12 & 70 & 100 & 89 & 85 & 76 & 59 & 57 \\
\hline 13 & 100 & 100 & 86 & 74 & 41 & 32 & 44 \\
\hline 14 & 46 & 50 & 34 & 17 & 24 & 14 & 3 \\
\hline 15 & 70 & 78 & 47 & 38 & 39 & 46 & 99 \\
\hline 16 & 32 & 48 & 32 & 53 & 32 & 50 & 46 \\
\hline 17 & 53 & 85 & 53 & 58 & 64 & 23 & 71 \\
\hline 18 & 82 & 18 & 81 & 48 & 88 & 60 & 52 \\
\hline 19 & 32 & 77 & 35 & 19 & 36 & 58 & 55 \\
\hline 20 & 100 & 87 & 77 & 53 & 74 & 46 & 48 \\
\hline Média & 70 & 72.35 & 59.5 & 54 & 57.3 & $43.5\left(^{*}\right)$ & 57.9 \\
\hline DP & 28.14 & 28.4 & 22.39 & 24.29 & 19.72 & 18.34 & 25.9 \\
\hline
\end{tabular}




\section{ANEXO B12}

Tabela B12: Coeficiente de correlação de Pearson entre pares de sinais basais nas bandas B0 a B6 e valor médio do grupo. $\left(^{*}\right)$ significativamente menor que 0,5 (teste $\mathrm{t}$ ), $\left({ }^{* *}\right)$ Significativamente diferente dos grupos B0 e B1 (ANOVA, p<0,05). DP (desvio-padrão)

\begin{tabular}{|c|c|c|c|c|c|c|c|}
\hline Indivíduo\banda & BO & B1 & B2 & B3 & B4 & B5 & B6 \\
\hline 1 & 0,9 & 0,8 & 0,7 & 0,8 & 0,6 & 0,6 & 0,7 \\
\hline 2 & 0,9 & 0,7 & 0,6 & 0,7 & 0,7 & 0,4 & 0,5 \\
\hline 3 & 0,5 & 0,4 & 0,3 & 0,3 & 0,6 & 0,3 & 0,7 \\
\hline 4 & 0,7 & 0,8 & 0,7 & 0,6 & 0,7 & 0,7 & 0,3 \\
\hline 5 & 0,5 & 0,4 & 0,2 & 0,3 & 0,5 & 0,3 & 0,5 \\
\hline 6 & 0,7 & 0,8 & 0,7 & 0,7 & 0,3 & 0,2 & 0,4 \\
\hline 7 & 0,9 & 0,8 & 0,7 & 0,4 & 0,5 & 0,2 & 0,4 \\
\hline 8 & 0,8 & 0,8 & 0,6 & 0,7 & 0,7 & 0,6 & 0,8 \\
\hline 9 & 0,1 & 0,1 & 0,4 & 0,1 & 0,5 & 0,2 & 0,1 \\
\hline 10 & 0,6 & 0,6 & 0,6 & 0,5 & 0,5 & 0,3 & 0,3 \\
\hline 11 & 0,6 & 0,9 & 0,4 & 0,5 & 0,4 & 0,3 & 0,9 \\
\hline 12 & 0,6 & 0,9 & 0,8 & 0,8 & 0,7 & 0,5 & 0,4 \\
\hline 13 & 0,9 & 0,8 & 0,7 & 0,6 & 0,4 & 0,3 & 0,3 \\
\hline 14 & 0,4 & 0,5 & 0,3 & 0,2 & 0,2 & 0,1 & 0,1 \\
\hline 15 & 0,6 & 0,7 & 0,5 & 0,4 & 0,4 & 0,4 & 0,9 \\
\hline 16 & 0,4 & 0,3 & 0,3 & 0,5 & 0,3 & 0,4 & 0,3 \\
\hline 17 & 0,5 & 0,7 & 0,5 & 0,5 & 0,5 & 0,2 & 0,6 \\
\hline 18 & 0,7 & 0,2 & 0,7 & 0,4 & 0,8 & 0,5 & 0,4 \\
\hline 19 & 0,3 & 0,6 & 0,4 & 0,2 & 0,3 & 0,5 & 0,4 \\
\hline 20 & 0,8 & 0,8 & 0,7 & 0,5 & 0,6 & 0,4 & 0,4 \\
\hline Média & 0,62 & 0,63 & 0,54 & 0,49 & 0,51 & $0,37(*)(* *)$ & 0,47 \\
\hline DP & 0,22 & 0,24 & 0,18 & 0,2 & 0,17 & 0,16 & 0,23 \\
\hline
\end{tabular}


Referências Bibliográficas

BRAVERMAN, I.M. The cutaneous microcirculation: ultrastructure and microanatomical organization. Microcirculation, v. 4, n. 3, p. 329-340, 1997.

2 BERARDESCA, E.; LEVEQUE, J.L.; MASSON, P. EEMCO guidance for the measurement of skin microcirculation. Skin pharmacology and applied skin physiology v. 15, n. 6, p. 442-456, 2002.

${ }^{3}$ POPEL A S and JOHNSON PC, Microcirculation and hemorreology, Annu. Rev. Fluid Mech., vol. 37, p. 43-69, 2005.

${ }^{4}$ SCHRAMM, J.C.; DINH, T.; VEVES, A. Microvascular changes in the diabetic foot. The international journal of lower extremity wounds, v. 5, n. 3, p. 149-159, 2006.

${ }^{5}$ WRIGHT, C.I.; KRONER, C.I.; DRAIJER, R. Non-invasive methods and stimuli for evaluating the skin's microcirculation. Journal of Pharmacological and Toxicological Methods, v. 54, n. 1, p. 1-25 2006.

${ }^{6}$ BRAVERMAN, I.M. The cutaneous microcirculation. J. Investig. Dermatol. Symp. Proc., v. 5, n. 1, p. 3-9, 2000.

7 OBERG, P.A.; TENLAND, T.; NILSSON, G.E. Laser-Doppler flowmetry--a non-invasive and continuous method for blood flow evaluation in microvascular studies. Acta medica Scandinavica, v. 687, n., p. 17-24, 1984.

8 CRACOWSKI, J.L.; MINSON, C.T.; SALVAT-MELIS, M.; HALLIWILL, J.R. Methodological issues in the assessment of skin microvascular endothelial function in humans. Trends in pharmacological sciences, v. 27, n. 9, p. 503-508, 2006.

9 STROM, N.A.; SAWYER, J.R.; ROBERTS, S.K.; KINGSLEY-BERG, S.M.; CHARKOUDIAN, N. Local sensory nerve control of skin blood flow during local warming in type 2 diabetes mellitus. Journal of Applied Physiology, v. 108, n. 2, p. 293-297, 2010.

10 MINSON, C.T.; BERRY, L.T.; JOYNER, M.J. Nitric oxide and neurally mediated regulation of skin blood flow during local heating. Journal of Applied Physiology, v. 91, n. 4, p. 1619-1626, 2001.

11 KNOTZER, H.; HASIBEDER, W.R. Microcirculatory function monitoring at the bedside-a view from the intensive care. Physiological measurement, v. 28, n. 9, p. R65-86, 2007. 
12 HUMEAU A, STEENBERGEN W, NILSSON H AND STRÖMBERG T, Laser Doppler perfusion monitoring and imaging: novel approaches. Medical and Biological Engineering and Computing, vol. 45, p. 421-435, 2007.

13 GEYER, M.J.; JAN, Y.K.; BRIENZA, D.M.; BONINGER, M.L. Using wavelet analysis to characterize the thermoregulatory mechanisms of sacral skin blood flow. Journal of rehabilitation research and development, v. 41, n. 6A, p. 797-806, 2004.

${ }^{14}$ KVANDAL $P$, LANDSVERK S A, BERNJAK A, STEFANOVSKA A, KVERNMO H D, KIRKEBØEN K A, Low-frequency oscillations of the laser Doppler perfusion signal in human skin, Microv. Res., vol. 72, p. 120-127, 2006.

${ }^{15}$ ROSSI, M.; CARPI, A.; GALETTA, F.; FRANZONI, F.; SANTORO, G. Skin vasomotion investigation: A useful tool for clinical evaluation of microvascular endothelial function? Biomedicine \& Pharmacotherapy, v. 62, n. 8, p. 541-545, 2008.

16 KELLOGG, D.L., JR. In vivo mechanisms of cutaneous vasodilation and vasoconstriction in humans during thermoregulatory challenges. Journal of Applied Physiology v. 100, n. 5, p. 1709-1718, 2006.

17TENLAND, T.; SALERUD, E.G.; NILSSON, G.E.; OBERG, P.A. Spatial and temporal variations in human skin blood flow. International journal of microcirculation, clinical and experimental / sponsored by the European Society for Microcirculation, v. 2, n. 2, p. 81-90, 1983.

18 HODGES G J, KOSIBA W A, ZHAO K, JOHNSON J M, The involvement of heating rate and vasoconstrictor nerves in the cutaneous vasodilator response to skin warming, $A m \boldsymbol{J}$ Physiol Heart Circ Physiol, vol. 296, p. H51_H56, 2009.

19 JAN, Y.K.; STRUCK, B.D.; FOREMAN, R.D.; ROBINSON, C. Wavelet analysis of sacral skin blood flow oscillations to assess soft tissue viability in older adults. Microvascular research, v. 78, n. 2, p. 162-168, 2009.

${ }^{20}$ GUYTON, A.C.; HALL, J.E. A Microcirculação e o Sistema Linfático: Trocas de Líquido no Capilar, líquido Intersticial e Fluxo da Linfa. In: A. C. GUYTON e J. E. HALL (Ed.). Tratado de Fisiologia Médica. Rio de Janeiro: Guanabara Koogan, 2002. p.93-101.

${ }^{21}$ BERNE, R.M.; LEVY, M.N.; KOEPPEN, B.M.; STANTO, B.A. A Microcirculação e os Linfáticos. In: R. M. BERNE, M. N. LEVY, et al... (Ed.). Fisiologia. Rio de Janeiro: Elsevier, 2004. p.387-398.

22 BERNE, R.M.; LEVY, M.N.; KOEPPEN, B.M.; STANTO, B.A. A circulação periférica e o seu controle. In: R. M. BERNE, M. N. LEVY, et al... (Ed.). Fisiologia, 2004.

${ }^{23}$ NILSSON, G.E.; TENLAND, T.; OBERG, P.A. Evaluation of a laser Doppler flowmeter for measurement of tissue blood flow. IEEE transactions on bio-medical engineering, $v$. 27, n. 10 , p. 597-604, 1980. 
24 BERNE, R.M.; LEVY, M.N.; KOEPPEN, B.M.; STANTO, B.A. Hemodinâmica. In: R. M. BERNE, M. N. LEVY, et al... (Ed.). Fisiologia. Rio de Janeiro: Elsevier, 2004. p.357-371.

25 DOUGLAS, C.R. Fisiologia do fluxo sanguíneo das estruturas orais. In: C. R. DOUGLAS (Ed.). Patofisiologia oral: Fisiologia normal e patológica aplicada a odontologia e fonoaudiologia. São Paulo: Pancast, 1998. p.461-476.

${ }^{26}$ STERN, M.D. In vivo evaluation of microcirculation by coherent light scattering. Nature, v. 254 , n. 5495 , p. $56-58,1975$.

${ }^{27}$ http://www.moor.co.uk. acesso 14 de abril 2011.

${ }^{28}$ NOGUEIRA, G.E.C.; ZEZELL, D.M.; EDUARDO, L.R.P.; VIEIRA JR., N.D.; BALDOCHI, S.L.; ROSSI, W. Desenvolvimento De Um Sensor De Fluxo Sangüíneo Via Técnica Laser Doppler. . In: ANAIS DO CBEB, 2000. Proceedings, p. 724-726.

29 NILSSON, G.E. Signal processor for laser Doppler tissue flowmeters. Medical \& biological engineering \& computing, v. 22, n. 4, p. 343-348, 1984.

30 TENLAND, T.; SALERUD, E.G.; NILSSON, G.E.; OBERG, P.A. Spatial and temporal variations in human skin blood flow. International journal of microcirculation, clinical and experimental / sponsored by the European Society for Microcirculation, v. 2, n. 2, p. 81-90, 1983.

${ }^{31}$ BIRCHER, A.; DE BOER, E.M.; AGNER, T.; WAHLBERG, J.E.; SERUP, J. Guidelines for measurement of cutaneous blood flow by laser Doppler flowmetry. A report from the Standardization Group of the European Society of Contact Dermatitis. Contact Dermatitis, v. 30, n. 2, p. 65-72, 1994.

32 WIDMER, R.J.; LAURINEC, J.E.; YOUNG, M.F.; MOHIUDDIN, M.W.; LAINE, G.A.; QUICK, C.M. The origin of the biphasic flow response to local heat in skin. Microcirculation, v. 15, n. 4, p. 349-357, 2008.

${ }^{33}$ NUNEZ, S.C.; NOGUEIRA, G.E.; RIBEIRO, M.S.; GARCEZ, A.S.; LAGE-MARQUES, J.L. He-Ne laser effects on blood microcirculation during wound healing: a method of in vivo study through laser Doppler flowmetry. Lasers in surgery and medicine, v. 35 , n. 5, p. 363-368, 2004.

${ }^{34}$ KELLOGG, D.L., JR.; JOHNSON, J.M.; KOSIBA, W.A. Competition between cutaneous active vasoconstriction and active vasodilation during exercise in humans. $A m \boldsymbol{J}$ Physiol, v. 261, n. 4 Pt 2, p. H1184-1189, 1991.

${ }^{35}$ IABICHELLA, M.L.; MELILLO, E.; MOSTI, G. A review of microvascular measurements in wound healing. The international journal of lower extremity wounds, v. 5, n. 3, p. 181-199, 2006. 
${ }^{36}$ HOUGHTON, B.L.; MEENDERING, J.R.; WONG, B.J.; MINSON, C.T. Nitric oxide and noradrenaline contribute to the temperature threshold of the axon reflex response to gradual local heating in human skin. Journal of Physiology-London, v. 572, n. 3, p. 811-820, 2006.

${ }^{37}$ ROUSTIT, M.; SIMMONS, G.; CARPENTIER, P.; CRACOWSKI, J.L. Abnormal digital neurovascular response to local heating in systemic sclerosis. Fundamental \& Clinical Pharmacology, v. 22, n., p. 90-90, 2008.

38 LISNEY, S.J.W.; BHARALI, L.A.M. The Axon Reflex - an Outdated Idea or a Valid Hypothesis. News in Physiological Sciences, v. 4, n., p. 45-48, 1989.

39 TEW, G.A.; KLONIZAKIS, M.; MOSS, J.; RUDDOCK, A.D.; SAXTON, J.M.; HODGES, G.J. Reproducibility of cutaneous thermal hyperaemia assessed by laser Doppler flowmetry in young and older adults. Microvascular Research, v. 81, n. 2, p. 177-182, 2011.

40 BONELLI, R.M.; KOLTRINGER, P. Autonomic nervous function assessment using thermal reactivity of microcirculation. Clin Neurophysiol, v. 111, n. 10, p. 1880-1888, 2000.

${ }^{41}$ ASO, Y.; INUKAI, T.; TAKEMURA, Y. Evaluation of skin vasomotor reflexes in response to deep inspiration in diabetic patients by laser Doppler flowmetry. A new approach to the diagnosis of diabetic peripheral autonomic neuropathy. Diabetes Care, v. 20, n. 8, p. 1324-1328, 1997

42VEVES, A.; AKBARI, C.M.; PRIMAVERA, J.; DONAGHUE, V.M.; ZACHAROULIS, D.; CHRZAN, J.S.; DEGIROLAMI, U.; LOGERFO, F.W.; FREEMAN, R. Endothelial dysfunction and the expression of endothelial nitric oxide synthetase in diabetic neuropathy, vascular disease, and foot ulceration. Diabetes, v. 47, n. 3, p. 457-463, 1998.

${ }^{43}$ ARORA, S.; SMAKOWSKI, P.; FRYKBERG, R.G.; SIMEONE, L.R.; FREEMAN, R.; LOGERFO, F.W.; VEVES, A. Differences in foot and forearm skin microcirculation in diabetic patients with and without neuropathy. Diabetes Care, v. 21, n. 8, p. 1339-1344, 1998.

${ }^{44}$ BROOKS, B.; DELANEY-ROBINSON, C.; MOLYNEAUX, L.; YUE, D.K. Endothelial and neural regulation of skin microvascular blood flow in patients with diabetic peripheral neuropathy: effect of treatment with the isoform-specific protein kinase $C$ beta inhibitor, ruboxistaurin. Journal of diabetes and its complications, v. 22, n. 2, p. 88-95, 2008.

${ }^{45}$ AKBARI, C.M.; SAOUAF, R.; BARNHILL, D.F.; NEWMAN, P.A.; LOGERFO, F.W.; VEVES, A. Endothelium-dependent vasodilatation is impaired in both microcirculation and 
macrocirculation during acute hyperglycemia. Journal of Vascular Surgery, v. 28, n. 4, p. 687-694, 1998.

${ }^{46}$ EDWARDS, C. M., MARSHALL, J. M., \& PUGH, M. The cutaneous vasoconstrictor response to venous stasis is normal in subjects with primary Raynaud's disease. Clinical Autonomic Research, v. 9, p.255-262 1999.

47 KAISER, D. R., MULLEN, K., \& BANK, A. J. Brachial artery elastic mechanics in patients with heart failure. Hypertension, v.38, p.1440-1445, 2001.

${ }^{48}$ CIVITA, L. L., ROSSI, M., VAGHEgGINI, G., STORINO, F. A. A., CREDIDIO, L., PASERO, G., Microvascular involvement in systemic sclerosis: Laser Doppler evaluation of reactivity to acetylcholine and sodium nitroprusside by iontophoresis. Annals of the Rheumatic Diseases, v.57, p.52-55, 1998.

49 SILBER, H. A., OUYANG, P., BLUEMKE, D. A., GUPTA, S. N., FOO, T. K., \& LIMA, J. A. C. Why is flow-mediated dilation dependent on arterial size? Assessment of the shear stimulus using phase-contrast magnetic resonance imaging. AJP-Heart and Circulatory Physiology, v.288, p.H822-H828, 2005.

50 HANSELL, J., HENAREH, L., AGEWALL, S., \& NORMAN, M.. Non-invasive assessment of endothelial function-relation between vasodilatory responses in skin microcirculation and brachial artery. Clinical Physiology and Functional Imaging, v.24, p.317-322, 2004.

51 DEANFIELD, J.; DONALD, A.; FERRI, C.; GIANNATTASIO, C.; HALCOX, J.; HALLIGAN, S.; LERMAN, A.; MANCIA, G.; OLIVER, J.J.; PESSINA, A.C.; RIZZONI, D.; ROSSI, G.P.; SALVETTI, A.; SCHIFFRIN, E.L.; TADDEI, S.; WEBB, D.J. Endothelial function and dysfunction. Part I: Methodological issues for assessment in the different vascular beds: a statement by the Working Group on Endothelin and Endothelial Factors of the European Society of Hypertension. J Hypertens, v. 23, n. 1, p. 7-17, 2005.

2 STEVENS, M.J.; EDMONDS, M.E.; DOUGLAS, S.L.; WATKINS, P.J. Influence of neuropathy on the microvascular response to local heating in the human diabetic foot. Clin Sci (Lond), v. 80, n. 3, p. 249-256, 1991

${ }^{53}$ STEFANOVSKA, A.; BRACIC, M.; KVERNMO, H.D. Wavelet analysis of oscillations in the peripheral blood circulation measured by laser Doppler technique. IEEE transactions on bio-medical engineering, v. 46, n. 10, p. 1230-1239, 1999.

${ }^{54}$ PFÜTZER, A.; FORST, T.; ENGELBACH, M.; MARGIN, T.; GOITOM, K.; BEYER, J.; KUNT, T. The Influence Of Isolated Small Nerve Fiber Dysfunction On Microvascular Control In Patients With Diabetes. DIABETIC MEDICINE, 18 489-494, 2001

${ }^{55}$ KOITKA, A.; ABRAHAM, P.; BOUHANICK, B.; SIGAUDO-ROUSSEL, D.; DEMIOT, C.; SAUMET, J.L. Impaired pressure-induced vasodilation at the foot in young adults with type 1 diabetes. Diabetes, v. 53, n. 3, p. 721-725, 2004. 
${ }^{56}$ WIGINGTON, G.;f NGO, B.; RENDELL, M. Skin Blood Flow In Diabetic Dermopathy. ARCHIVES OF DERMATOLOGY 140, 1248-1250, 2004.

${ }^{57}$ AVERY, M.R, VOEGELI, D.; BYRNE, C.; SIMPSON D. M. AND CLOUGH, G. F. Age and cigarette smoking are independently associated with the cutaneous vascular response to local warming. Microcirculation, v. 16 p.725-734, 2009

${ }^{58}$ ESEN, F.; AYDIN, G.S.; ESEN, H. Detrended fluctuation analysis of laser Doppler flowmetry time series. Microvascular Research, v. 78, n. 3, p. 314-318, 2009.

59 GRYGLEWSKA, B.; NECKI, M.; CWYNAR, M.; BARON, T.; GRODZICKI, T. Neurogenic and myogenic resting skin blood flowmotion in subjects with masked hypertension. J Physiol Pharmacol, v. 61, n. 5, p. 551-558, 2010.

${ }^{60}$ ROSSI, M.; CARPI, A.; DI MARIA, C.; GALETTA, F.; SANTORO, G. Spectral analysis of laser Doppler skin blood flow oscillations in human essential arterial hypertension. Microvascular Research, v. 72, n. 1-2, p. 34-41, 2006.

${ }^{61}$ KVERNMO, H.D.; STEFANOVSKA, A.; BRACIC, M.; KIRKEBOEN, K.A.; KVERNEBO, K. Spectral analysis of the laser Doppler perfusion signal in human skin before and after exercise. Microvascalar Research, v. 56, n. 3, p. 173-182, 1998.

62 KVERNMO, H.D.; STEFANOVSKA, A.; KIRKEBOEN, K.A.; KVERNEBO, K. Oscillations in the human cutaneous blood perfusion signal modified by endotheliumdependent and endothelium-independent vasodilators. Microvascular Research, v. 57, n. 3, p. 298-309, 1999.

63 BERNJAK, A.; CLARKSON, P.B.; MCCLINTOCK, P.V.; STEFANOVSKA, A. Lowfrequency blood flow oscillations in congestive heart failure and after beta1-blockade treatment. Microvascular research, v. 76, n. 3, p. 224-232, 2008.

${ }^{64}$ FOLGOSI-CORREA, M.S.; NOGUEIRA, G.E.C. Quantifying low-frequency fluctuations in the laser Doppler flow signal from human skin. Dynamics and Fluctuations in Biomedical Photonics Viii, v. 7898, n., p., 2011.

65 CORSI-CABRERA M, GUEVARA MA, ARCE C, RAMOS J. Inter and intrahemispheric EEG correlation as a function of sleep cycles. Prog Neuropsychopharmacol Biol Psychiatry. v. 20, n. 3, p. 387-405, 1996.

${ }^{66}$ RUMMEL C, MÜLLER M, BAIER G, AMOR F, SCHINDLER K. Analyzing spatiotemporal patterns of genuine cross-correlations. J Neurosci Methods v.191, n.1, p. 94100, 2010.

67 GRINSTED A., MOORE J. C. AND JEVREJEVA S. Application of the cross wavelet transform and wavelet coherence to geophysical time series Nonlin. Processes Geophys. v. 11, p. 561-566, 2004. 
68 GUEVARA M.A., CORSI-CABRERA M. EEG coherence or EEG correlation? International Journal of Psychophysiology v. 23, p. 145-153, 1996.

69 RODGERS J. L.; NICEWANDER W.A. Thirteen ways to look at the correlation coefficient. The American Statistician, v.42, n.1, p. 59-66, 1988.

70 NEFZGER, M. D. AND DRASGOW, J. "The Needless Assumption of Normality in Pearson's r," The American Psychologist, v. 12, p. 623-625, 1957.

${ }^{71}$ COHEN, J. Statistical power analysis for the behavioral sciences 1998.

72 LANDIS, J.R.; KOCH, G.G. The measurement of observer agreement for categorical data. Biometrics, v. 33, n. 1, p. 159-174, 1977.

73 JOHNSON JM, O'LEARY DS, TAYLOR WF, AND KOSIBA WA. Effect of local warming on forearm reactive hyperemia. Clin Physiolv.6, p. 337-346, 1986

74 KELLOGG, D.L., JR.; ZHAO, J.L.; WU, Y. Roles of nitric oxide synthase isoforms in cutaneous vasodilation induced by local warming of the skin and whole body heat stress in humans. J Appl Physiol, v. 107, n. 5, p. 1438-1444, 2009.

${ }^{75}$ KELLOGG, D.L., JR.; LIU, Y.; KOSIBA, I.F.; O'DONNELL, D. Role of nitric oxide in the vascular effects of local warming of the skin in humans. J Appl Physiol, v. 86, n. 4, p. 1185-1190, 1999.

76 BRACIC, M.; STEFANOVSKA, A. Wavelet-based analysis of human blood-flow dynamics. Bulletin of Mathematical Biology, v. 60, n. 5, p. 919-935, 1998.

77 SHEPPARD, L.W.; VUKSANOVIC, V.; MCCLINTOCK, P.V.E.; STEFANOVSKA, A. Oscillatory dynamics of vasoconstriction and vasodilation identified by time-localized phase coherence. Physics in Medicine and Biology, v. 56, n. 12, p. 3583-3601, 2011.

78 ROUSTIT, M.; BLAISE, S.; MILLET, C.; CRACOWSKI, J.L. Reproducibility and methodological issues of skin post-occlusive and thermal hyperemia assessed by singlepoint laser Doppler flowmetry. Microvascular Research, v. 79, n. 2, p. 102-108, 2010.

79 BASAR, E.; WEISS, C. Vasculature and Circulation - the role of myogenic reactivity in the regulation of blood flow. Amsterdam, Netherlands: Elsevier, 1981.

80 BERNARDI, L.; HAYOZ, D.; WENZEL, R.; PASSINO, C.; CALCIATI, A.; WEBER, R.; NOLL, G. Synchronous and baroceptor-sensitive oscillations in skin microcirculation: evidence for central autonomic control. Am J Physiol, v. 273, n. 4 Pt 2, p. H1867-1878, 1997.

81 STEFANOVSKA, A.; BRACIC, M. Physics of the human cardiovascular system. Contemporary Physics, v. 40, n. 1, p. 31-55, 1999. 
82 SHIOGAI, Y.; STEFANOVSKA, A.; MCCLINTOCK, P.V.E. Nonlinear dynamics of cardiovacular ageing. Physics Reports, v. 488, n., p. 51-110, 2010.

83 KIM, E.; YI, J.; HAN, S.; SHIN, J.; LEE, J.; KIM, S.; KIM, H. Clinical Factors Associated with Brachial Ankle Pulse Wave Velocity in Patients on Maintenance Hemodialysis. Electrolyte \& Blood Pressure, v. 6, n., p. 61-67, 2008

84 YASUMA, F.; HAYANO, J. Respiratory sinus arrhythmia: why does the heartbeat synchronize with respiratory rhythm? Chest, v. 125, n. 2, p. 683-690, 2004.

85 LEOR-LIBRACH, R.J.; BOBROVSKY, B.Z.; ELIASH, S.; KAPLINSKY, E. A common origin of the very low frequency heart rate and blood pressure variability--a new insight into an old debate. Auton Neurosci, v. 96, n. 2, p. 140-148, 2002.

${ }^{86}$ SÖDERSTRÖM, T.; STEFANOVSKA, A.; VEBER, M.; SVENSSONP, H. Involvement of sympathetic nerve activity in skin blood flow oscillations in humans. Am. J. Physiol, Heart Circ. Physiol. , v. 284, n., p. H1638-H1646, 2003.

87 WILSON, T.; ZHANG, R.; LEVINE, B.; CRANDALL, C. Dynamic autoregulation of cutaneous circulation: differential control in glabrous versus nonglabrous skin. Am $\mathrm{J}$ Physiol Heart Circ Physio, v. 289, n., p. H385-H391, 2005.

${ }^{88}$ FAGIUS, J.; WALLIN, B.G. Sympathetic reflex latencies and conduction velocities in patients with polyneuropathy. J Neurol Sci, v. 47, n. 3, p. 449-461, 1980.

89 TUMA, R.; DURAN, W.; LEY, K. Handbook of physiology: Microcirculation. amsterdam 2008.

90 STEWART, H.; TANEJA, I.; MICHAEL S. GOLIGORSKY, M.; MEDOW, M. Noninvasive Measure of Microvascular Nitric Oxide Function in Humans Using Very Low-Frequency Cutaneous Laser Doppler Flow Spectra ). Microcirculation, v. 14, n., p. 169-180, 2007.

91 HALCOX, J.P.; NARAYANAN, S.; CRAMER-JOYCE, L.; MINCEMOYER, R.; QUYYUMI, A.A. Characterization of endothelium-derived hyperpolarizing factor in the human forearm microcirculation. Am J Physiol Heart Circ Physiol, v. 280, n. 6, p. H24702477, 2001. 